\title{
ARE THE PEOPLE LISTENING TO GOVERNMENT'S GOOD ADVICE: SOURCE CREDIBILITY IN GOVERNMENT ATTRIBUTED SOCIAL MARKETING MESSAGES
}

by

A. D. Millard

\begin{abstract}
A thesis
submitted to Victoria University of Wellington

in fulfilment of the requirements for the degree of

Masters of Commerce and Administration
\end{abstract}

Victoria University of Wellington 


\title{
ARE THE PEOPLE LISTING TO GOVERNMENT'S GOOD ADVICE: SOURCE CREDIBILITY IN GOVERNMENT ATTRIBUTED SOCIAL MARKETING MESSAGES
}

by Andy Millard

\author{
Academic Supervisors: Jayne Krisjanous \\ Dr. Michel Rod \\ Faculty of Commerce and Administration \\ School of Marketing and International Business
}

\begin{abstract}
During 2008, the New Zealand government conducted over 53 separate social marketing programmes aimed at improving the lifestyle and behaviours of the New Zealand people. This situation has provided a niche environment to study the impact of high-volume governmentattributed social marketing advertising on the source credibility of the government (where the government is the main source and sponsor of social marketing). The research data was collected through fourteen semi-structured in-depth interviews with four social marketers and ten members of the public.
\end{abstract}

This study further sought to identify alternative sources of social marketing messages considered more effective than government, and as a logical part of this study, the repetition effect of various similar messages from one source, the New Zealand Government, in a social marketing context was examined.

This research has showed that the high-volume of social marketing messages has homogenised the source thoughts of the interviewed members of the public. It has led them to assume all social marketing is from government. Further, the high-volume has caused the target audience to abbreviate the cognitive response process illustrated by the Model of Cognitive Response compiled by Belch \& Belch (2007). Where their attitude towards the messages was favourable or it conformed to their beliefs, the target audience placed less priority on the importance of the source's credibility. This research compares and contrasts the social marketing data to well-accepted commercial marketing theory and principles, and attempts to provide a social marketing context to these theories. 
List of Figures and Tables ...............................................................................ii

Acknowledgements ......................................................................................

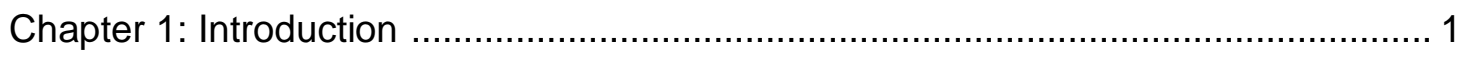

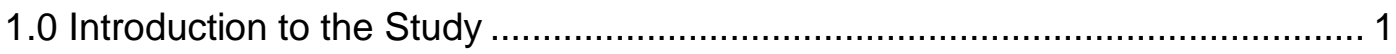

1.1 Social Marketing in New Zealand .............................................................. 5

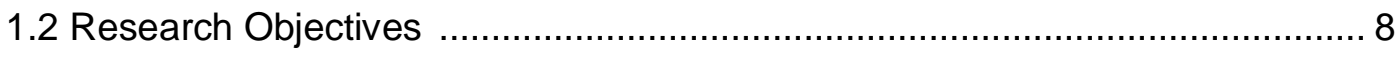

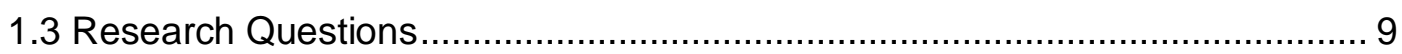

Chapter 2: Literature Review ....................................................................... 10

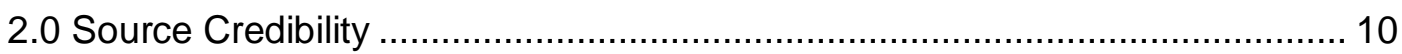

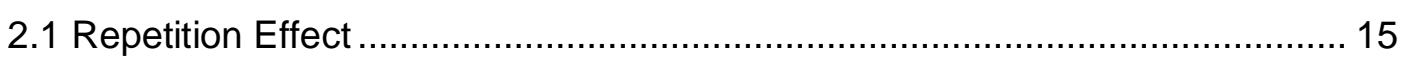

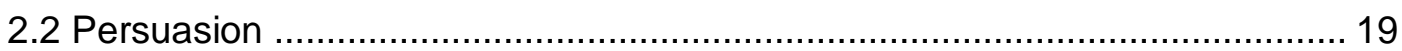

2.3 Attribution .................................................................................... 21

2.4 Social Marketing and Government........................................................ 24

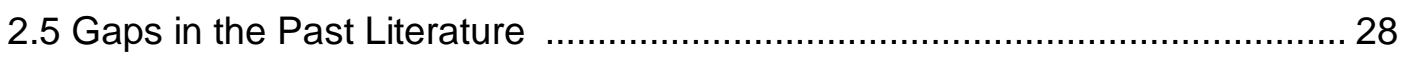

Chapter 3: Conceptual Framework ................................................................... 30

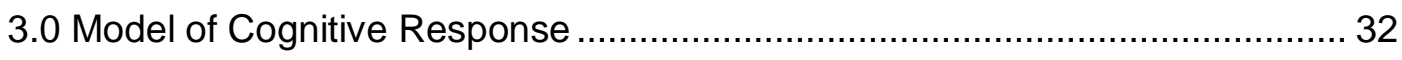

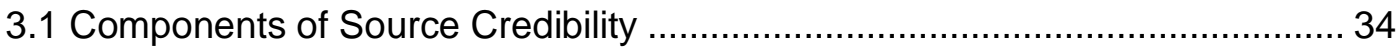

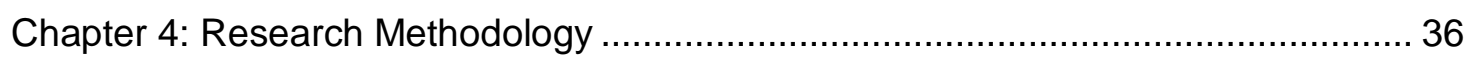

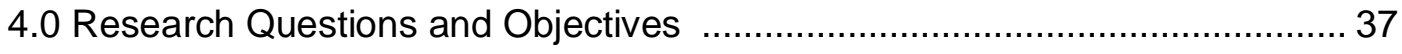

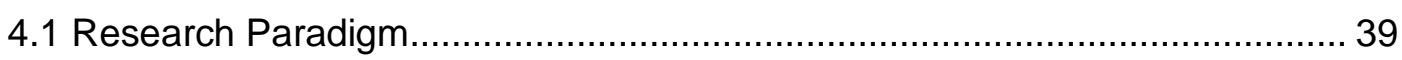

4.2 Research Methodology Choice ................................................................ 41

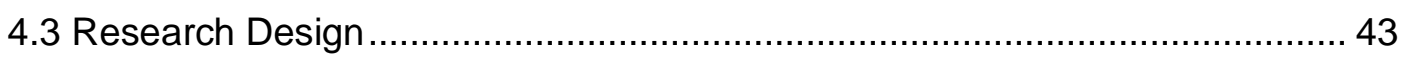

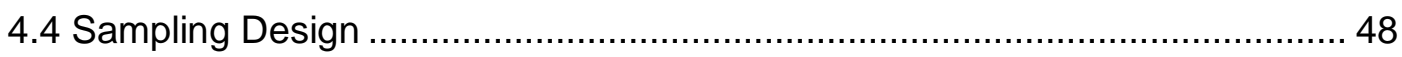

4.5 Data Collection and Recording Procedures .............................................. 49

4.6 Data Analysis and Interpretation Procedures ............................................ 52

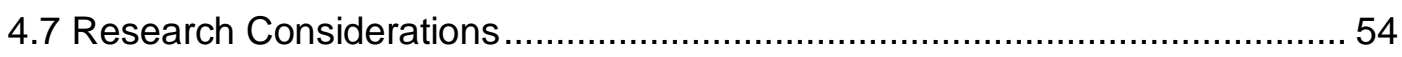

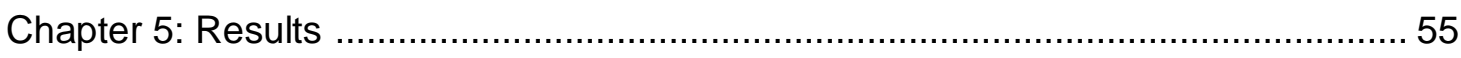

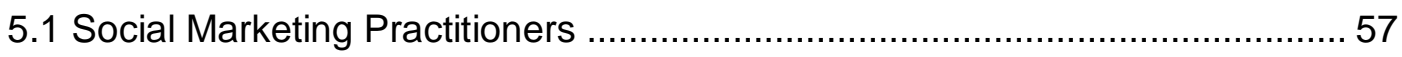

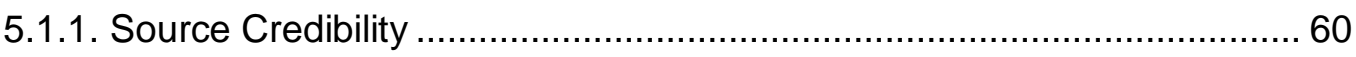

5.1.1.1. Source Credibility Perceptions................................................... 60

5.1.1.2. Alternative Effective Source(s).................................................. 66

5.1.1.3. Appropriateness of Strategy to Persuasion ................................... 68

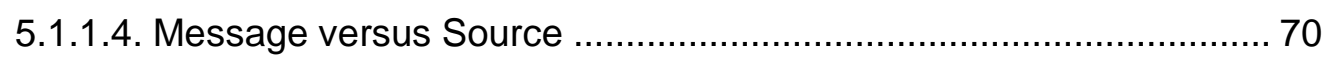

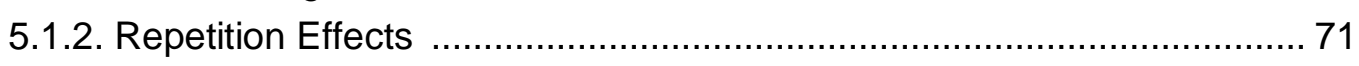

5.1.2.1. Advertising Frequency Intentions ................................................ 72

5.1.2.2. Cumulative Repetition Effects ................................................... 74

5.1.2.3. Impact of Cumulative Repetition ............................................... 77

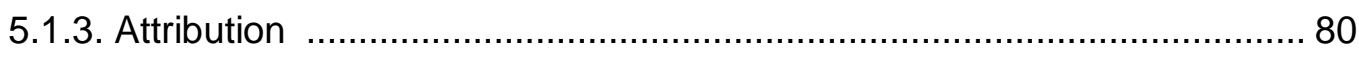

5.1.3.1. Attitude Towards Government Attribution ................................... 80

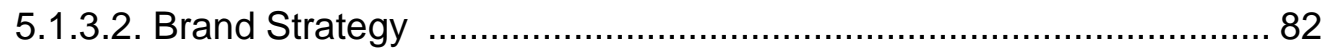

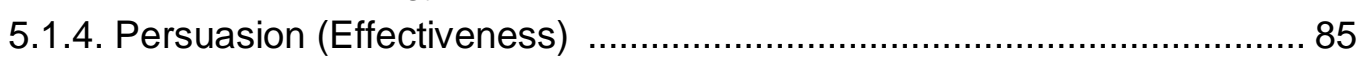


5.1.5. Summary of Results \& Implication to Members of the Public

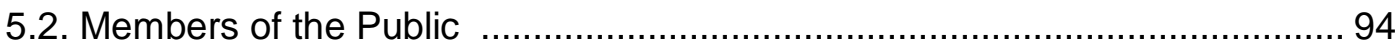

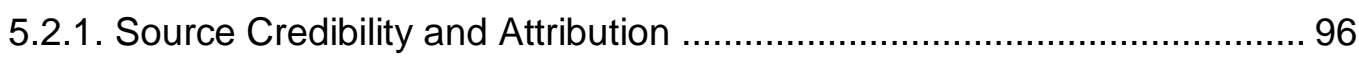

5.2.1.1. Source Credibility Perceptions .......................................................... 99

5.2.1.2. Alternative Effective Source(s)............................................... 101

5.2.1.3. Attitude of Government as Source ........................................... 103

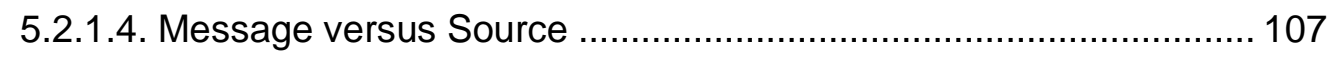

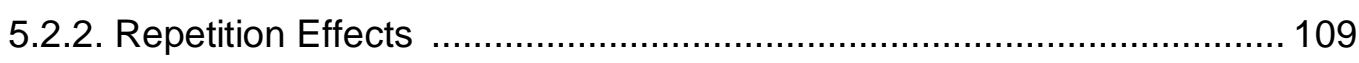

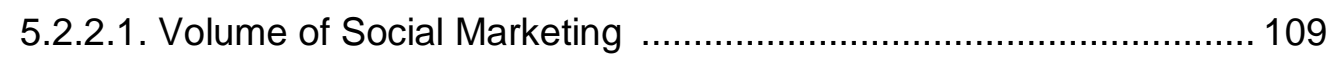

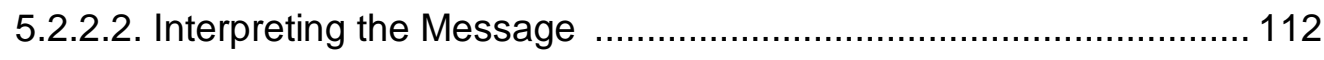

5.2.2.3. Distinguishing the Source ..................................................... 113

5.2.2.4. Impact of Repetition .......................................................... 115

5.2.3. Persuasion (Effectiveness) .......................................................... 117

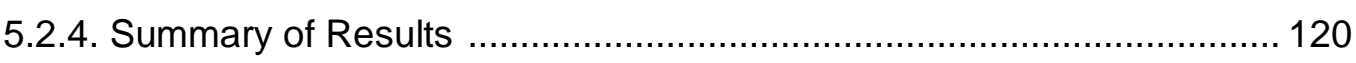

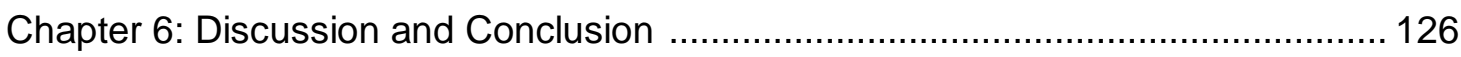

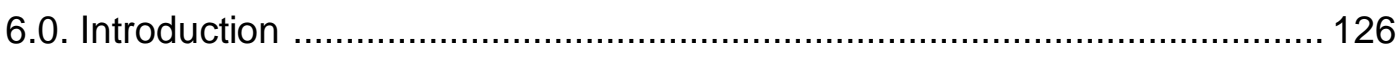

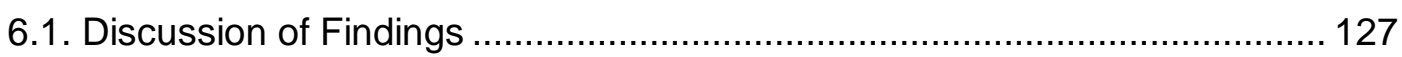

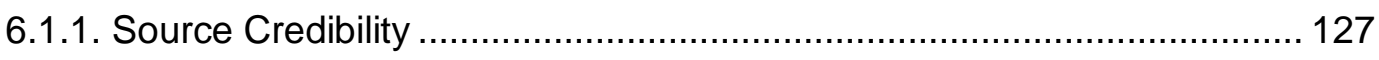

6.1.1.1. Predisposition of the Public........................................................... 127

6.1.1.2. Source Credibility Perception........................................................... 129

6.1.1.3. Alternative Source(s) ............................................................. 131

6.1.1.4. Message Processing Priority .................................................... 132

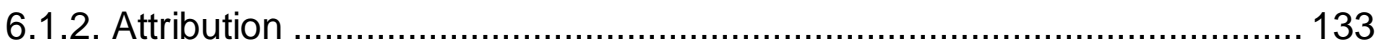

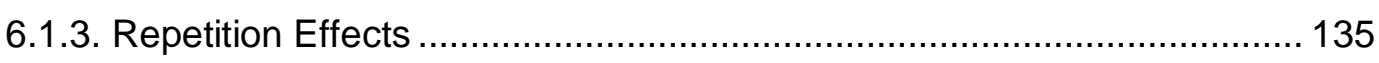

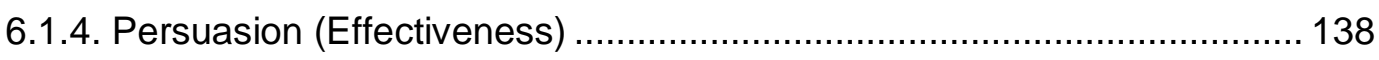

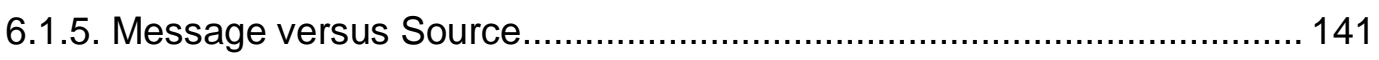

6.2. Summary of Main Points of Discussion ................................................... 142

6.3. Proposed Abbreviated Social Marketing Processing Model ....................... 144

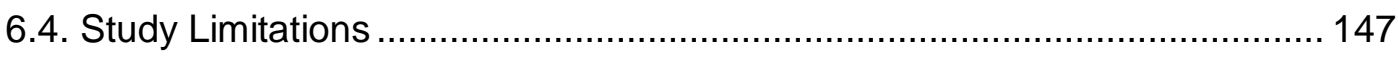

6.5. Recommended Future Research......................................................... 148

6.5.1. Generalisation ................................................................................. 148

6.5.2. Development of the Proposed Social Marketing Processing Model ....... 148

6.5.3. Other Related Research ............................................................... 149

6.6. Theoretical Contribution of this Study ................................................... 150

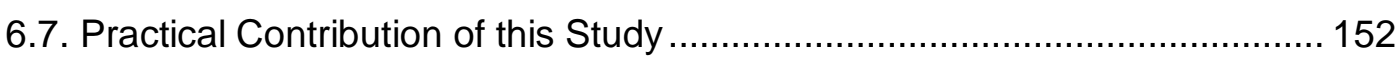

6.8. Conclusion and Final Remarks ......................................................... 154

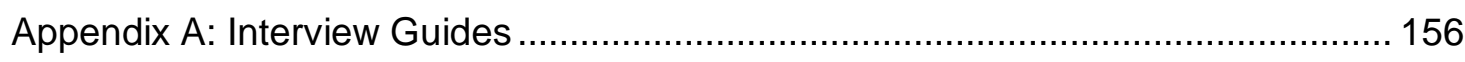

Appendix B: Information Guide for Interviewees .............................................. 163

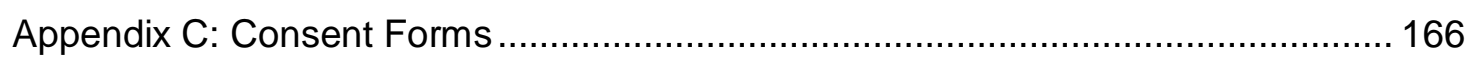

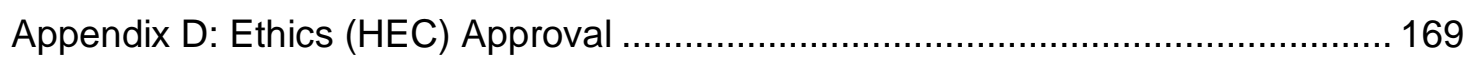

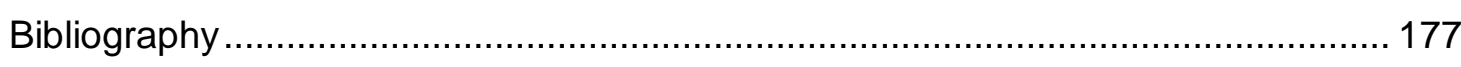




\section{LIST OF FIGURES AND TABLES}

\section{FIGURES}

Number

Page

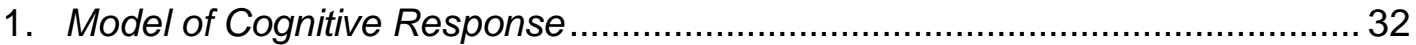

2. A Composite Model of Cognitive Response and Source Credibility .................. 34

3. Research Philosophy and Methodology Overview.......................................... 40

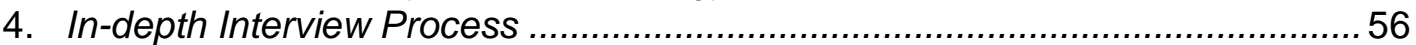

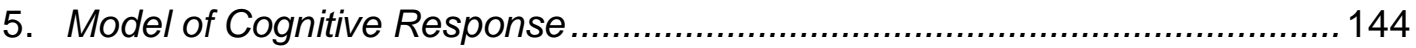

6. Proposed Abbreviated Social Marketing Processing Model .......................... 145

\section{TABLES}

Number

Page

1. Social Marketing Campaigns in New Zealand During 2008. 5 


\section{ACKNOWLEDGMENTS}

Firstly, I would like to thank my supervisors, Jayne Krisjanous and Associate Professor Michel Rod, for their encouragement and support throughout this research. I also extend my thanks to Professor Ashish Sinha for getting my brain 'moving' after so many years and to Dr. Janet Carruthers for showing enthusiasm and support for this study.

I would like to extend my gratitude and respect to Professor Nadine Henley, whose extensive work in social marketing is the inspiration for my modest research project, and whose words of encouragement provided the focus this project needed.

I would like to acknowledge the support of Sport and Recreation New Zealand (SPARC), my employer at the time, who was generous in allowing time and resources that assisted this study. In addition, I appreciate the opportunity to manage two of the most significant social marketing programmes of their time, Push Play and Mission-On.

This research would not have been possible without the kind cooperation and support of the many individuals involved. It was a pleasure to spend time learning more about their opinions and attitudes towards social marketing. In particular, I thank the social marketers for their honesty and frank discussions, also for their belief in my research that led to the deep discussions evidenced in this study.

Finally, I would like to thank my family. They are always wonderfully supportive and patient. My love and thanks to Mitch, Stefan and Anneliese. Also Mum and Dad, who always wanted the best for their children - thank you. This thesis is dedicated to you all. 


\section{INTRODUCTION}

1. Introduction

1.0. Introduction to the Study

A longitudinal study was conducted by Nielsen Global Omni (2007a) in the USA, UK and Australia investigating the source credibility of marketing healthy eating messages. In that study, $78 \%$ of interviewees claimed that the most credible source for healthy eating and nutritional messages was their general practitioner or medical professional (p. 12). However in New Zealand, the Ministry of Health, Ministry of Education, Health Sponsorship Council, Cancer Society, 5+ A Day Trust and the joint ministerial initiative called Mission-On are pursuing social marketing programmes promoting healthy eating without the use of medical practitioners or health professionals in their advertising as the message source.

Perman and Henley (2003) in their research into the effects of social marketing messaging on marijuana users in Western Australia found that most users believed: "government-sourced media campaign messages, school-based and parental sources were perceived to be biased and out-of-touch" (p. 1). It would appear that their research group, marijuana users, concurred with Nielsen Global Omni's (2007a) findings by stating that advice and information from medical professionals and medical websites, "would provide confidential, factual and trustworthy information" (p. 1).

The advertising landscape in New Zealand has been marked by the increasing presence of government-sponsored messages focused on improving the quality of life for the average New Zealander. By late 2008, many government departments and crown entities had adopted the role of providing advice and information to the community via marketing campaigns; predominantly television-based advertising. Between August 2007 and July 2008 government agencies via advertising agencies were responsible for over NZ\$102 million in media bookings for social marketing advertising (Nielsen Media Research AIS, 2008). In that year and within 
an average three-hour weekday primetime viewing period, the average New Zealander saw eighteen separate government-attributed social marketing television advertisements, all espousing their point-of-view on aspects of improving New Zealanders' lives (Nielsen Media Research AIS, 2008, p. 21).

In the majority of cases, social marketing advertisements are branded with the government agency (or agencies) branding to attribute the message to the government as the source or sponsor of the message. Furthermore, whether the advertisements utilise a spokesperson or actors to deliver the messages, some government social marketers make a conscious effort to attribute the message to a government source. This would appear counterintuitive when considering the research indicating that audiences of social marketing messages do not see the government as the most appropriate source of health or ethical social messages (Donovan \& Henley, 2003; Perman \& Henley, 2003; Henley, 2006; Hastings, 2007; Kotler \& Lee, 2008).

Overall, there is a widely held perception that, as government social marketing messages increase as a percentage of the total advertising landscape, the effectiveness of the messages are declining. The concern is that the government is becoming more intrusive and directive in their messages; more of a "Nanny State" and therefore the acceptance of the message is being offset by the individual's negative reaction to the perceived loss of freedom in decision making or pressure to act "for the public good" (Henley, 2006, p. 2).

Theoretically, as the volume of social marketing messages increase in general advertising, the more the individual will react against receiving the message. Moreover, when the number of government agencies participating in social marketing increases, the more the message effectiveness is influenced by the increase in the number of similar messages. Discussing the difficult ethical question that face governments in conducting social marketing, Donovan and Henley (2003) state: "some messages can backfire and increase the feeling of rebellion in the target market" (p. 164).

This potential rejection of social marketing messages was noted in Hasting's (2007) observations: "given the frequency of mass media efforts to dissuade people from taking up 
smoking (and in many countries a complete ban on pro-tobacco advertising), one would have expected an all-powerful media to have resolved the problem - and yet thousands of young people still take up smoking every year in Europe alone" (p. 85). Hastings (2007) also points out that the cost of complying with the myriad of different requests for lifestyle changes contained within the social marketing messages is too high: "similarly, the fact that in social marketing we have to compete with attractive alternative behaviours - taking it easy rather than exercising, a calming nicotine fix rather than an arduous quit attempt." (p. 153)

Anecdotally, New Zealand has moved into a social marketing condition that is rarely acknowledged in the literature. The high level of social marketing activity in New Zealand in 2008 was a phenomenon that does not appear to have been replicated in other countries. A review of current social marketing literature has seen no acknowledgement or discussion into the possibility of such a scenario, or the impact of a near-saturation condition in social marketing advertising in a single market.

The impact of this relatively high level of social marketing advertising in New Zealand is relevant to commercial marketing theories related to studies into the effect of high repetition advertising, albeit in the form of many similar social marketing advertisements from the same source, the New Zealand Government. Marketing journals do not appear to provide any significant insight into studies addressing the repetition effect of government-attributed social marketing advertising on the consumer.

Marketing practitioners embarking on social marketing programmes have drawn much from the theories and models used in commercial marketing, and as Andreasen states: "no one has attempted to set down a comprehensive conceptual framework for sound social marketing" (1995, p. xii). However, it would appear from the distinctive social marketing landscape in New Zealand that commercial marketing theory and models have not considered the impact of high-volume advertising from one source.

For the purpose of this research, social marketing is defined as the application of marketing technologies developed in the commercial sector to solutions of social problems where the 
bottom line is behaviour change. The difference from commercial sector marketing is the ultimate objective is to benefit the target audience and not the marketer (Andreasen, 1995, p. 8).

As a comparison, commercial marketing is a term used in this research to describe marketing used in the commercial sector. In this case, commercial marketing is used to describe the marketing techniques and activities performed to influence an exchange of products, services and money for financial profit. Commercial marketing's ultimate objective is to benefit the marketer (Andreasen, 1995; Kotler \& Lee, 2008).

This research has taken advantage of the current social marketing conditions in New Zealand in order to explore the impact of near-saturation government-attributed social marketing advertising on the source credibility of the New Zealand government, where the New Zealand government is the main source and sponsor of social marketing. It has also examined the repetition effect of various similar messages from one source, the New Zealand Government, in a social marketing context. 
The social marketing landscape in New Zealand has grown during the nine years of the centre-left Labour Government from December 1999 to November 2008. Table 1 indicates the extent of social marketing campaigns directed at the New Zealand population (4.2 million people) at the end of 2008. In all, 52 separate social marketing campaigns were undertaken by government agencies to address health, social and ethical issues, including chronic disease prevention, road safety, accidental death and injury, and anti-social behaviour. All listed campaigns included television and print advertising, as well as websites and other marketing activities. Between August 2007 and July 2008, government agencies were responsible for over $\mathrm{NZ} \$ 102$ million in media bookings with a further NZ\$85 million in marketing costs for social marketing advertising (Nielsen Media Research AIS, 2008).

Table 1 is a summary table of the observed social marketing campaigns conducted during 2008 by government agencies, either Ministries, Departments or Crown Entities.

Table 1 - Social Marketing Campaigns in New Zealand during 2008

\begin{tabular}{|lll|}
\hline Name of Campaign & Campaign Focus & Source \\
\hline R + A Day & Fresh Fruit \& Vegetable & $5+$ A Day Charitable Trust \\
\hline Ride Forever & Motorcycle Injury Prevention & $\begin{array}{l}\text { Accident Compensation } \\
\text { Commission }\end{array}$ \\
\hline Home Safety & Injury Prevention - Home Safety & $\begin{array}{l}\text { Accident Compensation } \\
\text { Commission }\end{array}$ \\
\hline Bikes Just Appear & Motorcycle Injury Prevention & $\begin{array}{l}\text { Accident Compensation } \\
\text { Commission }\end{array}$ \\
\hline $\begin{array}{l}\text { It's not the drinking, it's how we're } \\
\text { drinking }\end{array}$ & Alcohol Problems and Abuse & $\begin{array}{l}\text { Alcohol Advisory Council of New } \\
\text { Zealand }\end{array}$ \\
\hline Check, Clean, Dry & Didymo \& Other Aquatic Pest & BioSecurity New Zealand \\
\hline Let's Beat Diabetes & Prevention & Counties Manukau District Health \\
& Diabetes Awareness \& Prevention & Board \& Ministry of Health \\
\hline Get Ready Get Thru & Civil Defence Readiness & Department of Internal Affairs \\
\hline The Grim Harvest & Farm Safety & Department of Labour \\
\hline Take Care, So You Can Take Care & Farm and Workplace Safety & Department of Labour \\
\hline Energywise & Energy Efficiency & Energy Efficiency and Conservation \\
& & Authority \\
\hline $\begin{array}{l}\text { Parenting: The Best Day's Work } \\
\text { You'll Do }\end{array}$ & Parenting Skills & Families Commission \\
\hline Problem Gambling & Problem Gambling Cessation & Health Sponsorship Council \\
\hline Smokefree & Tobacco Control & Health Sponsorship Council \\
\hline SunSmart & Skin Cancer Prevention & Health Sponsorship Council \\
\hline Feeding Our Futures & Healthy Eating & Health Sponsorship Council \\
\hline
\end{tabular}




\begin{tabular}{|c|c|c|}
\hline Why Breast is Best & Breast Feeding & $\begin{array}{l}\text { Health Sponsorship Council and } \\
\text { Ministry of Health }\end{array}$ \\
\hline Stay on Top & National Pleasure Boat Safety & Maritime New Zealand \\
\hline Like Minds Like Mine & Mental Health Antidiscrimination & $\begin{array}{l}\text { Mental Health Foundation of New } \\
\text { Zealand }\end{array}$ \\
\hline Right House & Energy Efficient Homes & Meridian Energy (SOE) \\
\hline Smarter Homes & Energy Efficient Housing & $\begin{array}{l}\text { Ministry for the Environment \& } \\
\text { Department of Building and } \\
\text { Housing }\end{array}$ \\
\hline Buy New Zealand Made & Buy Local Campaign & Ministry of Economic Development \\
\hline Fuelled4School & Healthy Eating & Ministry of Education \\
\hline Team Up & Parenting \& Child Learning & Ministry of Education \\
\hline $\begin{array}{l}\text { Te Mana - Ki Te Maumata: Get } \\
\text { There With Learning }\end{array}$ & $\begin{array}{l}\text { Māori Support for Children \& } \\
\text { Learning }\end{array}$ & Ministry of Education \\
\hline Depression (John Kirwan) & National Depression Initiative & Ministry of Health \\
\hline $\begin{array}{l}\text { HEHA: Healthy Eating Healthy } \\
\text { Action }\end{array}$ & $\begin{array}{l}\text { Nutrition and Physical Activity } \\
\text { Education and Support }\end{array}$ & Ministry of Health \\
\hline Unpaid Fines & Fine Collection & Ministry of Justice - Collections Unit \\
\hline Family Violence: It's Not OK! & $\begin{array}{l}\text { National Campaign for Action on } \\
\text { Family Violence }\end{array}$ & $\begin{array}{l}\text { Ministry of Social Development and } \\
\text { the Families Commission }\end{array}$ \\
\hline Choke the Smoke & Reduction of Carbon Emissions & Ministry of Transport \\
\hline My Health My Body My Future & $\begin{array}{l}\text { National Cervical Screening } \\
\text { Programme }\end{array}$ & $\begin{array}{l}\text { National Screening Unit (Ministry of } \\
\text { Health) }\end{array}$ \\
\hline $\begin{array}{l}\text { Early screening is your best } \\
\text { prevention }\end{array}$ & National Breastscreen Aotearoa & $\begin{array}{l}\text { National Screening Unit (Ministry of } \\
\text { Health) }\end{array}$ \\
\hline Saves Lives Give Blood & Blood Donation Drive & New Zealand Blood Service \\
\hline Keep Looking When Your Cooking & Fire Prevention Campaign & New Zealand Fire Service \\
\hline Protect Our Children & Fire Prevention Campaign & New Zealand Fire Service \\
\hline Importance of Smoke Alarms & Fire Prevention Campaign & New Zealand Fire Service \\
\hline Don't Drink \& Fry & Fire Prevention Campaign & New Zealand Fire Service \\
\hline Speed of Fire & Fire Prevention Campaign & New Zealand Fire Service \\
\hline $\begin{array}{l}\text { If You Drink and Drive You're a } \\
\text { Bloody Idiot }\end{array}$ & Drink Driving Prevention & New Zealand Transport Agency \\
\hline Speeding - Slow Down & Speeding Prevention & New Zealand Transport Agency \\
\hline $\begin{array}{l}\text { Intersections - Bad calls can be } \\
\text { deadly }\end{array}$ & Care at Intersections & New Zealand Transport Agency \\
\hline Wake up to the warning signs & Fatigue Driving Prevention & New Zealand Transport Agency \\
\hline Always wear your safety belt & Seat Belt Safety & New Zealand Transport Agency \\
\hline Right Car & Energy Efficient Motor Vehicles & New Zealand Transport Agency \\
\hline Powersavers.co.nz & Energy Conservation & $\begin{array}{l}\text { Power Generators Industry Group } \\
\text { \& Ministry of Economic } \\
\text { Development - Energy \& } \\
\text { Resources }\end{array}$ \\
\hline Sorted & Financial Management & Retirement Commission \\
\hline Push Play: Feeling Greatness & Physical Activity Encouragement & Sport \& Recreation New Zealand \\
\hline Push Play: Parents & $\begin{array}{l}\text { Physical Activity - Youth } \\
\text { Encouragement }\end{array}$ & Sport \& Recreation New Zealand \\
\hline Quit & Anti-Smoking & The Quit Group \\
\hline Swim for Life & Drowning Prevention & Water Safety New Zealand \\
\hline Mission-On & $\begin{array}{l}\text { Nutrition and Physical Activity } \\
\text { Education and Support for Children }\end{array}$ & $\begin{array}{l}\text { Sport \& Recreation New Zealand, } \\
\text { Ministry of Health, Ministry of } \\
\text { Education \& Ministry of Youth } \\
\text { Development }\end{array}$ \\
\hline Sustainability & Government Sustainability Strategy & Pan Government Initiative \\
\hline
\end{tabular}

The significant growth of government sponsored social marketing campaigns over the last nine years has intensified the public debate that the government is being excessive in its desire to protect, govern or control particular aspects of the individual's life and choices, and the now-popular expression "Nanny State" was coined in reference to the Labour 
Government. Henley (2006) asked the question, "Should individuals be free to make lifestyle decisions (such as what, when and how much to eat and how much physical activity to take), without undue interference from the state, even when their decisions may lead to negative consequences (obesity, heart disease, diabetes)?" (p. 1).

Towards the latter half of 2007 and through 2008, there was evidence of a fundamental change in the public and media's attitude towards the volume of government-attributed social marketing campaigns. A Fairfax Media-Nielsen poll published in The Dominion Post newspaper on the $19^{\text {th }}$ November 2007 reported that, "Of 1082 voters, 57 per cent said the Government had more control over people's daily lives than they would like, while 37 per cent rejected the proposition". Commenting on the social marketing landscape during those times, Bridges (2009) stated, "In some recent media articles, journalists and commentators have begun to question the quantity and quality of social marketing messages coming into New Zealand living rooms during TV ad breaks" (p. 14).

In their 2003 study of source credibility, Forehand and Grier (2003) found private firms operating corporate societal marketing [CSM], "the potential negative reaction of consumers to the use of CSM was driven not simply by beliefs that the firm might benefit, but rather by the perception that the firm was being deceptive about the benefits it receives" (p. 354). So too, the New Zealand public has started to question the motivation of government agencies who have dominated the marketing channels with social marketing messages at a significant cost to the taxpayer without substantive evidence of the benefit to the public good (Bridges, 2009, p. 15). 


\subsection{Research Objectives}

This research seeks to explore the phenomenon associated with the high level of social marketing activity in New Zealand in 2008. This phenomenon does not appear to be replicated in other countries and no acknowledgement or discussion into the possibility of such a scenario occurring has yet been studied in the literature.

Exploring this phenomenon, this research will:

1. Examine the impact of the high volume of government-attributed social marketing advertising in New Zealand on the source credibility of the government, as the message source.

2. Explore whether the public believe the government is an appropriate message source for social marketing messages and if not, who or what would be a more appropriate messenger.

3. Investigate the repetition effects of multiple similar advertisements from one attributed source.

4. Develop a conceptual model to illustrate the effect of high exposure rates of similar advertisements from one source in a social marketing context.

5. Inform marketing practitioners and assist in planning the communication process in social marketing campaigns, as well as providing empirical evidence in consideration of the message source. 


\subsection{Research Questions}

Over the past ten years, there has been a steady increase in government sponsored social marketing programmes in New Zealand. These government agencies are motivated to improve the quality of life for all New Zealanders, now and in the future, by persuading and influencing current beliefs and behaviours through their marketing campaigns. However, with the ever increasing number of marketing messages from different government sources, the effectiveness of these marketing messages is thought to be declining as the message receivers (the public) respond to the perception that the sender (the government agencies) is being too directive and intruding into the area of personal responsibility. This research seeks to establish:

1. What is the impact of high volume government-attributed social marketing messages in New Zealand on the source credibility of the government, as the message source?

2. Does the public believe the government is an appropriate message source for social marketing messages? If not, who or what would be a more appropriate messenger?

3. How does the repetition of multiple similar advertisements from one attributed source impact on the source in a social marketing context? 


\section{Chapter 2}

\section{LITERATURE REVIEW}

\section{Introduction}

This chapter discusses the findings from a review of a broad range of marketing literature that discussed research into source credibility, repetition effects in advertising, persuasion and attribution. These findings have informed this research and provided direction for further exploration and discovery.

In the review of academic literature, studies into social marketing appear to be relatively few compared to other marketing disciplines. Discussion on source credibility in a social marketing context is uncommon, as are studies and discussion into repetition effects in social marketing advertising. Therefore, research findings and models have been drawn from commercial marketing and social sciences to attempt to explain the construct and component interactions of source credibility, repetition effects in advertising, persuasion and attribution.

\subsection{Source Credibility}

In this research, source credibility is the target audience's perception of the communicator's credibility, including beliefs about their knowledge, intelligence, and sincerity. This concerns the factors related to the credibility of the source (Hovland, Janis \& Kelley, 1953; Jones, Sinclair, \& Courneya, 2003).

Since the early 1950s, significant research has centred on source credibility within the communication process. Hovland and Weiss (1951), seminal writers in the area of source credibility, demonstrated the relationship between source credibility and attitude change. They concluded that high credible sources produced more influence on attitude change than low 
credible sources. They stated, "In 14 of 16 possible comparisons the "low-credibility" sources are considered less fair or less justified than the corresponding high credibility sources" ( $p$. 641). Hovland, Janis and Kelley (1953) furthered the research into the relationship between high and low credible sources and message comprehension to determine the antecedent components of source credibility, namely expertness (expertise) and trustworthiness (p. 21).

In discussing an audience's reaction to a government film, Hovland et al. (1953) stated, “... there is a tendency to reject communications which are perceived as being manipulative in intent" (p. 24). They concluded that the audience's attitude toward the expertness and trustworthiness of the communicator, the government, was perceived to be manipulative or dishonest in intent and therefore, due to this apparent untrustworthiness, the communicated message was discounted (p. 24).

Confirmations of Hovland et al. (1953) findings are present in the literature. Research indicates that, where there is doubt of the source's intent or motivation, the target audience will question the source's trustworthiness, therefore affecting the credibility of the source. Discussing their research into government-attributed anti-drug advertising Perman and Henley (2003) comment, "For users, all sources that were perceived to have an agenda were seen as untrustworthy. The inherent association between government sources and prohibition messages reduced credibility. Likewise, most parents and school programs were assumed to advocate prohibition, so they were not credible sources" (p. 28). Earlier research by Donovan and Henley (2003) indicated a possible cause in the reduced source credibility of the government: "Unfortunately, health, environmental, social, and other scientists do not always agree on many issues, leading people to being potentially somewhat sceptical or cynical about various warnings and threats issued by government organisations" (p. 77).

The same condition is present in commercial organisations were the trustworthiness is affected by organisation's obvious intentions or motivations as illustrated by Forehand and Greer (2003). They stated “... consumers are likely to know that firms have ulterior motives such as profit or image management and may be more distrustful of firms that profess purely public-serving motives" (p. 349). 
Hassan, Walsh, Shiu, Hastings, and Harris (2007) in their research into anti-smoking social marketing campaigns in eight EU countries discussed the moderating factor of source credibility in the effectiveness of the communication in these campaigns. Hassan et al. (2007) stated, "Hovland and Weiss demonstrated that people attached subjective a priori credibility levels to different sources, and that sources exhibiting expertise and trustworthiness are more effective in changing opinions" (p. 18). Their research highlighted the target audience's reliance on feelings of trust and knowledge and a lack of self-interest in the source, in order for the message to be effective and to influence higher levels of comprehension. They made the observation that, in Western EU countries perception of self-interest in commercial organisations affected the target audience's feeling of trust and therefore, the effectiveness of the message. In contrast, former communist Eastern EU countries felt government-attributed anti-smoking messages were less credible than commercial companies who represented conduits for fulfilment of Western values and lifestyles (Hassan et al., p. 26).

Focusing on a specific social marketing campaign addressing sun protection in Australia, Smith, Bauman, McKenzie, and Thomas (2005) conducted research into the impact of the message source on the overall effectiveness of the campaign. They concluded that after a number of similar campaigns between 1998 and 2000 the attribution of the message to the NSW Cancer Council was a positive influencer on the total message recall and effectiveness of the message. They stated, "Message source awareness could increase the perceived trustworthiness and importance of the information conveyed ..." (p. 50).

Similarly, in Western Australia, Donovan and Henley (2003) stated, “... many non-profit organisations and individuals do have high credibility. For example, a recent survey (Jalleh \& Donovan, 2001) showed that 66 per cent of Western Australians rate the Cancer Foundation of Western Australia as 'very credible' and a further 25 per cent rated it as 'somewhat credible'" (p. 77).

The influence of source credibility on message effectiveness and comprehension has been considered by other researchers in isolation to the other similar messages in the mass media. Not-for-profit and commercial companies conducting social marketing were not considered in 
the same manner as government-attributed social marketing campaigns. Many campaigns conducted by government agencies were considered in the same light as the earliest studies by Hovland and Weiss (1952) and Hovland et al. (1953). That is, that the audience believed that the government had an ulterior motive or there was a perceived self-interest. In particular, the audience's negative feelings were due to the lack of trustworthiness in the government source (Sternthal, Dholakia, \& Leavitt, 1978; Forehand \& Grier, 2003; Perman \& Henley, 2003; Hassan et al., 2007; Wall, 2007).

In conducting a research evaluation of anti-marijuana campaigns run between 1996 and 2001, Perman and Henley (2003) found the source credibility of government was not considered compelling in its impact on persuasion for the target audience. They stated, "Governmentsourced media campaign messages, school-based and parental sources were perceived to be biased and out of touch. Exceptions were medical professionals and medical websites, which some users believed would provide confidential, factual and trustworthy information" (p. 2). They further posit that, "Government as a source for anti-drug campaigns was seen as unreliable by users... alternative sources with more credibility that were suggested by the interviewees were medical Internet websites and medical practitioners; these were both considered sources of valid and accurate information, in a confidential environment" (p. 30).

Gotlieb and Sarel (1991) made several key observations, observing that consumers can best compare and contrast product offerings within advertisements when the advertising environment is uncluttered from similar advertisements. They also comment that a highly credible source will achieve more influence on the consumer in comparing different advertisements (p. 44). Anecdotally, in a high-volume advertising environment, the consumer could have difficulty interpreting and comparing similar advertisements reducing the effectiveness of those advertisements.

All social marketing messages have competitive messages: in anti-obesity social marketing advertisements, there are the counter advertisements for high, sugar, salt and fat food and beverage producers and in anti-smoking social marketing advertisements there are the tobacco company advertising and so on. As Hastings (2007) states, "Similarly, the fact that in 
social marketing we have to compete with attractive alternative behaviours - taking it easy rather than exercising, a calming nicotine fix rather than an arduous quit attempt" (p. 153).

Much research looking at source credibility is derived from commercial marketing research and practice. Many examples of source credibility research have been built on the initial work of Hovland and Weiss (1951) and Hovland et al. (1953) testing the construct using variable and moderating factors, including elaboration (Sternthal, Dholakia, \& Leavitt, 1978; Tormala, Brinol \& Petty, 2006; Tormala, Brinol \& Petty, 2007); emotional moderators (Forehand \& Grier, 2003; Reid, Soley \& Vanden, 1981); message framing (Jones, Sinclair \& Courneya, 2003; Buda, 2003; Arora, Stoner \& Arora, 2006); influence of source versus endorser (Lafferty, Goldsmith \& Newell, 2002; Kahle \& Homer, 1985; Daugherty, Logan, Chu \& Huang, 2008; Till \& Busler, 1998); timing of source identification (Homer \& Kahle, 1990); attribution/misattribution (Hassan et al., 2007; Smith, Bauman, McKenzie \& Thomas, 2005); media type (Finch, 1997); positive influence of high credibility source (Smith, Bauman, McKenzie \& Thomas, 2005; Hassan et, al, 2007; Herbig \& Milewicz, 1995); comparative advertising (Gotlieb \& Sarel, 1991); and exposure rates (Moore, Hausknecht, \& Thamodaran, 1986). In all cases, the findings confirm the validity of the components of expertise and trustworthiness to the source credibility construct. Namely, "In experimental investigations of the persuasive effect of source credibility, it has been frequently demonstrated that highly trustworthy and expert spokespeople induce a greater positive attitude towards the position they advocate than do communicators with less credibility" (Sternthal, Dholakia, \& Leavitt, 1978, p. 252).

However, an apparent omission in the literature was research into the cumulative effect of advertising on this construct. All research studied single advertisements in isolation from other similar messages or similar sources. 


\subsection{Repetition Effect}

"From printed page to the cathode ray tube, from posters to packaging, from sponsorships to direct mail - an avalanche of unwanted, undesired messages promote increased consumption" (Kitchen, 1994, p. 24).

There is no doubt that the repetition effects of advertising have an impact on the credibility of the advertising source (Craig, Sternthal, \& Olshan, 1972; Craig, Sternthal, \& Leavitt, 1976; Calder \& Sternthal, 1980; Stephens \& Warrens, 1984; Kisielius \& Sternthal, 1984; Naples, 1997; Nordhielm, 2002). To gauge this, it is necessary to draw on studies looking at the repetition effects of advertising on the target audience from commercial marketing research. This will inform the research of the potential impact of high repetition rates on the effectiveness of the social advertising and the possible effect that high repetition of a message will have on the credibility of the government source.

In the review of the literature, it is noted that the phenomenon described in the introduction that is, a high volume of similar messages from one attributed source does not appear to have been discussed. However, a significant quantity of research has centred on the repetition effect of a single advertisement on the target audience.

In discussing the influence, that repetition effect has on both process, learning and forgetting, Stephens and Warrens (1984) cite Grass (1968) stating, “... the effects of repetition followed an inverted U-shaped function. Initially, more exposure produced increased learning. At some point (two or four exposures in this study), however, satiation was reached and additional exposure begins to produce decay, or forgetting" (p. 23).

Calder and Sternthal (1980) elaborate further on this finding to confirm that continued repeat exposure to a television advertisement created negative feelings towards the product after a predetermined number of exposures (p. 185). In fact, in discussing the phases that the audience experience through high levels of exposure to the same television advertisement, Stephens and Warren (1984) describe the initial stages, "When repetition levels are much higher than those needed to learn, audiences become inattentive and lose motivation to recall" 
(p. 24). As the audience experiences further exposure, the audience's feelings towards the advertisement becomes unhelpful to the message retention, they observe, "Very high levels of repetition did not produce significantly better retention and, in fact, may have generated hostility among subjects" (p. 24).

The level of repetition at which the audience generates no further message retention or influence has been discussed at length in the literature. Naples (1997) posits that beyond three exposures in a four to eight week period "... builds effectiveness at a decreasing rate" ( $p$. 8), whilst Nordhielm (2002) cites Bornstein's (1989) research in which the downturn in affective response rate commonly occurs at approximately 21 exposures (p. 372). In discussing the results of her experiment, Nordhielm (2002) observes that an extremely high exposure rate of 80 exposures was required before reduced downturn in affective response was detected. Nordhielm notes, "This result is noteworthy because it contrasts with the results of many previous advertising repetition studies that have reported this downturn in affective response at advertisement repetition levels higher than 10 exposures" (p. 375). In a discussion of advertising volume, Kitchen (1994) cites Kotler (1988) in his claim that in an average day a single consumer is exposed to over 2,000 advertising messages. He states, "The majority of such exposures are screened out either by lack of interest or sensory overload" (Kitchen, 1994, p. 21). It would seem that the combination of repetition of advertising combined with the volume and variety of advertising traffic conceivably reduces the effectiveness of the collective advertising effort.

In contrast, social marketing television advertisements attributed to the New Zealand government reached its peak in November 2008. Eighteen separate advertisements per threehour prime time viewing period with an average of 1.8 exposures per advertisement per period were recorded (Nielsen Media Research AIS, 2008, p. 21). That equates to over 32 socialmarketing advertisements per evening. Referring to Nordlielm's research (2002) it may be fair to consider that within three days of exposure to these television advertisements a downturn in affective response to those advertisements would be detected. Further, it may be fair to 
assume that at some point these high exposure rates may generate hostility towards the advertisement as discussed by Stephens and Warren (1984).

Most behaviour-change advertising encourages high involvement or a deeper processing condition due to the nature of the advertising message and the analysis of long-term behaviour change and benefit (Hastings, 2007; Donovan \& Henley, 2003; Hassan et al., 2007). Significantly, Nordhielm (2002) noted, “... consistent with the hypothesis, in the deeper processing conditions, net positive thoughts tended to increase and then decrease with repeated exposure" (p. 379).

The level of involvement in decision-making has been discussed at length in the literature. The higher the level of decision-making required in the product or service, the more likely the high repetition will negatively influence the retention and persuasion of the message. Nordhielm (2002) posits the possibility that at a moderate repetition level, the exposure serves to allow deeper processing by the audience (p. 379). Supporting this, Haugtvedt, Schumann, Schneier, and Warren (1994) commented, “... increased persuasiveness in some previous repetition studies could have emerged because of the greater processing of substantive aspects of the advertisements, whereas in other studies increased persuasiveness may have been due to increased exposure to positive cues (e.g. more attractive endorsers) across exposures to the advertisements" (p. 177).

Conversely, Moore et al. (1986) claimed that the increased exposure affects the audience's ability to process complex messages and concepts contained in the advertisement. They claimed, “Limiting the consumer's opportunity to elaborate upon advertising information should reduce the amount of information learned during any given exposure" (p. 87). In the New Zealand context, the volume of similar messages in a regular viewing period challenges the opportunity of the audience to process the message before the next advertisement. Wright (1980) stated, “... the number of cognitive responses evoked by advertising claims should decline as exposure rates increases" (p. 174). 
In looking at the ability of an audience to process complex messages from high repetition advertisements, Kisielius and Sternthal (1984) observed, "The experiment was based on the premise that cognitive elaboration requires a substantial amount of time. If this assumption is correct, limiting the time given to subjects to process information should reduce the cognitive elaboration that would otherwise occur" (p. 58).

The focus of advertising researchers has been to investigate the nature of the repetition function, which has been shown to vary according to several moderating factors. For example, repetition effects appear to be mediated by: commercial pool size (Calder \& Sternthal, 1980); familiarity with the product (Craig, Sternthal, \& Leavitt, 1976); pool size of surrounding commercials (Calder \& Sternthal, 1980); optimal exposure rates (Naples, 1997, Nordhielm, 2002, Sternthal, Dholakia, \& Leavitt, 1978); level of persuasion and counter-persuasion in the messaging (Kisielius \& Sternthal, 1984, Haugtvedt et al., 1994, Sternthal, Dholakia, \& Leavitt, 1978); volume of other marketing communications (Kitchen, 1994, Stephens \& Warrens, 1984); patterns of individual information processing (Mehta, 1994, Calder \& Sternthal, 1980); the level of involvement in decision making (Smith \& Swinyard, 1982, Kitchen, 1994); delay between time of exposure and time of response measurement (Craig, Sternthal, \& Leavitt, 1976); and impact on repetition on audience attention levels (Moore, Hausknecht, \& Thamodaran, 1986, Calder \& Sternthal, 1980).

It is fair to conclude from the literature that the higher the repetition effect of an advertisement the more negative influence it will have on the audience's opinion of the advertisement. As Nordhielm (2002) stated, “... initial repetitions generate mostly positive habituation, so the number of positive thoughts increases over these initial presentations, whereas later repetitions generate increasing tedium and therefore more negative thoughts." (p. 372) Further, "Very high levels of repetition did not produce significantly better retention and, in fact, may have generated hostility among subjects" (Stephens \& Warrens, 1984, p. 24). 


\subsection{Persuasion}

The concept of persuasion is a critical outcome to all advertising, regardless of purpose. The core purpose of social marketing is to achieve and maintain desirable social change and without the ability of the marketing activities to persuade the target audience to initiate behaviour change, the activity has been for naught (Donovan \& Henley, 2003, p. 1). Hassan et al. (2007) stated, “... a central aim of any social marketing campaign is the attainment of audience behaviour compliance.... without a high level of motivation for behavioural change, consequential behavioural compliance is either unlikely to take place or will be short-lived" ( $p$. 17).

Persuasion in advertising can be moderated by the selectivity an individual places on the advertised message. Donovan and Henley (2003) cite Donovan (1992) and Egger et al. (1993) in the discussion on the three core types of selectivity a target audience exhibits in their attention, perception and retention of a social message. Most appeal is derived from messages that have personal relevance, agree with people's existing attitudes and beliefs and where the recall of that message from memory is recalled in a more favourable way towards the individuals existing attitudes and beliefs. To illustrate the point, Donovan and Henley (2003) remark, "... smokers who find it difficult to quit or who want to keep smoking tend to avoid antismoking messages, but pay attention to news reports that question or contradict the relationship between smoking and ill health." (p. 64).

Further to this selectivity, if the audience has a pre-disposition towards the message then the source credibility does not have to be high in relative terms for the message to be effective. Sternthal et al. (1978) commented that, “... their highly credible source induced greater persuasion when message recipients were adamantly opposed to the communicator's position, but the less credible source was more influential when the issue was one towards which individuals were likely to have a favourable disposition" (p. 252).

Tormala, Brinol, and Petty (2006) further examined the relationship between source credibility and message persuasiveness and concluded, "When the persuasive message was strong, 
high credibility sources produced more persuasion than did low credibility sources. When the persuasive message was weak, high credibility sources produced less persuasion than did low credibility sources" (p. 689).

Discussing the implication of their experiments, Kisielius and Sternthal (1984) noted of their audience that they: “... formed favourable associations with the message position when the communicator was highly credible, thus enhancing advocacy-consistent judgement" (p. 62). Their findings support a direct relationship between high credibility and persuasion and a strong advocacy for the view supported by the highly credible source and the intention to act.

Government, as the source of social marketing campaigns, sees itself as an authoritative and objective source appropriate to the social message (Bridges, 2009, p. 16). Concerning this, Cialdini and Goldstein (2002) affirmed, “... we tend to defer to the counsel of authority figures and experts to help us decide how to behave, especially when we are feeling ambivalent about a decision or when we are in an ambiguous situation." (p. 49). However, in the development of the Persuasion Knowledge Model, Friestad and Wright (1994) claimed that persuasion is only achieved when the target of advertising believes that the agent (source) is knowledgeable, trustworthy and their message relevant to the target (audience). 


\subsection{Attribution}

"We presume that the consumers seek valid attitudes towards the puppet masters, not their puppets." (Friestad \& Wright, 1994, p. 8)

For the purpose of this research, attribution is the establishment of an organisation or individual as the creator and source of an advertisement or marketing activity (Kelley, 1973; Folkes, 1988).

Fundamental to this research is the target audience's attitude towards the perceived source of the message. Anecdotally, if there is a less than favourable attitude towards the government, then all social marketing messages attributed to the government will be less effective than messages attributed to alternative sources. Hassan et al. (2007) stated, "In the realm of socially orientated communications, the level of effectiveness of the social marketing messages will likely depend on the perceived sources of the message" (p. 19).

In Perman and Henley's (2003) evaluation of the anti-drug social marketing campaigns conducted in Western Australia, they observed, "Government-sourced media campaign messages, school-based and parental sources were perceived to be bias and out of touch. Exceptions were medical professionals and medical websites, which some users believed would provide confidential, factual and trustworthy information." (p. 2). Therefore, the audience would perceive the attribution of anti-drug messages from medical practitioners as more effective and trustworthy than the same message attributed to the government.

In attributing the advertising to a source, use of an endorser to communicate the message may appear to mask or divert the consumer's attention from the true source of the advertisement. However, Friestad and Wright (1994) discussed this issue in the context of mass media advertising and concluded the consumers' perceptions of the spokesperson or actors as playing a part and were not perceived as the agent (or source) of the message ( $p$. 8). Moreover, consumers will seek to understand why a spokesperson or actor is communicating the message and seek to understand who is the agent (or source) of the 
message. They further stated, “... the consumer has been depicted in attribution theory accounts as trying to understand why someone is speaking on behalf of the marketer" (p. 21).

In essence, Buda (2003) furthers Friestad and Wright's observation by confirming that consumers will actively seek to clarify the message source and accuracy. He noted, "Attribution theory suggests that consumers, when presented with a message, will make an effort to assess whether the message provides an accurate representation and/or whether the source of the message lacks credibility" (p. 158).

Lafferty, Goldsmith, and Newell (2002) identified that consumers did not perceive an endorser or actor in an advertisement to be a single communicator. The consumers perceived that an endorser is only a single part of the communication and the source (or owner) of the communication is also contributed to the message. In this way, they have identified corporate credibility is linked with three separate variables that interact to influence the consumers attitude towards the message. Conversely, the consumer links the endorser to only one variable (pp. 6-7).

The literature also considers brands as being similar to endorsers and actors. Lafferty, Goldsmith, and Newell (2002) contended that the consumer would actively seek to attribute the advertisement to an owner or source. In this way, the use of brand to hide or divert attention from the true source of the advertisement, at least in theory, will be ineffective as the audience will actively seek the owner (Buda, 2003).

In the New Zealand context, it is possible that with the high volume of government-attributed social marketing advertising consumers will misattribute all social and altruistic advertising to government sources. This misattribution may be detrimental to the message effectiveness, as discussed by Hassan et al. (2007): "At the same time, we do know that consumers attach varying levels of credence to different sources, and consequently, misattribution can reduce advertising effectiveness" (p. 16). "It is therefore pertinent that the likelihood and consequences of misattributions of governmental promotional messages be examined and understood" (p. 19). 
Considering Perman and Henley's (2003) findings that the government was not the most appropriate source of anti-drug messages, both Smith et al. (2005) and Donovan and Henley's (2003) findings that not-for-profit organisations - the NSW Cancer Council and Cancer Foundation of Western Australia - were positive influencers to the sun protection message and misattribution to a government source could reduce the effectiveness of the campaigns.

McGinnies and Ward (1974) contended that, "A persuasive communication for which no particular source is identified may be assumed to have emanated from a credible communicator" (p. 369). This may not be the case in New Zealand. It may be more appropriate to assume that when no particular source is identified, the consumer may attribute the communication to the most prolific or usual source. Moreover, further exploration into the high volume social marketing environment may reveal that consumers may not attribute the message to a particular government source rather generally to the 'government'. Discussing government-attributed social marketing advertising Hassan et al. (2007) commented, “... these studies assume that consumers can attribute the message to the intended source. There is increasing evidence, however, that consumers can get confused about the actual sponsor of the message" (p. 16). 


\subsection{Social Marketing and Government}

Fox and Kotler (1980) discussed the evolution and development in social marketing in the previous 10 years, since the early 1970s. In their discussion they stated, "In various nations of the world, companies are promoting the consumption of products that are undesirable or potentially harmful, for example cigarettes, alcoholic beverages, and highly refined foods which contribute to lung and heart disease, liver damage, overweight, and other problems" ( $p$. 27). They went on to discuss the reaction of governments and public interest groups to combat this large-scale advertising by creating counter-argument in the mass media, known generally as 'social marketing'.

In the majority of cases, this counter argument is championed by the government as a means to prevent chronic disease or harm from ethical dilemmas in society. Generally, government is the only organisation with the motivation and the financial resources to conduct social marketing against the large promotional budgets behind these deleterious products (Fox \& Kotler, 1980; Andreasen, 1995; Hassan et al, 2007; Wall, 2007; Bridges, 2009). Wall (2007) further stated, "Commercial companies with powerful resources at their disposal are one of the main sources of competition any government faces when trying to induce people away from using products that are harmful to their health or a waste of vital resources" (p. 124).

However, the scale required to make significant influences in chronic disease prevention is placed into context with Bridges' (2009) quote of Andreasen from his presentation to the 2008 World Social Marketing Conference in Brighton, England: "Gillette paid \$100 million to launch its Mach 3 Razor. We get $\$ 500,000$ to wipe out AIDS" (p. 16).

Within the literature, there is the belief that the government of any country has more to gain from effective social marketing than simply the imparting of information and advice, "One argument that is often used to justify interference from the State is that the economic costs of allowing unsafe/unhealthy behaviours have to be borne by the community" (Henley, 2006, p. 2). Bridges (2009) argued that the benefit to government is wider than simply the reduction in the cost of unsafe and unhealthy behaviour but to all government services: "Social marketing 
exists to reduce the cost of, and demand for, government services, particularly health services" (p. 15).

There is a consensus in the literature and the popular press that some level of government advice and information is acceptable. Bridges (2009) noted, "Most New Zealanders, unless they are Libertarians, probably accept that at some level, government have a role to play in helping to solve some of the major social and environmental problems" (p. 14). Henley (2006) indicated that on the whole, some level of government intervention through social marketing is acceptable and stated, "A survey of opinion in the UK in 2004 by the King's Fund, an independent think tank, found that the public generally supported government initiatives to encourage healthier school meals; ensure cheaper fruit and vegetables; pass laws to limit salt, fat and sugar in foods; stop advertising junk foods for children and regulate for nutrition labels in food in their report, The UK wants a Nanny State. " (p. 2).

The discussion in the existing literature focuses on social marketing as a small percentage of the advertising landscape. It is anticipated that this phenomenon would change New Zealand society's general feeling toward government social marketing campaigns as a whole. Henley (2006) comments, "At the extreme, people may be afraid that social marketing could be used by the State as a way to control the thoughts of the vulnerable, a view expressed some years ago by the participants in a survey towards social marketing by Lacznich, Lusch and Murphy in 1979" (p. 2). This may raise the question of a Libertarian viewpoint: Henley (2006) again comments, “... the Libertarian ethical viewpoint would question whether governments, through social marketers, have the right to try to influence people's lifestyle decisions, such as how much and what to eat, etc. In the rise of the Nanny State, Holt argued that the governments are extending the range of their regulatory powers, restricting free markets and intruding into areas of personal responsibility, all under the guise of acting for the public's good" (p. 2).

New Zealand's popular press is questioning the levels of government intervention in the average New Zealander's life, especially in the form of social marketing. The Dominion Post newspaper confronted the Prime Minister of the day, Helen Clarke, accusing her and her 
government of creating a "Nanny State" with the levels of social marketing advertising (The Dominion Post, 2007). This public scrutiny and comment is consistent with Donovan and Henley's (2003) who commented that, “... as social marketing is usually funded by governments (taxpayers) or non-profit organisations (charitable donations) the way the funding is used is a matter of public trust and should be subject to scrutiny at the highest ethical standards" (p. 161).

Overall, the long-term effectiveness of social marketing has not been extensively researched. It is fair to say that some individual campaigns have been assessed as being successful. However, equally there appears to be examples that show social marketing to be ineffective in influencing behaviour change in the target market (Perman \& Henley, 2003; Henley, 2006; Hassan et al., 2007; Wall, 2007; Kotler \& Lee, 2008; Bridges, 2009). An example of this relates to a government campaign targeting binge drinking, Wall (2007) elaborated: "The students surveyed in Northern Ireland thought that most government initiatives were ineffective. Their main concern was the considerable implications of excessive drinking for long-term health, suggesting a promising demarketing theme that has so far been used only in advertising directed to an older audience" (p. 133).

In another example, one of the prominent New Zealand social marketing campaigns is that created to address problem gambling in the community. In a recent conference presentation, the manager of the campaign's evaluation reported that the television advertisements created to combat problem gambling were in fact, encouraging problem gamblers to continue to gamble. In their evaluation research, problem gamblers admitted that the sound effects and the vision of gambling machines heightened their desire to gamble (Walker, 2008).

The value of Government social marketing is as yet unclear. Wall (2007) stated, "...the longterm impact of government advertising is unclear. Larger scale public surveys had earlier found that people had been prompted to consider stopping smoking by advertising, but were conducted soon after a campaign had run, whereas the student smokers judged it an ineffective way to change their behaviour" (p. 134). 
The combination of unsuccessful campaigns and the high volume of government-attributed social marketing in New Zealand, Donovan and Henley (2003) have already sounded a warning, "We also know that some messages can backfire and increase feelings of rebellion in the target market. Is it ethical for the social marketer to contribute to a campaign that clearly will not be effective?" (p. 164). 
Despite increased prevalence in social marketing in the past twenty years, it is surprising that so little empirical research has been conducted on the source credibility of the government, as a major social marketing source and the possible impact of increased volumes of social marketing messages. In the literature review, several key gaps in the current social and commercial marketing literature were discovered. These gaps are discussed below:

- The consensus in the literature has served to confirm the validity of the components of expertise and trustworthiness to the source credibility construct (Hovland \& Weiss, 1951). However, study into source credibility in social marketing is uncommon in the academic literature (Perman \& Henley, 2003; Smith, Bauman, McKenzie, \& Thomas, 2005).

- Literature discussing the research into the repetition effects of advertising has been limited to the examination of one advertisement from one source in isolation to other messages from that source. An examination of the cumulative effect of a large volume of similar advertisements from one source does not appear to feature in the literature.

- The literature does not explore characteristics or the impact that high volumes of social marketing will have on the target audience, specifically for this research, the impact on the source's credibility.

- In the persuasion studies reviewed in the literature, there are many studies addressing the effectiveness and influence on persuasion when the target of the communication or advertisement believes the agent (source) is knowledgeable, trustworthy and their message is relevant to the target audience (Sternthal, Dholakia, \& Leavitt, 1978; Cialdini \& Goldstein, 2002). However, no studies have 
appeared to consider these qualities in government, as a source, where the authority is implied from the position in society of government.

- Research findings on attribution in the literature establishes the likelihood the target audience would actively seek to determine the source or ownership of an advertisement despite the use of brands, spokespeople and actors (Friestad \& Wright, 1994). However, the studies have not explored attribution or misattribution of the source of social marketing messages in a high volume social marketing environment.

These identified gaps in the academic literature have directed the investigation in this study. These gaps are encompassed in the research questions and objectives. 


\section{CONCEPTUAL FRAMEWORK}

\section{Introduction}

This chapter outlines a conceptual framework from commercial marketing that has guided this research. The conceptual framework has described the target audience's processing of advertisements, which has assisted the researcher in the development of the semi-structured interview questions. The literature review has established a broad set of advertising frameworks that incorporate source credibility, repetition effects in advertising, persuasion and attribution used predominantly in selling products and services, that will provide direction for further exploration.

The construct of source credibility was established in the earliest studies by Hovland \& Weiss (1951-1952) and Hovland et al. (1953). The consensus in the literature has served to confirm the validity of the components of expertise and trustworthiness to the source credibility construct. As stated by Sternthal et al. (1978), "In experimental investigations of the persuasive effect of source credibility, it has been frequently demonstrated that highly trustworthy and expert spokespeople induce a greater positive attitude towards the position they advocate than do communicators with less credibility." (p. 252) However, the literature has not discussed or considered the possibility that government agencies initially were a highly credible and persuasive source but, as the social marketing prevalence has grown, the government's persuasive power and credibility has declined.

So too, literature discussing the research into the repetition effects of advertising has been limited to the examination of one advertisement in isolation. An examination of the cumulative effect of a large volume of similar advertisements from one source does not appear in the literature. However, the literature does establish a consensus in the core elements and relationship between high repetition in advertising and the influence on persuasion. There is agreement that the effects of repetition in advertising follow an inverted U-shaped curve where 
more exposure produced increased learning. However, at some point, satiation is reached and additional exposure begins to produce decay, even rejection and hostility (Stephens \& Warrens, 1984).

The review of literature on persuasion served to inform the research into the effects of the change in source credibility on persuasion in advertising and, by inference, the effectiveness of the social marketing campaign. For the most part, the literature supports the assertion that a highly credible source will incite more persuasion on the consumer that a low credible source.

As New Zealand has entered an uncommon condition of profusion in social marketing advertising, a large number of government agencies have created independent brands or utilised spokespeople or actors in the message creative. Research on attribution is important in establishing the likelihood that consumers will not attribute the social marketing messages to government and therefore, not attribute the accumulated advertising to one source. However, there is agreement in the literature indicating that the consumer would actively seek to determine the source or ownership of an advertisement despite the use of brands, spokespeople and actors (Friestad \& Wright, 1994). Further exploration into the high volume social marketing environment may reveal that consumers may not attribute the message to a particular government source rather generally to "the Government".

This research uses the Model of Cognitive Response compiled by Belch and Belch (2007) and the precedence and the general concept as an informing framework and combines the source credibility construct developed by Hovland et al. (1953) to serve as a baseline conceptual communications framework to guide this research. 


\subsection{Model of Cognitive Response}

The Model of Cognitive Response was complied by Belch and Belch (2007) from a series of studies into consumers' cognitive processing of advertising messages [Refer Figure 1]. The model is one of the most widely used commercial marketing models to illustrate the relationship between the consumer's thoughts following their exposure to an advertisement and those thoughts subsequent influence on the purchase intentions of the consumer.

In this research, the model provides a useful framework for exploring the interplay between the advertising exposure and the source credibility thoughts as well as the influence this relationship will have to the engagement of the target audience.

In essence, the model suggests that the individual, once exposed to the advertisement, will

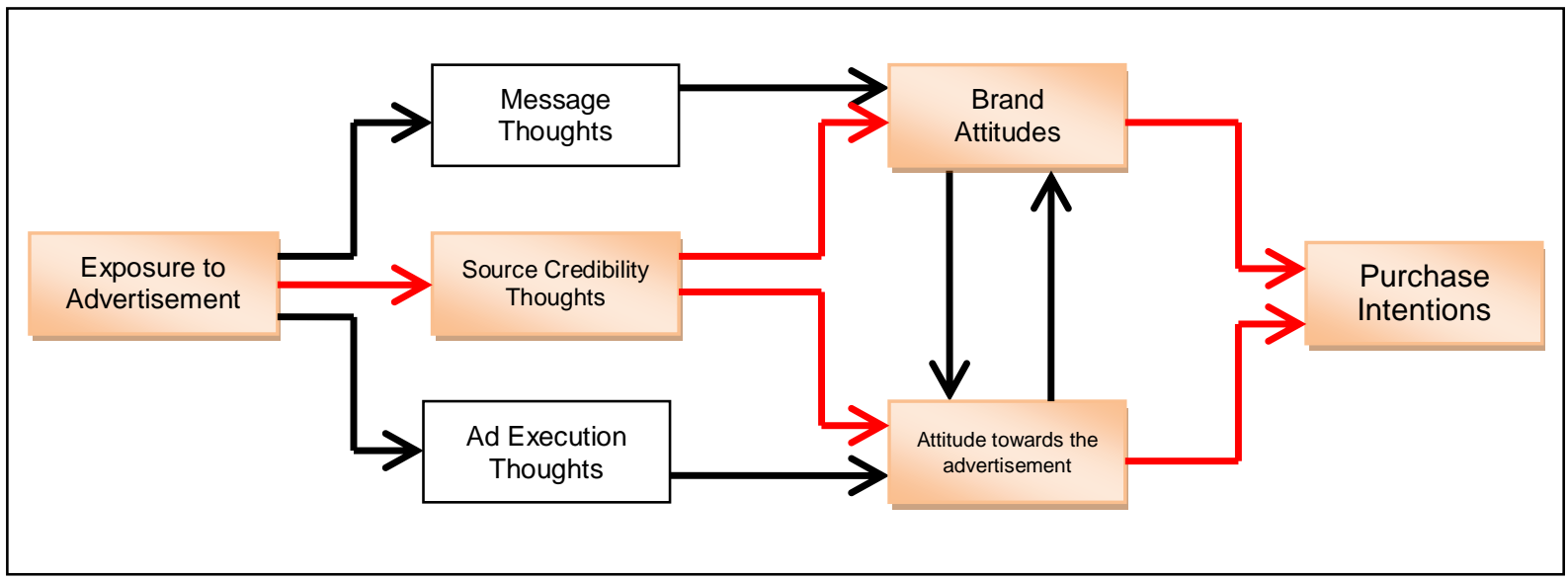

Figure 1: Model of Cognitive Response (Belch \& Belch, 2007, p. 156)

process a series of thoughts or cognitive responses towards the product, service or message in the advertisement; the source of the message and the advertisement itself. In processing these thoughts, the consumer will respond either positively or negatively towards each of the three attributes (Message, Source Credibility or Advertisement Execution) which will then determine the influence these thoughts will have on the consumer's intent to purchase in accordance with the advertised message. 
This research investigates what impact exposure to a high volume of similar advertisements from a similar source has on the source credibility thoughts and subsequently, what effect it has on the persuasiveness through motivating and influencing the individual to consider behaviour change.

The model has been derived from commercial marketing based research and its application to social marketing is not evident in the literature. 


\subsection{Components of Source Credibility}

In the use of Belch and Belch's (2007) Model of Cognitive Response, it has been helpful to this research to overlay the source credibility construct established by Hovland et al. (1953) to better identify the antecedent variables influencing the source credibility. The authors established that the construct contained two variables, namely Trustworthiness (Trustworthy) and Expertise. [Refer Figure 2]

The construct Expertise has two underlying components of Well Informed/Knowledgeable and Intelligence. Hovland et al. (1953) established that a source that is perceived to be well informed, knowledgeable and intelligent in the subject matter is considered to have demonstrated expertise and therefore, established higher source credibility than those who are not perceived to be well informed, knowledgeable or intelligent.

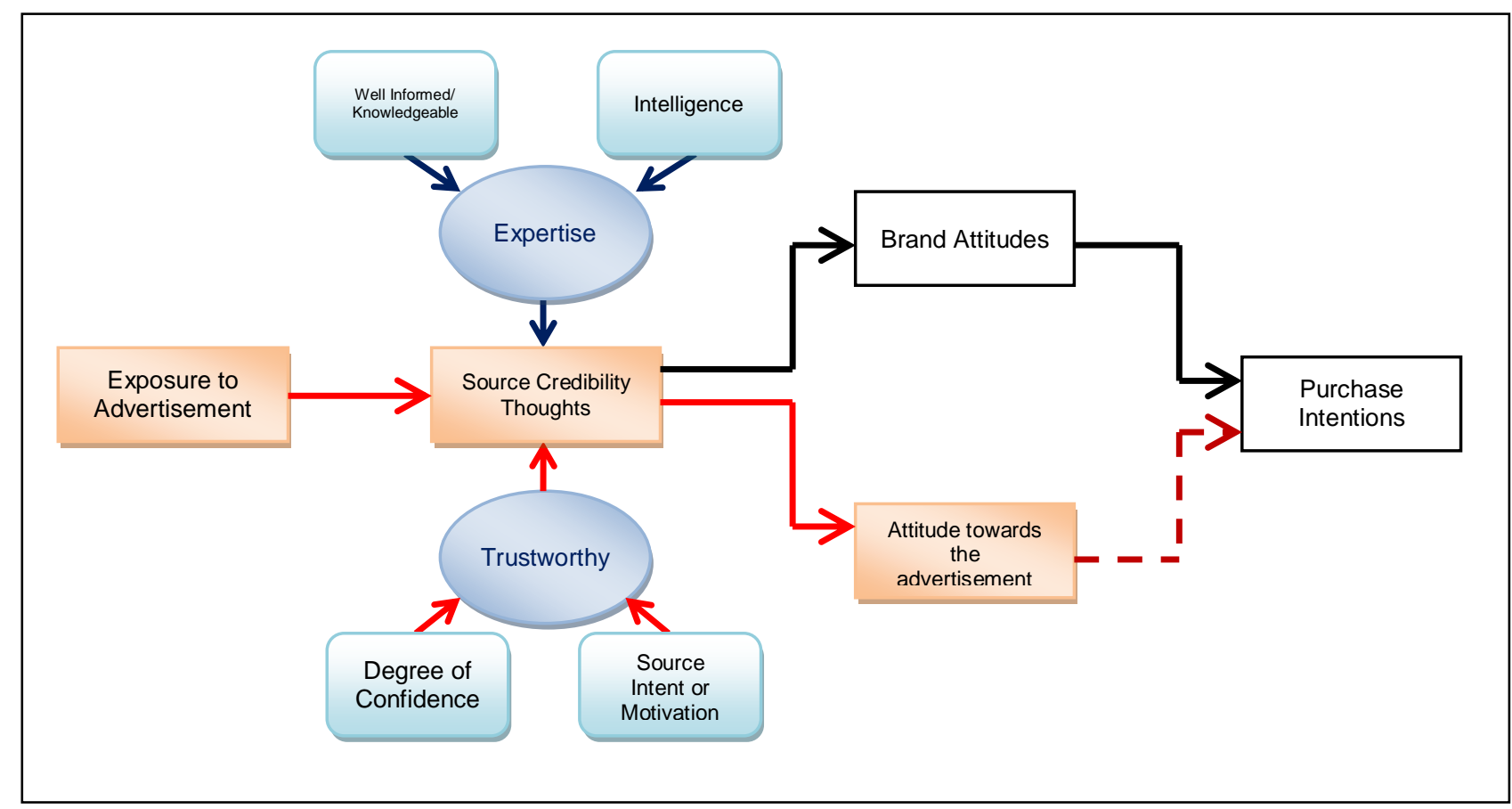

Figure 2: A Composite Model of Cognitive Response and Source Credibility (Belch \& Belch, 2007, p. 156; Hovland, Janis, \& Kelley, 1953, p. 21)

Similarly, the construct Trustworthiness (Trustworthy) has two underlying components of Degree of Confidence and Source Intent or Motivation. Where a source that is perceived by 
the audience as being confident in the subject matter and is not deceitful about their motivation or intent, is considered more credible than one that is perceived to be unconfident and manipulative or dishonest in intent.

The review of the literature has indicated the area of Trustworthiness; particularly its component area of Source Intent or Motivation is of most interest to this research. Anecdotally, it is believed that the New Zealand government agencies initially were a highly credible and persuasive source, however as the social marketing prevalence has grown, the government's persuasive power and credibility has declined. This research therefore examined the possibility that the increase in government-attributed social marketing has caused the target audience to perceive the government as being manipulative or dishonest in their intent (Hovland \& Weiss, 1951).

Furthermore, there is a recognised gap in the academic literature in referring to the effect of a high repetition of similar advertisements from one source on the audience's attitude towards the advertisements and the source. This research has identified that the Model of Cognitive Response (Belch \& Belch, 2007), as per Figure 2, is inadequate in explaining the impact of the audience's thoughts associated with the volume of similar advertisements from the same source.

The creation of a composite model [Refer Figure 2] using of Belch and Belch's (2007) Model of Cognitive Response overlaid with the source credibility construct established by Hovland et al. (1953) has assisted the researcher to identify the antecedent variables and therefore, those key elements that were explored in the interview questions. This ensured that the interview questions were focused on answering the research questions. 


\section{RESEARCH METHODOLOGY}

4. Introduction

The literature review (Chapter 2) identified four key areas of inquiry for this research, source credibility, repetition effects in advertising, persuasion and attribution. Chapter 3 discussed

Belch and Belch's (2007) Model of Cognitive Response with Hovland \& Weiss (1951-1952) source credibility constructs applied as a broad conceptual model of enquiry for this research. This chapter gives an overview of traditional philosophical paradigms and methodological approaches to marketing research. It will also explain the selection of the philosophical and methodological stance of this study, which has followed a postpostivist paradigm and used a qualitative research design (Creswell, 2003). The research design will be discussed and detailed including discussion on the proposed data collection and data analysis strategies.

This chapter will also review the research questions and objectives of this research, in particular, describing the justification for the selected research paradigm and methodology, the accuracy of the investigation into the relationship between volume and diversity of government-attributed social advertising and its impact on the source credibility of the government, as the messenger. In exploring this relationship, the research has examined the effects of repetition on advertising, specifically multiple similar messages from one source. 


\subsection{Research Questions and Objectives}

Following the identification of the gaps in the literature, it is appropriate to revisit the research questions and the research objectives in order that they have reflected the gaps and are appropriate to the selection and justification of the research methodology.

The research has investigated the following questions:

1. What is the impact of high volume government-attributed social marketing messages in New Zealand on the source credibility of the government, as the message source?

In order to further provide information that may assist social marketing practitioners to better understand the nuances in managing the communication process for social marketing messages, two sub-questions are also addressed:

2. Does the public believe the government is an appropriate message source for social marketing messages and if not, who or what would be a more appropriate messenger?

3. How does the repetition of multiple similar advertisements from one attributed source impact on the effectiveness of social marketing messages?

\section{Research Objectives}

According to Cavana, Delahaye, \& Sekaran (2001) research objectives are likely to be framed as research questions and the distinction between both research questions and objectives is minimal due to the little knowledge of the variables affecting the problem (p. 114). Therefore, similarity exists between the research questions and the research objectives in this study.

The research objectives of this study are to:

1. Examine the impact of the high volume of government-attributed social marketing advertising in New Zealand on the source credibility of the government, as the message source. 
2. Understand whether the public believe the government is an appropriate message source for social marketing messages and if not, who or what would be a more appropriate messenger.

3. Investigate repetition effects of multiple similar advertisements from one attributed source on the effectiveness of social marketing messages.

4. Develop a conceptual model to illustrate the effect of high exposure rates of similar advertisements from one source in a social marketing context.

5. Inform marketing practitioners and assist in planning the communication process in social marketing campaigns, as well as providing empirical evidence in consideration of the message source. 


\subsection{Research Paradigm}

As identified in the literature review, there are a number of gaps in the literature (Section 2.5) that, as a result, cause difficulty in answering the research questions or applying existing marketing theories and studies to this rarely seen condition of near-saturation in social marketing advertising in a single market. In this case and where the research begins with a question for which little research or theory exists, the study is therefore exploratory and aims to generate theory. It is perhaps appropriate to assume the Constructivism paradigm of philosophical assumptions (Creswell, 2003). However, this research has explored the suitably and the applicability of the widely accepted theories of Belch and Belch's (2007) Model of Cognitive Response and Hovland and Weiss' (1951-1952) antecedent source credibility constructs, as discussed in Chapter 3. Therefore, a Postpostivist paradigm is one that proposes that there are laws or theories that govern the world, and these need to be tested or verified and refined so that we can understand the world. Thus, in scientific method - the accepted approach to research by postpostivists - an individual begins with a theory and collects data that either supports or refutes the theory (Creswell, 2003).

It is clear from the literature review, that Belch and Belch's (2007) Model of Cognitive Response and Hovland and Weiss' (1951-1952) antecedent source credibility constructs are well regarded and heavily cited commercial marketing theories. However, it is not clear whether these theories are applicable and appropriate to the cognitive response processing of the target audience of social marketing advertising or whether the overlay of source credibility construct is appropriate to this research. This type of understanding and exploration might not be arrived at by statistical procedures or other means of quantification. It requires the exploration and probing of a person's feelings, attitudes, emotions and opinions, as well as the influence of need, culture and experience. Therefore, gathering data by means of interviews and observations, techniques normally associated with qualitative research methods would be appropriate (Strauss \& Corbin, 1998). 
The postpostivist paradigm best suits this research, where the distinct theoretical orientation of the qualitative study in which theory becomes the starting-point for a study not an end-point (Creswell, 2003). In this respect, this study is descriptive in nature where the research will seek to broadly describe the characteristics of the variables of interest in this situation. The goal of a descriptive study is to offer a profile or to describe relevant aspects of the phenomenon, namely the high volume social marketing environment in New Zealand in 2008 (Cavana, Delahaye, \& Sekaran, 2001).

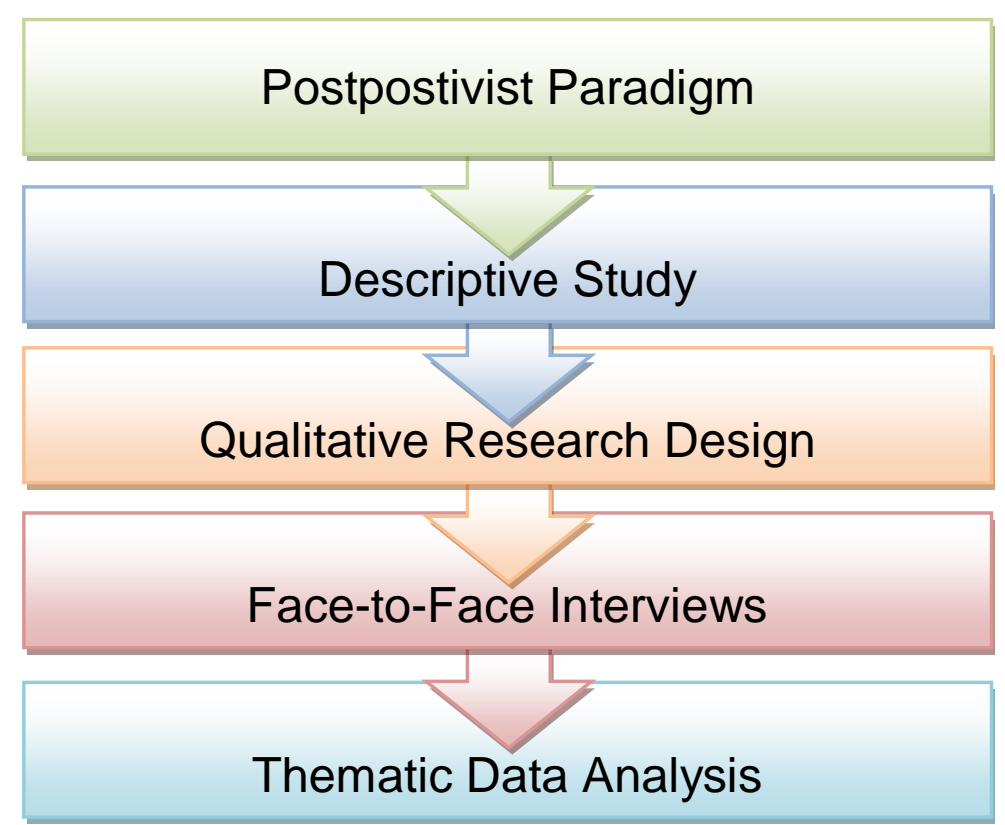

Figure 3: Research Philosophy and Methodology Overview (Adapted from Creswell, 2003; Cavana et al, 2001; Wolcott, 2008) 


\subsection{Research Methodology Choice}

Qualitative research strategy addresses topics which are either completely new, have never been addressed before in this way, or to which existing theories do not apply. Qualitative researchers aim to understand individual situations, experiences, attitudes, opinions and beliefs, therefore this process of understanding forms a key characteristic of the approach (Creswell, 2003). In this way, qualitative research strategy is appropriate to the study of the high volume government-attributed social marketing environment of 2008. Importantly, the research has discovered the individual's interpretation of the social marketing intensity of that time, their attitudes, opinions and perceptions of those social marketing messages.

However, in using existing commercial marketing models and theories namely, Belch and Belch's (2007) Model of Cognitive Response and Hovland and Weiss' (1951-1952) antecedent source credibility constructs, the selection of a qualitative research approach is not consistent with the postpostivist paradigm according to Creswell (2003). Creswell (2003) claims that a qualitative approach is one in which the inquirer often makes knowledge claims based on constructivist perspectives or advocacy/participatory perspectives and suggests that the only methological choice available in the postpostivist paradigm is quantitative research design. However, Creswell (2003) later discusses the increasing use of a theoretical lens or perspective by qualitative researchers to guide their study and raise questions they would like to address. By providing this theoretical lens or perspective, researchers are using this to guide the research as to what issues are important to examine and the people that need to be studied. It will also assist the researcher to understand how they should position themselves in the study and the types and approaches to the structured interviews, focus groups or observations (2003, p. 131).

Supporting Creswell's (2003) later comments, Cavana et al. (2002) observed that where the theoretical framework demonstrates a reasonable knowledge of the research variables, the researcher is more likely to be interested in more detailed information and specific investigation about the variables. Accordingly, the researcher would be more likely to use 
semi-structured or structured interviews, focus groups and questionnaires (p. 115). This research study is designed to loosely explore variables of Belch and Belch's (2007) Model of Cognitive Response and further, has investigated the antecedent components of Hovland and Weiss' (1951) source credibility construct. In broad terms, this empirical model and theory provides the means to guide semi-structured face-to-face interviews consistent with gathering the appropriate data required to address the research questions (Cavana, Delahaye, \& Sekaran, 2001). 


\subsection{Research Design}

Research design comprises a bundle of skills, practices and assumptions that the researcher employs as he or she moves from paradigm to the empirical world. The design put paradigms of interpretation into motion (Denzin \& Lincoln, 2005).

Three interconnected, generic activities define the qualitative research process. They go by a variety of different labels, including theory, analysis, ontology, epistemology, and methodology. The researcher approaches the world with a set of ideas, a framework (theory, ontology) that specifies a set of questions (epistemology) that the researcher then examines in a specific ways (methodology, analysis) (Denzin \& Lincoln, 2005).

Cavana et al. (2001) suggest four parameters of design for the researcher to consider, namely, type of investigation, study setting, units of analysis, and time horizon. Miles and Huberman (1994) suggest a similar four parameters: setting, actors, events, and process. Miles and Huberman's (1994) four parameters are discussed by Creswell (2003), who adds further parameters of "type". Therefore, the five parameters for consideration and the most appropriate means to describe the research process intended for this study, will be:

- $\quad$ Setting - Where will the research take place?

- $\quad$ Actors - Who will be observed or interviewed?

- $\quad$ Events - What will the actors be observed or interviewed doing?

- $\quad$ Process - The evolving nature of events undertaken by the actors within the settings.

- $\quad$ Type - What type of data will be collected?

Setting - the setting for this research is a location that is convenient and appropriate for the interviewee. In all cases, the interview took place in Wellington for two reasons; firstly, the Phase 1 interviewees (Actors) are social marketing practitioners and their offices are located in Wellington, and secondly, the Phase 2 interviewees (Actors) are members of the public and 
therefore, it will be more convenient and economical for the researcher to have the interviews take place in Wellington.

Actors - This research has interviewed in two cohorts, Phase 1 and Phase 2. In Phase 1, the key informant actors are four government social marketers. These actors were selected by their involvement in generating social marketing advertising during 2008 with a chronic disease prevention or injury and/or death prevention focus. In Phase 2, the key informant actors were ten members of the public. These actors were selected by applying a number of characteristics discussed later in this Chapter, section 4.8 (Miles \& Huberman, 1994).

Events - This research is specifically investigating the government-attributed social marketing environment in New Zealand during 2008. In Phase 1, the interviews have focused on the marketing planning and execution strategies of the social marketers during this period. In Phase 2, members of the public have been interviewed to explore their opinions and perceptions of social marketing during this period.

Process - In Phase 1 of the research, the social marketers have been interviewed using a semi-structured interview technique. Broad questions have been designed, within the interview guide, to direct the interviewees to discuss their opinions, attitudes and facts surrounding their social marketing generation activities during 2008. In Phase 2, members of the public were also interviewed using a semi-structured interview technique. In addition to general open-ended questions addressing the social marketing in 2008, Phase 2 interviewees were shown digitally reproduced television commercials from three chronic disease prevention advertisements namely: Push Play [physical activity]; Feeding Our Futures [nutrition]; and Smokefree [anti-smoking]. In viewing those television advertisements, these key informant actors were guided by the same questions for each advertisement and to respond to a number of different topics related to the television commercials (Miles \& Huberman, 1994).

Type - The type of data to be collected is opinions, reactions, attitudes and facts from the interviewee's memory. In the case of Phase 1 interviewees, the social marketers, the enquiry 
has explored the process and execution of the social marketing programmes in which they were involved. Further, the interviews covered the interviewees' attitudes, opinions and reactions to the social marketing environment in 2008. In addition to providing specific responses to the research questions from both personal and organisational perspectives, the social marketers also provided insights and responses that served to inform the questions asked in Phase 2 of the research, in-depth interviews of ten members of the public.

For the Phase 2 interviewees, members of the public, the study has explored the interviewees' attitudes, opinions and reactions to the social marketing environment in 2008 and three government-attributed social marketing television advertisements from that period.

The distinction between the two groups of interviewees has enabled the researcher to compare and contrast the intentions of the practitioners and their campaigns with the public perception, attitudes and observations of those campaigns. In essence, it has provided a means to assess whether the social marketing campaigns intentions and objectives related to the research questions have been achieved. 


\subsection{Sampling Design}

The idea behind qualitative research is to purposefully select participants that will best help the researcher understand the problem and the research question. This does not necessarily suggest random sampling or selection of a large number of participants, as typically found in quantitative research. (Creswell, 2003; Miles \& Huberman, 1994)

The sampling design used in this study consists of a non-probability, purposive design. In the instance of the Phase 1 interviewees, the social marketing practitioners, judgement sampling was employed to select those interviewees that could best assist in addressing the research problem and questions. This study sought to draw Phase 1 interviewees from those social marketing practitioners focused on chronic disease prevention and/or death and injury prevention. Judgement sampling, although restricted in generalisability, will sometimes be the best sampling design choice, especially where, in this case, there is a limited population that can supply the necessary information (Cavana et al., 2001, p. 267).

Phase 2 interviewees, members of the public, were selected using a non-probability, purposive design also; however, Miles and Huberman (1994) identified snowballing as an effective technique for identifying participants. Utilising existing relationships with colleagues, friends and acquaintances, the researcher used the 'snowballing' technique to identify potential interviewees with the pre-selection criteria, discussed below, and based on the recommendations of colleagues, friends and acquaintances. Ten suitably qualified interviewees were selected for the Phase 2 interviews (Cavana et al., 2001, p. 264). Each identified interviewee was contacted by email and/or by telephone and invited to join the study. The invitation included a brief introduction to the study's purpose [Refer: Appendix B], the manner in which their name was obtained, the format of the interview, and detail on the researcher (Lofland \& Lofland, 1984). 
Interviewees for this study were selected based on the following criteria:

1. All interviewees required a basic understanding of social marketing campaigns in order to be able to recognise, in general, social marketing television advertisements.

2. All interviewees were in New Zealand throughout 2007 and 2008 and considered themselves regular television viewers (minimum of 2 hours average per day), as the study sought to understand the opinion and attitudes of the social marketing advertising at that time. The most easily recalled aspects of the social marketing campaigns of this period are television advertisements therefore, the interviewees' television-viewing habits are important to this study.

3. As the Phase 1 interviewees, social marketers, were located in Wellington, to minimize accessibility challenges and focus the study, all interviewees were located in the Wellington metropolitan area to facilitate face-to-face data collection (Cavana et al., 2001).

The study included no other criteria to select or eliminate participants, including any requirements based on level of education, age, marital status, race, ethnicity, cultural or religious preference or background, or sexual orientation. Their selection is based on the suitability described earlier in this section.

In terms of sample size, qualitative studies typically utilise relatively small samples to produce detailed, rather than exhaustive and generalisable, understanding of the research question (Miles \& Huberman, 1994; Strauss \& Corbin, 1998; Cavana, Delahaye, \& Sekaran, 2001;). While quantitative researchers use complex mathematical formulae to make sample size considerations, sample size considerations in qualitative studies are neither mathematical nor systematic (Onwuegbuzie \& Leech, 2005). Determining adequate sample size in qualitative research is ultimately a matter of judgment and experience in evaluating the quality of the information collected against the uses to which it will be put, the particular research method 
and purposeful sampling strategy employed, and the research product intended (Lofland \& Lofland, 1984).

Sample size and sampling considerations usually are made with the goal of making statistical generalisations, which involve generalising findings and inferences from a representative statistical sample to the population from which the sample was drawn. Generalisability is defined in qualitative research as the extent to which a researcher can generalise the account of a particular situation or population to other individuals, times, settings, or context. (Onwuegbuzie \& Leech, 2005; Creswell, 2003)

Onwuegbuzie and Leech (2005) summarise the studies into qualitative sample sizes by identifying that Creswell (2002) has recommended that 3-5 participants for use in case study research. In citing other examples of sample sizes, Onwuegbuzie and Leech (2005) state that in phenomenological studies, sample size recommendations range from six to 10 and in grounded theory research, sample size guidelines ranged from 15 to 20 participants to $20-30$ participants. Finally, in regards to focus groups, Onwuegbuzie and Leech (2005) make the following recommendations cite the following numbers from various authors: 6-9 participants citing Krueger (2000); 6-10 participants cite Langford, Schoenfeld, \& Izzo (2002) and Morgan (1997); 6-12 participants citing Johnson \& Christensen (2004) and Bernard (1995); and 8-12 participants citing Baumgartner, Strong, \& Hensley (2002). In general, sample sizes in qualitative research should not be too small that it is difficult to achieve data saturation, theoretical saturation, or informational redundancy. At the same time, the sample should not be too large that it is difficult to undertake a deep, case-oriented analysis (Onwuegbuzie \& Leech, 2005).

This research has used the following sample sizes:

- Four Phase 1 interviewees, social marketers, were selected. This sample is representative of the 52 social marketing programmes identified in 2008.

- Ten Phase 2 interviewees, members of the public, were selected. 


\subsection{Data Collection and Recording Procedures}

This study used the most common qualitative data collection instrument, the interview to elicit the depth and breadth of information required to explore the research questions (Denzin \& Lincoln, 2005; Creswell, 2003). The data collection method chosen for this study has primarily been the use of extensive in-depth, semi-structured face-to-face interviews with the individual interviewees, with each interview being audio taped and the recording then transcribed (Creswell, 2003).

The interview provides a unique opportunity to uncover rich and complex information from the interviewee. The face-to-face interactive process can, under the guidance of an experienced interviewer, encourage the interviewee to share intrinsic opinions and to dredge previously unthought-of memories or attitudes from the unconscious mind. This rich and rare material invariably includes tacit knowledge from the interviewee (Cavana, Delahaye, \& Sekaran, 2001).

In conducting a semi-structured interview, the researcher had two basic strategies - present the questions and then concentrate on managing the process by using interview skills to elicit information. The interviewer has channelled the discussion and responses by switching between the planned questions based on defined, pre-identified topics outlined in an interview guide and general discussion [see Appendix A: Interview Guides] (Cavana, Delahaye, \& Sekaran, 2001; Denzin \& Lincoln, 2005).

The main advantage of face-to-face interviews in this study has been that the researcher can adapt the questions as necessary, clarifying doubts and ensure that the responses are properly understood by repeating and rephrasing the questions. In addition, the researcher can also note non-verbal communication cues from the interviewee in the interview notes. The body language has provided insights to the interviewee's feelings and attitude, that has provided further insights for the researcher (Cavana, Delahaye, \& Sekaran, 2001). 
The limitations of semi-structured face-to-face interviews include interviewees providing "indirect" information or information not relevant to the study, the researcher's presence may bias the interviewee's discussion, and people are not equally articulate and perceptive. Other limitations of interviews include geographic limitations that may bias the overall response, interviewees may feel their anonymity may not be maintained considering their presence with the researcher, and the lack of generalisability of the study (Cavana, Delahaye, \& Sekaran, 2001; Creswell, 2003; Denzin \& Lincoln, 2005).

The researcher has been the primary instrument for data collection and analysis for this study. The researcher's interviewing skills are important in establishing a balanced rapport. Essentially, the interviewer must remain casual and friendly, exhibiting a style of "interested listening" on the one hand, but must be directive and impersonal on the other. The semistructured interview style has assisted the interviewer to provide consistent direction to the interviewee and ensure the key inquiry areas are covered in his or her responses without causing the interviewee to limit their candid and open responses (Denzin \& Lincoln, 2005, p. 702).

In this study, the use of a semi-structured interview guide of open-ended questions for each of the interviewee groups, Phase 1 and Phase 2, is used to maintain a direction to the interviewee's discussion to ensure topic areas identified in the research questions and objectives are covered. Cavana et al. (2001) discovered open-ended questions helped each participant share their experience in their own way. Each interview began with simple nonthreatening questions to collect demographic statistics or organisational information, which established a sense of comfort (Lofland \& Lofland, 1984). The open-ended questions in the interview guides are designed to provide flexibility and ensure that the interviewer has the ability to make adjustments, to improvise or exercise independent judgement to ensure the quality of the data being collected from the individual interviewees as outlined by Strauss \& Corbin (1998) and Denzin \& Lincoln (2005). 
Each of the interviewees has been asked the same questions contained in the interview guide relative to their interviewee type, either Phase 1; social marketers, or Phase 2; members of the public [see Appendix A: Interview Guides]. Each interview was digitally recorded using a digital voice recorder. Each recorded interview was converted to an audio computer and transcribed into text format for import into NVivo® qualitative analysis software for further analysis (Cavana, Delahaye, \& Sekaran, 2001; Creswell, 2003). 


\subsection{Data Analysis and Interpretation Procedures}

Once the data was gathered, the researcher was faced with the decision of how to analyse the data. Qualitative data analysis explores the themes and patterns that existed in the data (Miles \& Huberman, 1994). In this study, the data was analysed through thematic analysis methods. Cavana et al. (2001) state that themes can be identified in two-ways - by using pre-planned questions or by content analysis (p. 170). In this study, the decision to utilise a semi-structured interview for data collection assists the researcher to maintain broad focus on the research questions and gaps identified in the literature (Miles \& Huberman, 1994; Cavana et al., 2001).

Thematic analysis focuses on identifiable themes and patterns of living and behaviour (Aronson, 1994). Further, this study sought to identify themes and patterns in relation to the interviewees' attitudes, opinions and reactions. Firstly, themes and patterns were identified within each group of interviewees and then through all the data.

Aronson (1994) identifies four steps in performing thematic analysis. They are:

1. Audio recording of the interviews were transcribed into text form for analysis. From the transcribed conversations and responses, patterns of experiences, attitudes and opinions can be listed. These patterns can come from direct quotes or paraphrasing common ideas.

2. All data was then analysed into the already classified patterns. All responses that fit into a specific pattern were identified and tagged with the appropriate pattern or common response.

3. Once the data was sorted by general classifications, the next step in the thematic analysis process was to combine and catalogue related patterns into sub-themes. Themes are defined as units derived from patterns such as conversation topics, vocabulary, recurring attitudes, recurring activities, meanings, feelings, etc. Themes are identified through bringing together components or fragments of ideas that emerge from interviewees stories or responses which are pieced together to form a comprehensive 
picture of the collective experience of the sample (Aronson, 1994; Strauss \& Corbin, 1998; Creswell, 2003). This section of analysis was assisted with the use of the semistructured interview questions and therefore, general themes were predetermine, which allowed for more consistent coding.

4. Finally, the valid arguments were established from the sub-themes in order that several themes and common responses can be compared and contrasted to the literature. This provides the researcher with the framework to make inferences and conclusions in the data (Aronson, 1994). At this point in the analysis, quotes from the interviewees that represented the themes and sub-themes identified in the analysis process were isolated to be used in the discussion of results. These representative quotes were those statements that best represent the essence of commonality of the interviewee's opinions.

This study has utilised the qualitative data analysis software NVivo®. This software has facilitated storing, coding, sorting, and retrieving data (Bazeley, 2007). While the software has assisted the researcher analyse a large amount of qualitative data, the data has required continuous review to ensure the original intent of the interviewees discussions remained intact (Creswell, 2003; Bazeley, 2007).

There is a widely held perception that using computer software for qualitative data analysis helps to ensure rigour in the analysis process. This is due to the belief that the computer software will find and include every recorded use of a term or phrase in the query procedure. It ensures a more complete set of data is used for interpretation than might occur in manual analysis (Bazeley, 2007). In this study, the use of the computer software has ensured that the thematic analysis has been maximised through the use of search techniques that would be difficult to replicate in a manual system. 


\subsection{Research Considerations}

Cavana et al. (2001) identifies that it is not always possible to conduct investigations and studies that are 100 per cent scientific due to the difficulties in collecting and measurement of data in the subjective areas of feelings, attitudes, opinions, emotions and perceptions. A good theoretical base and sound methodological design denotes a research study that mitigates the amount of error and demonstrates rigour (p. 32).

This research has attempted to demonstrate good methodological design and implementation through data collection rigour, accuracy and objectivity as outlined by Creswell (2003); however, the following limitations may influence the findings of this study:

- The researcher's background in social marketing could influence the responses of the Phase 1 interviewees, social marketing practitioners, in this study.

- The small sample size may restrict the ability to generalise the study findings (Miles \& Huberman, 1994; Cavana, Delahaye, \& Sekaran, 2001; Creswell, 2003).

- Utilising a snowball technique to identify potential interviewees may limit the pool of individuals invited to participate in the study (Miles \& Huberman, 1994).

- Using a one-hour face-to-face interview may fatigue interviewees or cause inaccurate responses (Lofland \& Lofland, 1984).

- Geographically, the interviewees are restricted to the Wellington metropolitan area to facilitate ease in collecting data. This may limit the findings' generalisability. 


\section{Chapter 5}

\section{RESULTS}

\subsection{Introduction}

This chapter details the data gathered through fourteen in-depth interviews, with four social marketing practitioners and ten members of the public, the methodology of which was discussed in the previous chapter. Their responses have been placed into four major categories: source credibility, repetition effects, attribution and persuasion (effectiveness). This chapter will focus on the output of the thematic analysis of the collected data, which examines the patterns, and themes that have been identified within the data.

The chapter will also summarise the analysed data to address the research questions and realise any additional information that is considered relevant to the research. This data will be represented in clustered summary tables and sample quotes to provide an indication of the broad range of relevant information collected from the interviewees. Although some basic discussion of the results will occur in this chapter, drawing conclusions from the data and comparison with the literature will be conducted in the following chapter, Chapter 6 .

Data was collected through semi-structured in-depth interviews of two distinct groups of interviewees, social marketing practitioners [social marketers] and members of the public. In Phase 1 of data collection, social marketers were interviewed to establish the attitudes and strategies behind four significant social marketing campaigns being conducted in New Zealand in late 2008. The interviewees were selected by considering the major objective of their campaigns, being chronic disease prevention and/or death or injury prevention. Cumulatively, the interviewees represented approximately $12.7 \%(\$ 23.5 \mathrm{M})$ of the reported $\$ 185 \mathrm{M}$ social marketing expenditure in 2008 (Nielsen Media Research AIS, 2008).

In addition to providing specific responses to the research questions from both personal and organisational perspectives, the social marketers also provided insights and responses that 
served to inform the questions asked in Phase 2 of the research, in-depth interviews of ten members of the public [Refer Figure 4]. The distinction between the two groups of interviewees enabled the researcher to compare and contrast the intentions of the practitioners and their campaigns with the public perception, attitudes and observations of those campaigns. In essence, it has provided a means to assess whether the social marketing campaigns intentions and objectives related to the research questions have been achieved.

This chapter will firstly detail the findings from the social marketers and then, outline the data collected from members of the public. In the findings from the members of the public, source credibility and attribution have been combined as one topic. In the interview process, it emerged that interviewees referred to source attribution and credibility processing of an advertisement in the same instance and it was difficult for the researcher to separate the responses accordingly.

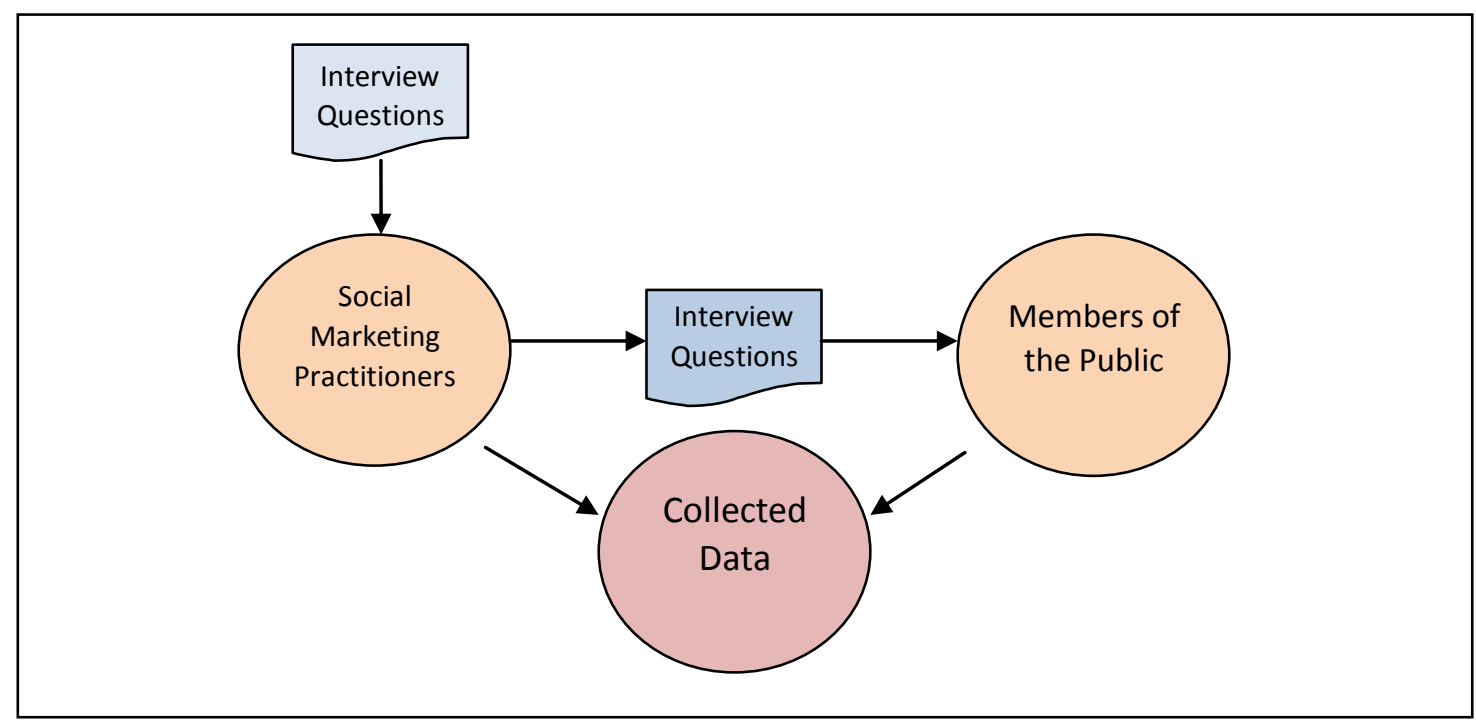

Figure 4: In-depth Interview Process 


\subsection{Social Marketing Practitioners}

Introduction

The researcher interviewed four government social marketers. The in-depth interviews sought to identify the intentions and actions within their social marketing campaigns to do with source credibility, repetition effects, attribution and finally, persuasiveness (effectiveness). This group was also asked to comment on the general social marketing environment during 2008, particularly in reference to other high profile campaigns.

The benefit of the data collected from this group is the opportunity to analyse the strategy determination and execution to establish whether they had considered the core subject areas and whether these actions were interpreted and received by members of the public, as intended.

The four interviewees all had the following characteristics:

- All were employed by government agencies (Ministry, Department or Crown Entity) with a significant social marketing commitment.

- $\quad$ They were the senior manager in charge of the social marketing campaign during 2008.

- Their responsibility included leading and managing the decision-making for the campaign including the determination of campaign objectives, strategy, creative, branding, media determination and budget management.

- All the campaigns were centred on chronic disease prevention and/or death and injury prevention.

- All campaigns were considered to be "at their peak" during 2008. 
- All campaigns were multi-channelled in their execution including electronic media (television and radio), print, outdoor, event and web advertising. Two interviewees were in the initial stages of using cell phone advertising and text tools as advertising channels.

In the interview process, a series of questions were included to reveal details of the planning process of the interviewee's organisations in order to understand their consideration of the four core research areas. In this discovery, it was revealed that the operating style of the interviewees appeared to be very similar in nature from the planning process through to the method of choosing their marketing activities. All organisations represented conducted their marketing decision-making in isolation to other government agencies conducting social marketing. This was most telling within agencies that have shared objectives or shared messages. For example, a number of agencies that share the same root cause of the chronic disease that they are marketing against, be it alcohol, tobacco or high sugar, salt or fat foods, did little consultation with each other when conducting their campaign planning or strategy development.

Although all agencies claimed that they had a strong relationship with other government based social marketing agencies, all said that they included only minor input from those agencies and did not collaborate in the delivery of similar messages. To illustrate this point, one social marketer stated,

“... we were becoming very aware that parents were becoming an increasingly targeted audience for campaigns. ... the intention was that we were actually going to come together again and really comprehensively look at our messaging, how we could improve $i t, \ldots$ is there a single message to parents that we could do together. It never happened".

Social Marketing Practitioner (1)

All interviewees acknowledged that they did share similar messages and objectives with other government agencies. One stated, 
"... so there are campaigns like family violence, road safety, water safety, fire safety that are aligned to us. So we've kind of started much more dialogue with them around how do we deal with this."

Social Marketing Practitioner (2)

The only apparent collaboration existed in the determination of the advertising placement and timing, which will be discussed in the section on repetition effects, Section 5.1.3.

All social marketers interviewed had similar core target audiences. Moreover, three of the four interviewees were specifically targeting the 18-39 year old age groups. They all stated that their key target audiences also included parents, Māori, and Pacific Islanders. 


\subsubsection{Source Credibility}

In addressing the first research question, the researcher collected data related to the impact that the high volume of social marketing messages during 2008 had on the credibility of the government agencies, as the source of these messages. The interviews with the social marketers focused on the decision-making linked to branding and attribution, as well as the interviewee's general opinion of the credibility of their organisation as a source of social marketing messages. The interviews addressed the interviewee's own social marketing campaign and then addressed their general assessment of the other social marketing messages they observed during 2008. The researcher intended on generating two main responses, namely justified assessment of their own social marketing campaign and secondly, a more objective assessment of other social marketing campaigns. The researcher noted that interviewees were more open to critically analysing other social marketing messages than their own campaign.

\subsubsection{Source Credibility Perception}

Interviewees were asked to provide an insight into the impact that the high volume of social marketing had on their organisation's (a government agency) credibility as a social marketing source and the impression of their target audience's reactions to government as a social marketer. There was significant discussion in response to questions on source credibility, branding and association of social marketing to government sources.

Three major themes emerged from the research into the interviewee's attitudes and opinions on government as a credible source. Firstly, the effect of the high volume of social marketing on government source credibility; secondly, the suitability of government as a credible messenger; and finally, that government's authority and power presupposes credibility.

The first theme was the potential detrimental impact of high volume of social marketing messages on the campaign source's credibility, being the government and ultimately the 
effectiveness of the message. Three of the four interviewees expressed concerns over the perceived negative impact caused to government, as the attributed source of social marketing messages, by the volume of social marketing.

The researcher found throughout the interviews, the interviewees believed the high volume of social marketing created a heightened public awareness of government as the source of social marketing messages and this in turn, created a negative predisposition towards any government message that could be considered directive or interfering with the public's free choice. Therefore, the interviewees expressed their belief that government attribution was detrimental to the effectiveness of the message. Although the interviewees acknowledged this, the researcher did not see evidence in the data of their subsequent design of their campaigns.

Representative comments from the interviewees of the impact of the high volume of government-attributed social marketing are detailed below. The majority of these comments were negative to the idea of government association with the social marketing messages and their audience's perception of government as the messenger.

"...if you use celebrities you've got to be careful, they've got to have a connection with the message. And I really don't think a Ministry of Health person delivering those messages is going to work."

Social Marketing Practitioner (4)

"I think it does then exactly impose what the government doesn't want, is the idea of a nanny state. Because most people don't necessarily know [Programme] is a government programme."

Social Marketing Practitioner (1)

"... it would be very clear that government is telling you to do something, which we try to avoid."

Social Marketing Practitioner (4)

"... there was some concern because we were [a government agency], 'oh here's another authority telling me what to do"' 
"That we actually thought it would serve as a deterrent, there are some people who like to do what the Government says but there are a list of people that say, 'I'm sick of the government telling me what to do. I pay my taxes, isn't that enough?'"

Social Marketing Practitioner (4)

"Good or bad, we have to acknowledge that government is not the most convincing source for social marketing because I think the public is generally not that positive towards government instructions, guidelines or demands".

Social Marketing Practitioner (3)

Discussing attribution in more detail, the social marketers were inclined to defend the use of government attributed branding in their own campaigns but were critical of the use in other social marketing campaigns highlighting the potential negative impact that the association with government would have on the campaign's effectiveness.

"I think if you want the target audience to know who the message is from then that's why you brand. We do, rightly or wrongly, because our masters demand that the New Zealand public know their money is going to reduce [problem behaviour]."

Social Marketing Practitioner (3)

The second theme to emerge from the data was the suitability of government as a credible source. As previously discussed, social marketers believe, the high volume of governmentattributed social marketing has created a predisposition in the public against government messages. Although this predisposition may exist, interviewees believe that government is the only source motivated and sufficiently resourced to conduct social marketing on the large scale necessary to address competitive advertising of deleterious goods such as alcohol and high sugar, salt and fat foods. Each interviewee cited the extensive resources, research and knowledge expertise necessary to develop a comprehensive social marketing programme.

All interviewees acknowledged that government was not the most credible source of social marketing messages. Three of the four interviewees had conducted research demonstrating that government was not considered the most effective or credible source of social marketing 
messages in the opinion of their target audience. Notwithstanding, all interviewees justified their agencies continued position as the source of social marketing due to their knowledge expertise and resources.

Some of the highlighted comments made by the interviewees in discussions on the suitability of government as a credible source are detailed below:

"I guess just to tell people that the government is trying to do the right thing or trying to let on that they are spending the taxpayer's money responsibility."

Social Marketing Practitioner (3)

"The programme or the message has the credibility; I don't think the government does."

Social Marketing Practitioner (4)

“... I don't think people would actually say, 'they would know after all they're government'. So I would not necessarily argue that being government makes you credible."

Social Marketing Practitioner (1)

"When we did the [government programme] research ... Government wasn't high on the list [of credible sources] and that is the reason, like I said before, we didn't want the New Zealand Government brand all over it".

Social Marketing Practitioner (4)

"Yes there would be more effective sources than us to be sure but our message is effective, no doubt. So it falls into the too hard category."

Social Marketing Practitioner (3)

"The truth is that they have probably never asked their target audience whether their message being attributed to the government is more or less effective. My guess is that it's probably not improving the effectiveness of the message." 
The final theme to emerge was government's authority and power presupposes credibility. As previously discussed, the social marketers interviewed were critical of the attributed government source of other social marketing campaigns prominent during the period. It was noted by the researcher that interviewees highlighted around fifteen campaigns that, in the interviewee's opinions, excessively used government's authority and power to presuppose credibility. Three of the four interviewees identified social marketing messages that implied credibility by threat or enforcement of legal compliance. All interviewees believed that this served to compound the negative disposition towards government social marketing messages held by the public.

“... being government doesn't make you credible. It just makes you powerful”

Social Marketing Practitioner (1)

"I think the error has been made because government agencies have been intent on branding their marketing with agencies' logos, etc to say two things: one, they are saying we are the government and listen to us because we are the smart ones and two, we are the government and do what we say."

Social Marketing Practitioner (3)

"At the end of the day, does knowing its [Agency] making them change their behaviour or does the message and the way we're conveying that creates that behaviour change?"

Social Marketing Practitioner (2)

"We have talked about it and there are few better messengers or owners at least but I guess we pay the money, so we can take the credit or brickbats, if that's the case."

Social Marketing Practitioner (3)

"In the sense that people might get sick of being told what to do but I think in a way [programme], to some degree, has been a little bit different to a lot of social marketing campaigns, we don't actually tell people what to do."

Social Marketing Practitioner (4) 
In the discussions on this topic, two interviewees contrasted the high volume of social marketing messages with the marketing conducted by companies promoting deleterious products such as high sugar, salt and fat foods or alcohol, as being more damaging to the audience than government social marketing messages. They believed it ironic that the public would have a negative disposition towards government messages caused by high volumes of social marketing whilst accepting the high volumes of commercially motivated advertising messages from the likes of Coca-Cola, McDonalds and various beer companies.

"One of the things I have found ironic is the view that parents and children don't want to be told what to do. Whereas I would argue the food industry has been telling us what to eat for a very long time."

Social Marketing Practitioner (1) 


\subsubsection{Alternative Effective Source(s)}

As discussed in the previous section, the majority of interviewees acknowledged that government is not the most effective source of social marketing messages. Moreover, interviewees expressed concern that the attribution of social marketing messages to government may have a negative impact on the effectiveness of those messages. In addressing the second research question, the researcher aimed to identify, if government is the not the most effective source of social marketing messages, then who or what organisation would be a more effective source? The interviewees were asked to identify more effective source or sources for their particular message.

Two distinct themes emerged from the collected data; the first theme indicated interviewees could identify a specific organisation or group of similar organisations that, in their opinion, would be a more effective source to their target audience. The second theme to emerge was the belief that the interviewee's government agency was not the sole contributor to the social marketing effort and importantly, the more effective message was derived from multiple sources throughout the intervention process.

"Yes there are more effective sources than us to be sure but our message is effective, so it falls into the too hard category."

Social Marketing Practitioner (3)

Three of the four interviewees identified an alternative source they believed to be more effective than their organisation. In the majority of examples provided, medical professionals and organisations with a medical imperative were considered more credible and effective sources of social marketing messages focused on chronic disease, injury and death prevention.

"When we did [Agency] research, we went through who people looked to for information. And it was quite interesting, like GPs are very high on that list." 
"The organisations that were quite high up the list, particularly for health related things are the health related agencies. Like, not the Ministry of Health but the Heart Foundation, Diabetes NZ, Cancer Society. Those ones are specialists in those health areas and are seen as very credible."

Social Marketing Practitioner (4)

Only two interviewees emphasised that government, through their agency, played a part in the change process influenced by social marketing, and did not represent the entire social marketing effort.

"We're part of or one of the messengers and we can do that at a national level but what we also need to do is support local people and the people around the [behaviour] to get that message."

Social Marketing Practitioner (2)

"So we have people like Counties Manukau DHB, Nelson Marlborough DHB have actually invested around $\$ 10$ million each in social marketing over the past three or four years."

Social Marketing Practitioner (1)

"...in an ideal world people are getting prompts and messages to support change in their behaviour from a range of sources and that's truly marketing isn't it?"

Social Marketing Practitioner (2)

All the alternatives offered were all non-government entities. Another key source was the families and friends of victims of the problem behaviour. Social marketers believed that messages from affected parties, particularly close family, would be extremely effective, however agree that this source would not have the resources or knowledge to pursue social marketing and although could be effective spokespeople, the audience would still seek out the source.

"Perhaps the [behaviour] message for a cop who has to tell the parents that their son is dead would be rather effective." 


\subsubsection{Appropriateness of Strategy to Persuasion}

One of the strong themes to emerge from the collected data was the reasons for government's involvement in social marketing. All interviewees noted the dichotomy of government's involvement in social marketing, in particular, where the association with government was detrimental to the effectiveness of the message. However, the government was the source of the high volumes of social marketing. Interviewees believed that government were the only organisation with the mandate, research and resources to conduct social marketing at the level necessarily to address the target audience and, although there may be more effective sources, they believed that it was more efficient for government to be the main source for combating negative social behaviours.

"...that's partly why the organisation has been set up, you know education and information is part of our Act and not only that we have the other resources to support the other things that need to happen to create change not just in and of itself."

Social Marketing Practitioner (2)

"... the only reason you have government intervening or being involved is because these messages wouldn't make the light of day otherwise."

Social Marketing Practitioner (1)

Further to the issue of resourcing, namely funding a social marketing programme, three of the four interviewees believed that the government was prepared to fund social marketing programmes during the research period, providing that money could be controlled by the responsible government agency. They believed that the centralisation of funding was necessary to provide a suitably scaled programme to address the national target audience and maintain accountability for the use of taxpayer's funds.

Central to the theme of why the government engages in social marketing was the belief from the interviewees that if government did not engage in social marketing, who would? Three of 
the four interviewees held strong opinions that the engagement of government in social marketing was necessary to provide a counter-argument in the community to the commercial promotion of deleterious products. Overall, there was consensus that although government is not the most effective source, it was the only source credible and sufficiently resourced to influence behaviour change in individuals. Moreover, interviewees thought the government would be objective and transparent in their intentions, where as third party organisations may not be as altruistic.

"You know because there's no profit in it. There is no money to be had from this kind of approach and so if it's not government, unless you've got a Bill Gates kind of benevolent someone who's had to fund this kind of thing."

Social Marketing Practitioner (1)

"If you get different agencies working together, you can give a common message; different people will read it and take something different out of it. It can lead to the same behaviour change that you're all looking for."

Social Marketing Practitioner (2)

Not all interviewees believed that the government is the most efficient or effective social marketers. Generally, three of the four interviewees were critical of other government agencies social marketing campaigns and questioned the effectiveness of their campaigns in influencing change in their target audience's behaviour. Moreover, they questioned whether these campaigns offered good value-for-money for the apparent results being achieved by their social marketing campaigns.

"We come back to the question of whether all social marketers are of the same standard and I'll say a resounding no. In short, no it is not the best use of government money in its current form." 


\subsubsection{Message versus Source}

In this study, the focus on understanding the impact of high volumes of social marketing on the source credibility of the government was a primary question for the researcher however, unforeseen to the researcher was the emergence of a strong response around the importance of the message versus source in social marketing advertising. The interviewees were divided with $50 \%$ (two of the four interviewees) making a strong claim that the source was an important influencer in the advertising messaging. The other $50 \%$ claimed an almost altruistic belief that the message was the most important and that the source of the message was irrelevant to the achievement of the organisations objectives.

Three of the four interviewees believe that the message is more important than the brand or attributed source. However, all interviewees placed a great deal of emphasis on their expert role in delivering the social marketing programme and being seen to do so.

"At the end of the day, does knowing it's [Agency] making them change their behaviour or does the message and the way we're conveying that creates that behaviour change?"

Social Marketing Practitioner (2)

"Actually sounds a bit dumb but I think most of our audience see the message before they see the owner. Does it matter?"

Social Marketing Practitioner (3)

"So is it about [Agency] or is it about the message? Do we care that Joe Bloggs living in Timaru knows that [Agency] makes an ad. We would say we care about the message."

Social Marketing Practitioner (2)

"I think it's the alignment that they [target audience] see alcohol in but the important thing is it doesn't matter whose they think it is so long as they take the right message out of it." 


\subsubsection{Repetition Effects}

This section of the study aims to provide the researcher with data addressing the third research question namely, "How does the repetition of multiple similar advertisements from one attributed source impact on the effectiveness of social marketing messages?" During the interviews, the researcher directed the social marketing practitioner's responses with a series of questions aimed at stimulating discussion on the repetition effects of social marketing advertising from one attributed source, government, on the message effectiveness.

Initially, interviewees were asked to discuss their organisations advertising strategy in regards to repetition of advertising and the results of such a strategy on the overall impact on the message. Interviewees were then asked to consider the wider issues of the cumulative effects of many social marketing messages from various government sources and what aspect of the advertising communication that repetition could affect.

In the discussion, the interviewees identified the influence that may be witnessed through several related agencies producing social marketing against a common root cause. For example, agencies producing social marketing against the deleterious behaviours caused by alcohol may choose to communicate their message in conjunction with other similar messages at high-risk times of the year.

This section will report the collected data in two areas, the intention of the social marketers and their agency and secondly, the interviewees' opinions of the potential impact that advertising repetition may have when accumulated with other social marketing advertising from other government agencies. 


\subsubsection{Advertisement Frequency Intentions}

Interviewees were favourable towards maximising the advertising frequency of their messages, particularly on television. All interviewees favoured a high frequency and reach advertising strategy to maximise the impact of their advertisements on the target audience. However, three quarters of the interviewees mentioned that the barrier to increased frequency was the lack of budget.

"Frequency unfortunately is often dictated by budget. Given more money, I would have, would want to have a [programme] ad out there every day of the year, 365 days of the year. I would like someone to turn on a TV, open a newspaper, read a magazine and there would be something about [programme] there."

Social Marketing Practitioner (4)

There is clear evidence that a primary driver of social marketers is reaching their target audience. Two thirds of the interviewees relied on media buyers from their advertising agencies to purchase suitable media to maximise the likelihood of their target audience seeing their social marketing message. Interviewees referred to the achievement of TARPS, a measure of reach and frequency, to determine the effectiveness of the media to deliver the message to the target audience. This section provides some of the highlighted quotes from the interviewees illustrating their intention on producing a high frequency advertising strategy.

"So every time we launched a new campaign we would have higher frequency so there would be the higher cut through. What we would then do is we would have maintenance frequency."

Social Marketing Practitioner (1)

"We always rely on the agency, the media people to give us an indication of what we need to do to reach our target audience and achieve our TARPS.' 
"I don't think that we have a specific frequency versus reach type of strategy, the truth is probably that we have to get more of the audience's attention, hence the high frequency."

Social Marketing Practitioner (3)

"[Media Buyers] what they were trying to achieve for us, to reach a certain number of people, so they planned around that in the budget that we had available."

Social Marketing Practitioner (2)

Interviewees acknowledged that the advertising landscape in the research period was intense and they were aware of the focus of many social marketing efforts to address the same target audience. Three of the four interviewees discussed their desire to maximise their advertising frequency to cut-through other advertising in order to gain more recall from their audience. This cut-through, they acknowledged, might be at the expense of other social marketing messages.

"We are probably trying to get them to ignore the Push Play or the quit smoking ads to look at ours."

Social Marketing Practitioner (3)

Two thirds of the interviewees acknowledged that they were competing against other social marketing organisations, government agencies, for the time and attention of a similar audience. They agree that in the some cases they are promoting a similar message to their target audience. 


\subsubsection{Cumulative Repetition Effects}

As social marketers, the interviewees were aware of the social marketing landscape and their organisations desire to implement normal marketing practices of maximising the effectiveness of their advertising and the communication of key messages to their target audience. Normal marketing planning and intentions were evident in the discussions. However, it was clear that the social marketers did not initially consider other social marketing messages as competition. Moreover, only one interviewee acknowledged that other government agencies conducting social marketing were competition for their target audience's time and attention.

"I don't think that we are making the consumer choose between giving up smoking or stopping drinking and driving. I don't think it is a choice between one or other type of behaviour. It's more of a 'and' not a mutually exclusive choice for the target audience."

Social Marketing Practitioner (3)

However, in the discussion the social marketers acknowledged that the number of social marketing messages in the public domain in late 2008 was extremely high and the likelihood of the target audience being impacted by the high repetition of similar messages from the same general source was not considered.

"I guess the only real competition we have between us is the competition for their attention and time."

Social Marketing Practitioner (3)

Three themes emerged from the collected data in relation to the cumulative effect of social marketing advertising. Firstly, some interviewees indicated that they were not considerate of other similar social marketing campaigns. Secondly, some interviewees indicated that they conducted their social marketing activities in concert with other government agencies' campaigns and finally, there were some practitioners that set about to avoid other organisation's marketing activities in planning their media schedules. 
The first theme to emerge was the total absence of consideration for other social marketing activities that existed in the advertising landscape. Three quarters of interviewees made reference to other agencies, particularly those that shared the same root cause of their targeted behaviour, however they indicated that they did not share joint strategies or any joint delivery of their programmes.

"... we were becoming very aware that parents were becoming an increasingly targeted audience for campaigns. ... the intention was that we were actually going to come together again and really comprehensively look at our messaging, how we could improve $i t$, ... is there a single message to parents that we could do together. It never happened".

Social Marketing Practitioner (1)

The second theme to emerge from the collected data was the social marketers who advertised in concert (not partnership) with other agencies with similar messages. Half of the interviewees indicated that they were more likely to launch new advertising or conduct increased activities when other similar agencies were conducting their campaigns. They acknowledged that the cumulative effect on the target audience of similar messages was, in their opinion, more effective than in isolation. Although these campaigns were considered in concert with other agencies, interviewees stated there were no joint programmes or combined activities.

"We know that say ALAC will talk to us and launch their campaign in concert with us. Essentially, we have the same message but we are the lead agency. We hadn't thought about the cumulative effect of all these social marketing messages."

Social Marketing Practitioner (3)

"We didn't look at frequency in relation to other campaigns. What we do, we coordinate when the TVCs would come on, to when the radio was on, to when the magazine articles would come out, to when helpful little resources would come out and then we would select the time based on viewer stats of our target audience." 
The final theme to emerge came from the data revealed that fifty percent of interviewees identified that the cumulative effect of other social marketing campaigns could have a negative impact on the effectiveness of their campaign. Their concerns were that the high repetition of similar messages from government could cause the target audience to react negatively towards government due to the high number of directive social marketing advertising targeting them. These interviewees made a strategic decision to avoid other similar messages in the public domain, as practically possible, to minimise messages confusion.

"So we've talked to the domestic violence people. We've talked to ALAC. We've talked to Smoke-free to see who is doing what at various times, so that we don't launch a campaign at exactly the same time."

Social Marketing Practitioner (4)

In addition, two of the four interviewees recognised that the high volume of social marketing messages from the different government agencies caused difficulty in planning for any specific delivery strategy.

"If we all waited for each others campaigns to finish and there are so many social marketing campaigns in New Zealand. You watch on a Sunday night, you can watch up to nine different campaigns." 


\subsubsection{Impact of Cumulative Repetition}

All interviewees acknowledged the volume of social marketing messages in the public domain during 2008 was high relative to other advertising. In this study, understanding the impact of high repetition on the effectiveness of the social marketing messages was first measured as the ability of the target audience to interpret the messages and to distinguish the source. Moreover, if the target audience is having problems interpreting the message contained in the advertisement or struggle to understand who is communicating the message, the overall effectiveness is questioned. In secondary questioning, the researcher also collected data on other impacts.

"We have not been too smart in this regard. We have contributed to filling up the ad breaks with hundreds of social marketing messages all trying to talk to the same audience. We have probably cancelled out each other's messages by just getting our audience to tune out or flick over to the other station."

Social Marketing Practitioner (3)

In the interviews, the researcher directed the discussion towards the two main themes and asked the interviewees to consider the likely impact of their target audience's ability to interpret the message and their ability to recognise the source within their social marketing advertisements. The researcher also asked the interviewees to consider any other impact they would consider potentially influential to the effectiveness of their messages.

All interviewees acknowledged that the high volume and variety of social marketing would create a challenge for the target audience to recall or remember the advertising detail. All interviewees observed that social marketing advertisements have been kept simple in their creative delivery and therefore, interpretation of the message should be very simple. Three of the four interviewees did however agree that the similarity of the social marketing messages, particularly with agencies that share the same root cause, could create difficulty for the target audience to identify the core message. Conversely, the interviewees did note that the volume 
of similar messages could reinforce a simple message across a number of different advertising delivery methods or different creative styles.

"[Agency] recently got [a researcher] to do a piece of research for them and their ads and the drink driving and the domestic violence are all starting to cross over."

Social Marketing Practitioner (4)

All interviewees commented that the link between the source and the advertising was starting to blur causing the misattribution of advertising to the wrong source. $50 \%$ of interviewees had experienced source misattribution of social marketing messages to their agency caused by a similarity of messages.

"It depends on the message and what we think the audience is taking out of it. For example, we know that some people think the drink driving are ours and we know that some people think the ad with the little boy is ours, well that's family violence."

Social Marketing Practitioner (2)

"Is it driving? Is it drinking? Is it violence? You get to the driving ones, are they telling you about driving or are they telling you about drinking? But then you see the end of the ad and there is about five different logos along the bottom."

Social Marketing Practitioner (4)

Two of the four interviewees contradicted their opinion into the impact of the source to the effectiveness of the social marketing message. In both cases, the marketers believed that the message was more important to their audience than the source, however believed the importance of branding in the advertisements.

"Yes people need to know who it's coming from. Yes I think it becomes important but actually I don't think they do."

Social Marketing Practitioner (1)

Interviewees acknowledged that the volume of social marketing advertising was not a consideration for their organisations, although they do consider that an issue now exists. They 
hypothesised that the challenge placed on their target audience to interpret both the messages and source in such a cluttered advertising environment would add an additional factor, which is whether their target audience has the patience to spend time decoding the advertisements to gather the relevant information. All interviewees did conclude that if nothing else, interpreting the message should be their priority.

"Well, no it doesn't matter to them at the end of the day social marketing is about the audience."

Social Marketing Practitioner (2)

"The thing is, if people get the message does it really matter who gave them the message."

Social Marketing Practitioner (4) 


\subsubsection{Attribution}

This area of interest for the researcher revolved around the intention of the social marketers to associate or disassociate with the government through the direct attribution of the message with their organisation and/or other government organisations. The questions and discussions aimed to delve further into the branding and attribution strategy of the interviewees' campaigns. This area overlaps with discussions reported in Section 5.1.1.1, where the researcher found interviewees expressed concern at the potential detrimental impact of the high volume of social marketing on government, as the campaign's source, and ultimately, on the effectiveness of the social marketing message. In this discussion, three of the four interviewees expressed concerns over the perceived negative impact caused by government as the directly attributed source of social marketing messages i.e. attributed through direct reference or the use of government brands. This section will report the interviewees' organisations intentions to attribute their message, their branding strategy being an extension of this attribution.

\subsubsection{Attitude towards Government Attribution}

All interviewees made a conscious strategic decision on whether to associate or disassociate directly with their government connections. Two of the four interviewees made an effort to disassociate their social marketing campaigns to any government source, choosing instead to develop an independent campaign brand that had no reference to government. The other two interviewees felt the attribution of their campaigns to government, their agency, was beneficial to the persuasiveness of their message.

Those interviewees who developed an independent brand and made a conscious decision to avoid government attribution made comment that they also were required to seek special exemption to the New Zealand government's all-of-government branding policy. This issue was unexpected for the researcher with all interviewees acknowledging the New Zealand government's all-of-government branding policy predetermined the attribution of their 
campaigns to government and in some cases, required special exemptions to avoid having to brand the social marketing advertisements with the government brand.

In April 2007, the New Zealand government introduced an all-of-government brand for all government agencies including crown entities. The State Services Commission stated, "The purpose of the new brand is to improve the visibility and accessibility of government services through increased public recognition, to provide more unity across diverse agencies, and improve the transparency of government funding of services" (2008). Further, the all-ofgovernment brand policy states that the core objectives of this branding policy is to increase visibility of services by linking government-funded services, programmes and products through consistent imagery and to develop and promote credibility and trust (2008).

Three of the four interviewees admitted that the impact of the government association was an area of testing they believed was important yet had not done. All interviewees felt that the allof-government branding removed their ability to maximise the effectiveness of their message.

"There has been some debate about the use of all-of-government branding, it's fair to say that our target audience is not too keen on it - we think that. We are yet to test it with them but we actually think that it will put them off the message."

Social Marketing Practitioner (4)

"We agreed, when we did our next concept testing for each campaign, we would test with our consumers how they would respond if they thought there was a government programme and it carried a government brand."

Social Marketing Practitioner (1)

"We hadn't tested it at the time but we felt that associating a government brand with something like that could actually have the opposite effect."

Social Marketing Practitioner (4) 


\subsubsection{Brand Strategy}

In responses concerning the branding strategy of the social marketing organisations, the researcher identified three themes from the data. The first theme was the development of a brand strategy to associate with government. Secondly, a brand strategy to disassociate with government and generate an anonymous brand linked to the social marketing campaign. The third theme concerned the development of a brand identity that is unique to the campaign to maximise target audience recall.

As discussed in the previous section, two of the four interviewees advocated an association with government as a positive influence to support their core message. Consequently, these interviewees' brand strategy contained a strong element of government association. There was also a belief that the all-of-government branding forced the interviewees to adopt branding that had a strong association, regardless of the interviewees' feelings towards this association.

"We usually have our logo and [Agency], seeing as we are partners and the ever present all-of-government branding. I guess just to tell people that the government is trying to do the right thing or trying to let on that they are spending the taxpayer's money responsibly."

Social Marketing Practitioner (3)

"It is the difference between promoting an organisation and promoting a message. We do [brand ads] but then we're required to. You're required by this standard to say who has made the ad."

Social Marketing Practitioner (2)

"The use of the all-of-government branding, it's fair to say that our target audience is not keen on it - we think that, we are yet to test it with them but we actually think it will put them off the message a bit but so does the Police logo, if the logic is the same." 
$"$...but we feel that associating a government brand with something like the [programme] could actually have the opposite effect, it would be very clear that government is telling you to do something."

Social Marketing Practitioner (4)

The second theme that was evident in the data was those interviewees who developed brand strategies for their social marketing campaigns that excluded any reference to government, to hide the association with government. These interviewees were those that felt that the direct attribution with government was detrimental to the effectiveness of their message. In some cases, these interviewees had furthered that strategy by applying for a special exemption to the implementation of the all-of-government branding to further avoid this attribution.

"We felt a strong negative factor against government constraining people's behaviours so we put up a case for an exemption to the all-of government branding which we were given a twelve month exemption."

Social Marketing Practitioner (1)

"In terms of the all-of-government branding and in particular, I think because of our [other SM programmes] there is, we felt a strong negative factor against government constraining people's behaviour."

Social Marketing Practitioner (2)

The discussion did raise some contradictions in responses from the interviewees. Although there was an equal divide between the social marketers on the attribution with government and the positive or negative influence that this attribution may have on the effectiveness of their social marketing message, the interviewees did alter their responses depending on the conditions discussed with the researcher. In some cases, interviewees believed the association with government was a positive influence to their message but disliked the imposed all-of-government branding as being too bombastic. Similarly, interviewees believed that the association with government was potentially a negative influence on the social marketing campaign message but still included branding that associated the message with government. It was obvious to the researcher from the discussions that this was a very complex area for discussion and much effort had been applied to associating or disassociating 
with government. Moreover, some of the interviewees believed that their aim to remain anonymous from government in the delivery of their social marketing messages had been successful with the target audience naive to the source of their message, through the use of only campaign specific branding.

The final theme to appear from the collected data was evidence of the contradiction that existed in the responses from the social marketing practitioners. The final theme was the development of brand strategy by some agencies to deliver a unique brand relevant to the campaign. Two of the four interviewees highlighted the advantages of developing a unique, stand-alone brand relevant to the social marketing programme that would hold brand values more aligned with the campaign than the government agency. The responses indicate that this brand development decision making is separate from the overall association or disassociation with government.

"We want them to engage with the brand which has its own message and it's kind of ideology and want them to buy into those ideologies."

Social Marketing Practitioner (1) 


\subsubsection{Persuasion (Effectiveness)}

In the final stages of the interviews with the social marketing practitioners, the researcher directed a series of questions to establish how the interviewees measured the success of social marketing campaigns both those that they were responsible for and those they observed during 2008. Understanding the factors that social marketers believe are important to the success of a social marketing campaign is helpful in measuring the impact of high volumes of social marketing messages on the effectiveness of those campaigns. However, the researcher failed to gain a significant level of correlation in the data to provide a clear opinion of the factors that constituted success. Interviewees indicated a number of factors that were important internally, within their government agency, and externally in the execution of the social marketing campaign. Very few references were made directly to the influence the campaign made to changing behaviour in the target audience.

" ...been successful, that's a big question. I think it's incredibly powerful. It is an important part of the public health toolbox. Has it been successful? I think it probably would have been partially successful given the longitude of social marketing and how long it has to run and how many other things have to happen."

Social Marketing Practitioner (1)

In whether social marketing is successful in motivating or influencing change in the target audience, the interviewees were divided. Three quarters of the interviewees believed that social marketing through advertising was not working. They demonstrated little faith in their own programmes' success from seeing very few effective campaigns in the New Zealand environment, the anti-speeding campaign being the notable exception.

"I think it depends on the campaign. The driving [speeding] ones work in New Zealand. The biggest thing that helps driving [speeding] is the fact that they've got how many policemen out there to pull you over and give you a ticket."

Social Marketing Practitioner (4)

Other responses indicated that the social marketing campaigns had failed to deliver the necessary influence over the target audience due to the lack of correct execution. All 
interviewees felt the vast majority of government organisations poorly handled the overall execution of the social marketing campaigns.

"It still stuns me that the vast majority of government social marketing is led by policy and programme advisors with little or no marketing experience."

Social Marketing Practitioner (3)

"It depends on what's associated with the campaign. If you just watch the ads, they're not effective."

Social Marketing Practitioner (4)

Included in the responses was the negative reaction that all interviewees had to the more extreme shock-style social marketing advertisements. Three of the four interviewees believed that these types of advertisements failed to communicate the core message and in fact, repulsed the target audience before they could properly engage with the message.

"The ad is so horrific, I really do wonder at how effective it is. Because it is so awful that everyone always says, 'oh I walk away or I turn it off'. I just think it's gone to the other extreme."

Social Marketing Practitioner (4)

Finally, other relevant comments on the effectiveness of social marketing campaigns were observed below:

"You have to shed a tear for what could have been with some solid marketing professionals, solid research and a considered intervention model."

Social Marketing Practitioner (3) 


\subsubsection{Summary of Results and Implications to Members of The Public}

This section summarises the results of the thematic analysis of the data collected from the social marketers surveyed in the first phase of this study. The analysis has revealed a number of distinct themes addressing the research questions. Finally, this section will also highlight areas identified in the analysis that will guide the interviews in Phase 2 of this study.

In addressing the first research question, the researcher collected data related to the impact that the high volume of social marketing messages during 2008 had on the credibility of the government agencies, as the source of these messages. Three major themes emerged firstly, the effect of the high volume of social marketing on government source credibility; second, the suitability of government as a credible messenger; and finally, that government's authority and power presupposes credibility. In the first theme, three of the four interviewees expressed concerns over the perceived negative impact caused to government. The interviewees believed the high volume of social marketing created a heightened public awareness of government as the source of social marketing messages and this in turn, created a negative predisposition towards any government message that could be considered directive or interfering with the public's free choice. Therefore, the interviewees expressed their belief that government attribution was detrimental to the effectiveness of the message.

The second theme to emerge from the data was the suitability of government as a credible source. As previously discussed, the predisposition of the public against government messages may exist however, interviewees believed that government is the only source motivated and sufficiently resourced to conduct social marketing on the large scale necessary to address competitive advertising of deleterious goods. Interviewee believed the government is the logical choice of source and cited the extensive resources, research and knowledge expertise necessary to develop a comprehensive social marketing programme.

The final theme to emerge was government's authority and power presupposes credibility. Three of the four interviewees identified social marketing messages that implied credibility by 
threat or enforcement of compliance by legal ramifications. All interviewees believed that this served to compound the negative disposition towards government social marketing messages held by the public.

All interviewees acknowledged that government was not the most credible source of social marketing messages. Three of the four interviewees had conducted research demonstrating that government was not considered the most effective or credible source of social marketing messages in the opinion of their target audience. Moreover, interviewees expressed concern that the attribution of social marketing messages to government may have a negative impact on the effectiveness of those messages.

In addressing the second research question, "Does the public believe the government is an appropriate message source for social marketing messages and if not, who or what would be a more appropriate messenger?", the researcher aimed to identify who or what organisation would be a more effective source. The interviewees were asked to identify more effective source or sources for their particular message. Two distinct themes emerged from the collected data; the first theme indicated interviewees could identify a specific organisation or group of similar organisations that, in their opinion, would be a more effective source to their target audience. The second theme to emerge was the belief that the interviewee's government agency was not the sole contributor to the social marketing effort and importantly, the more effective message was derived from multiple sources throughout the intervention process.

Three of the four interviewees identified an alternative source they believed to be more effective than their organisation. In the majority of examples provided, medical professionals and organisations with a medical imperative were considered more credible and effective sources of social marketing messages focused on chronic disease, injury and death prevention. Only two interviewees emphasised that government, through their agency, played a part in the change process influenced by social marketing, and did not represent the entire social marketing effort. 
Three of the four interviewees held strong opinions that the engagement of government in social marketing was necessary to provide a counter-argument in the community to the commercial promotion of deleterious products. Overall, there was consensus that although government is not the most effective source, it was the only source credible and sufficiently resourced to influence behaviour change in individuals. Moreover, interviewees thought the government would be objective and transparent in their intentions, whereas third party organisations may not be as altruistic.

Unforeseen to the researcher was the emergence of a strong response around the importance of the message versus source in social marketing advertising. The interviewees were divided with two of the four interviewees making a strong claim that the source was an important influencer in the advertising messaging. The other two interviewees claimed an almost altruistic belief that the message was the most important and that the source of the message was irrelevant to the achievement of the organisations' objectives. Three of the four interviewees believed that the message is more important than the brand or attributed source.

In response to the third research question, "How does the repetition of multiple similar advertisements from one attributed source impact on the effectiveness of social marketing messages?" the collected data was divided into two areas. Firstly, the intention of the social marketers and their agency and secondly, the interviewees' opinions on the potential impact that advertising repetition may have when accumulated with other social marketing advertising from other government agencies.

The advertisement frequency intentions of the government agencies aimed to identify if the agencies, by their unconsidered actions, were compounding the repetition effects by generating high frequency advertising. Interviewees were favourable to maximising the advertising frequency of their messages, particularly on television. All interviewees favoured a high frequency and reach advertising strategy to maximise the impact of their advertisements on the target audience. Interviewees acknowledged that the advertising landscape in the research period was intense and they were aware of the focus of many social marketing 
efforts to address the same target audience. Three of the four interviewees discussed their desire to maximise their advertising frequency to cut-through other advertising in order to gain more recall from their audience. This cut-through, they acknowledged, might be at the expense of other social marketing messages. Three quarters of the interviewees acknowledged that they were competing against other social marketing organisations, government agencies, for the time and attention of a similar audience. They agree that in the some cases they are promoting a similar message. However, it was clear that the social marketers did not initially consider other social marketing messages as competition. Moreover, only one interviewee acknowledged that other government agencies conducting social marketing were competition for their target audience's time and attention

In the interviews, the social marketers acknowledged that the number of social marketing messages in the public domain in late 2008 was extremely high and the likelihood of the target audience being impacted by the high repetition of similar messages from the same general source seemed highly likely although the issue had not been considered.

Three themes emerged from the collected data in relation to the cumulative effect of social marketing advertising. Firstly, some interviewees indicated that they were not considerate of other similar social marketing campaigns. Secondly, some interviewees indicated that they conducted their social marketing activities in concert with other government agencies' campaigns and finally, there were some practitioners that set about to avoid other organisation's marketing activities in planning their media schedules. The first theme to emerge was the total absence of consideration for other social marketing activities that existed in the advertising landscape. Three quarters of interviewees made reference to other agencies, particularly those that shared the same root cause of their targeted behaviour, however they indicated that they did not share joint strategies or any joint delivery of their programmes.

In the second theme to emerge from the collected data were the social marketers who advertised in concert with other agencies with similar messages. Half of the interviewees 
indicated that they were more likely to launch new advertising or conduct increased activities when other similar agencies were conducting their campaigns. They acknowledged that the cumulative effect on the target audience of similar messages was, in their opinion, more effective than in isolation. Conversely, the other fifty percent of interviewees identified that the cumulative effect of other social marketing campaigns could have a negative impact on the effectiveness of their campaign. Their concerns were that the high repetition of similar messages from government could cause the target audience to react negatively towards government due to the high number of directive social marketing advertising targeting them.

Interviewees identified high repetition could affect the effectiveness of the social marketing messages and this would be demonstrated in the ability of the target audience to interpret the messages and to distinguish the source. Therefore, if the target audience is having problems interpreting the message contained in the advertisement or struggling to understand who is communicating the message, the overall effectiveness is questioned.

All interviewees acknowledged that the high volume and variety of social marketing would create a challenge for the target audience to recall or remember the advertising detail. They observed that social marketing advertisements have been kept simple in their creative delivery and therefore, interpretation of the message should be very simple. Three of the four interviewees did however agree that the similarity of the social marketing messages, particularly with agencies that share the same root cause, could create difficulty for the target audience to identify the core message. Conversely, the interviewees did note that the volume of similar messages could reinforce a simple message across a number of different advertising delivery methods or different creative styles. All interviewees commented that the link between the source and the advertising was starting to blur causing the misattribution of advertising to the wrong source.

In the discussion of attribution and understanding how the social marketers addressed their concerns around attribution to government, the researcher discovered extensive consideration was given to the campaign branding strategy to decide whether to associate or disassociate 
directly with their government. Two of the four interviewees advocated an association with government as a positive influence to support their core message. Conversely, the other $50 \%$ of interviewees developed brand strategies for their social marketing campaigns that excluded any reference to government, to hide the association with government. It was evidenced in the interviews that the interviewees gave considerable attention to their decision to associate or disassociate with government. Where the social marketing practitioner chose to disassociate, they appeared to go to significant lengths to develop and maintain a high degree of anonymity to avoid government association.

Finally, in series of questions were asked to establish how interviewees measured the success of social marketing campaigns both those that they were responsible for and those they observed during 2008. Unfortunately, the researcher failed to gain a significant level of correlation in the data to provide a clear opinion of the factors that constituted success.

In whether social marketing is successful in motivating or influencing change in the target audience, the interviewees were divided. Three quarters of the interviewees believed that social marketing through advertising was not working. They demonstrated little faith in their own programmes' success while seeing very few effective campaigns in the New Zealand environment, the anti-speeding campaign being the notable exception.

One of the aims of interviewing social marketers was to provide insights and responses that served to inform the questions asked in Phase 2 of the research, in-depth interviews of ten members of the public. The distinction between the two groups of interviewees will enable the researcher to compare and contrast the intentions of the practitioners and their campaigns with the public perception, attitudes and observations of those campaigns. The following areas have been identified in the content analysis of Phase 1 data and will be explored further in Phase 2 of this study by their inclusion in the interview questions and discussions. 
The areas for further exploration will include:

- Determining whether a pre-disposition towards government-attributed messages exist in the public perception.

- Exploring whether government-attribution has a negative impact on the social marketing messages.

- Identifying other more credible and effectives sources for the social marketing messages.

- Investigating the importance of message over the messages source and further, to understand the importance of source in the communication process undertaken by the public.

- Investigating the impact of high volume social marketing on the public's ability to interpret the messages, distinguish the messages source and recall the core messages details.

- Finally, understanding whether the government agencies effort to disassociate with government and remain anonymous through branding strategies and other actions has been successful as perceived by the public. 


\subsection{Members of the Public}

Introduction

Phase 2 of the research focused on the gathering the opinions and attitudes of social marketing conducted in New Zealand in 2008 by a representative group of New Zealander public to address the research questions. Data was collected from ten interviewees using semi-structured face-to-face interviews. During the interview process, interviewees were asked the same series of questions addressing their opinions and attitudes towards social marketing messages under both unprompted and prompted conditions. Initially, interviewees were asked a series of questions regarding social marketing advertisements that the interviewees could recall from memory. In the prompted condition, interviewees were shown three television advertisements from high profile social marketing campaigns that were prominent in 2008 and asked the same questions in reference to the prompted advertisements. These television commercials were from the Push Play physical activity campaign, the Feeding Our Futures healthy eating campaign and the Smokefree anti-tobacco campaign.

The semi-structured interview questions used in Phase 2 of the research study were developed to include specific discussion areas identified through the Phase 1 research into the practices and opinions of social marketing practitioners. Using the data collected in Phase 1 allowed the researcher to target questions to specific observations of the social marketing campaigns thereby directing discussions to address the research questions.

Phase 2 interviewees were directed to the same areas of enquiry as the social marketers in the first phase of this study. The intention was to compare and contrast the intended outcomes and actions of the social marketers with the observations and opinions of the public towards these actions. In essence, the study will see if the intentions and logic used in the social marketing campaigns are being observed in the same way by their target audience, the public, as intended. 
The Phase 2 interviewees were similar to the New Zealand population for gender and ethnicity with a skew towards more highly educated individuals compared to the 2006 Census.

- Gender - interviewees were females $60 \%$ and males 40\%. The 2006 New Zealand Census recorded females 55\% and males 45\% (Statistics New Zealand, 2007).

- Ethnicity - interviewees were NZ European 70\%, Maori 20\% and Asian 10\%. The 2006 New Zealand Census recorded NZ European 67.6\%, Maori 14.5\% and Asian 9.2\% (Statistics New Zealand, 2007).

- Education - interviewees were secondary school qualified $40 \%$ and post school qualified 60\%. The 2006 New Zealand Census recorded post school qualified 40\%, secondary school qualified 35\% and no qualifications 25\% (Statistics New Zealand, 2007).

- Location - all interviewees to the Phase 2 research were residents of the Wellington region.

The data collected from the interviewees in the second phase of this study were analysed to explore the themes and patterns that exist in the data. The pre-planned interview questions assisted the process of data analysis by maintaining a broad focus on the research questions and discussion topics. The input of the Phase 1 data also assisted the analysis process by predetermining some themes and subject areas to be explored.

Interviewees to Phase 2 of the study met the requirements as detailed in Section 4.8., and it was noted that the sample size of ten interviewees was satisfactory in achieving data saturation by the seventh or eighth interview. The sample size of ten interviewees allowed for more detailed analysis rendering significant thematic trends, also assisted by the semistructured interview process.

The results of the data analysis are detailed in this section for the Phase 2 interviewees, members of the public. The results will be reported in the broad themes that emerged from the 
data and detail any specific responses that highlight the fundamental nature of the data. As with the Phase 1 research, the data was to be reported in four broad subject areas to reflect the research questions, namely source credibility, attribution, repetition effects and persuasion (effectiveness). However, in the findings of the second phase data, source credibility and attribution have been combined as one topic. In the interview process, it emerged that interviewees referred to source credibility and attribution of source processing of an advertisement in the same instance and it was difficult for the researcher to separate the response accordingly.

In interviewing the members of the public, the researcher observed behaviour from the interviewees that was worth noting. In generally discussing social marketing, interviewees were quite unfavourable to being told what to do by government or any other source of social marketing messages. Their responses were quite critical of government providing messages to highlight unacceptable behaviour or provide positive guidance on better ways to behave, particularly when interviewees were asked to provide unprompted opinions and responses. However, this attitude and response appeared to change when the interviewees were provided with visual prompts in the form of television commercials or when the researcher verbally prompted the interviewee with examples of social marketing messages. When prompted, interviewees reacted more favourably to the social marketing messages and the core message contained within the advertisements. This has been detailed in section 5.2.1.3, where $70 \%$ of interviewees were favourable towards government as the source of social marketing messages after the interviewees were prompted with examples of social marketing.

\subsubsection{Source Credibility and Attribution}

In addressing the first research question, the researcher collected data that related to the impact that the high volume of social marketing messages during 2008 had on the credibility of the government agencies that were the source of these messages. In the finding, the researcher discovered the interviewees processed attribution of a source and the source 
credibility to the social marketing advertisement in the same instance and therefore, the data analysis was combined.

This section of the study acknowledges $70 \%$ of the interviewees believed that the volume of social marketing advertising was high in relative to other general advertising (Refer Section 5.2.2.1.) and as a result, interviewees were asked if they could attribute a particular source or sources from the unprompted and prompted social marketing advertisements. The interviewees were then asked their attitudes and opinions on the credibility of that organisation or individual as the source of the social marketing messages. It is noted that of the three television advertisements used as prompts for the interviewees only one was branded to attribute to government, the balance of the television advertisement used independent, unique campaign brands with no reference to government or the government agency responsible for the social marketing campaign.

In response to the attribution of a source of the social marketing advertisements, the analysis of the collected data revealed two themes. The first theme was the correct attribution of the advertisements and the second theme was the interviewees' default, if the identification was inconclusive.

The first identified theme was the correct attribution of the source despite the branding used and the extent to which the government agencies went to avoid being associated to government. Over $70 \%$ of interviewees could clearly attribute the correct source to three quarters of the unprompted and prompted social marketing advertisements discussed. This included the advertisements that utilised independent brands such as Push Play. In the case of Push Play prompted advertisement, $90 \%$ of the interviewees identified the source as a government agency with $80 \%$ identifying the specific agency responsible for the social marketing programme. In the Smokefree prompted advertisement, $100 \%$ of the interviewees identified the source as a government agency with $70 \%$ identifying the specific agency responsible for the social marketing programme. In the case of the Feeding Our Futures prompted advertisement, no interviewees could attribute a source to the advertisements and 
immediately at the conclusion of the advertisement only $20 \%$ of interviewees could not identify the campaign brand. However, $70 \%$ of interviewees assumed that the source was a government agency.

The second theme that emerged from the collected data was the interviewees' default assumption of source, if the attribution of a source was inconclusive. In the discussions surrounding the attribution of source, interviewees who could not identify the source or where the identification of the source was inconclusive, the interviewee's default was to assume the source was government. This default assumption was evident throughout the data collection irrespective of associated or independent brands. This was most evident in the Feeding Our Futures prompted advertisement, where none of the interviewees could attribute a source to the message nor could $80 \%$ of the interviewees attribute the campaign brand to the advertisement immediately following their viewing of the advertisement. Despite the fact that the interviewees failed to attribute a source, they all attributed the source to government.

"I read it at the end and I've forgotten the name. Again, I would assume that the government was behind that."

Member of the Public (1)

"Some kind of health related government, yeah government organisation."

Member of the Public (10)

"Yeah it's probably a government ad because they're the people who are supposed to be socially responsible for our welfare. Absolutely part of their job because we put them in power to make our lives better."

Member of the Public (1)

"I think it's like a subliminal thing. I think it can be on in the background and you're absorbing it without realising that you are absorbing it. On the other side of the coin, you can deliberately switch off and the more you automatically switch off then it becomes that you don't notice the ads been on."

Member of the Public (9) 


\subsubsection{Source Credibility Perception}

Following the attribution of a source to the social marketing advertisements, interviewees were asked to provide an opinion of the source's credibility, whether the high volume of social marketing messages had affected that credibility and how this credibility influenced the persuasion of the social marketing message. In the discussions, interviewees were asked if they believed that the source was trustworthy and knowledgeable.

The collected data indicates that where the source could be correctly attributed interviewees believed the source was credible and where the source was assumed to be government rather than conclusively identified, less than half of the interviewees believed that the source was credible - i.e. trustworthy and knowledgeable. In the case of the prompted advertisements of Push Play and Smokefree, $100 \%$ and $80 \%$ of the interviewees respectively believed the source agencies were trustworthy and knowledgeable. Conversely, were the source could not be conclusively identified but where the interviewees assumed the source as government as in the Feeding Our Futures prompted advertisements, only $40 \%$ of interviewees believed that the source was trustworthy and knowledgeable. Similarly in some of the unprompted examples provided from interviewees recall, social messages that were not easily attributed to a source believed the source to be credible, however did not agree they were knowledgeable or trustworthy.

"So is Feeding Our Futures credible, is that the question? Because I don't know who they are, maybe it doesn't matter because the message still is credible. So maybe where it comes from doesn't matter."

Member of the Public (8)

"Because I don't know anything about them I guess I'd have to, well I'd have to err on the side of saying if they're the organisation set up to pursue that and promote that then I guess they're credible." 
In the collection of this data, the researcher identified that in the cases where the interviewee could easily interpret the message in the high volume environment and their attitude to the messages was favourable, less priority was placed on the importance of the source's credibility. Interviewees referred to the credibility of the social marketing campaigns or the core message rather than the credibility of the source. The analysed data also revealed that interviewees gave less importance to processing source credibility thoughts than advertisement creative or message thoughts. Early in the interview process, it was apparent to the researcher that interviewees gave little regard to the credibility of the source, particularly where the interviewees agreed with the core message or were the source was believed, rightly or wrongly, to be government. This fact was particularly apparent where these social marketing messages were subject to high frequency media schedules and were similar to other social marketing messages during the period.

"I keep coming back to the government but I'm not sure that they would make any difference to me. It would probably matter more if I disagreed with the message."

Member of the Public (1)

Moreover, interviewees stated that they did not consider the credibility of the source until they had considered whether the message creatively appealed to them and whether the message was engaging. This concept will be reported in more detail in section 5.2.1.4.

"Well, I probably process the ad first. I listen to the message, if I agree then I'm happy and in the most, don't care who sent it. If I disagree, then I probably tune out or change channel. Very occasionally, if it is something I strongly disagree with then I will want to know who it's from."

Member of the Public (5) 


\subsubsection{Alternative Effective Source(s)}

In addressing the second research question, the researcher aimed to identify, if government is not the most effective source of social marketing messages, then who or what would be a more effective source. Interviewees were asked to identify an alternative source for the unprompted and prompted social marketing messages discussed in the study that they believed would be more effective and credible than the identified source. In the analysis of the data, two distinct results emerged relative to the unprompted and prompted data. As previously discussed, the researcher observed behaviour from the interviewees where they were quite unfavourable towards government attributed social marketing messages, particularly when interviewees were asked to provide unprompted opinions. However, this attitude appeared to change when the interviewees were provided with visual prompts or verbal examples of social marketing messages. When prompted, interviewees reacted more favourably to the identified source of the message.

In response to the unprompted questions on a more effective alternative source, $30 \%$ of the interviewees identified medical professionals and medical organisations as a more effective alternative to the government. $60 \%$ of interviewees considered that these messages should come from a combination of organisations and individuals, such as family members and community leaders, to work together to address the issues from several different perspectives.

"Generally, I don't think that government as a messenger is compelling. They are always telling you what to do. To be more effective it needs to be those organisations who are telling you because they care not because they have to. Doctors, teachers, parents and friends have more desire to do the right thing than government."

Member of the Public (8)

"...a combination of both [government and spokesperson] having that cut through these days with the sort of youth, if you're appealing to youth."

Member of the Public (10)

"You know there is a whole lot of organisations that are working together to make roads safer but yeah, it probably wouldn't make a difference who the message came from." 
In response to prompted questions, interviewees were more likely to agree that government is an effective source, particularly if the interviewee agreed with the social marketing message. Prompted by the three social marketing television advertisements, interviewees believed that the attributed source was equal in credibility and effectiveness to the alternatives that were suggested. In terms of the Smokefree prompted television advertisement, $60 \%$ of interviewees claimed that either medical professionals or medical organisations would be a suitable alternative to government as a source of smoking cessation marketing. They did believe that they would be similar in their effectiveness compared to the government sources. Some $40 \%$ of interviewees indicated that the source did not really matter, as the message was consistent with their beliefs.

As a second choice of alternative, $30 \%$ of interviewees also claimed victims or victims' families would be a compelling source and identified one such antismoking advertisement that uses a cancer victim as spokesperson. Some $20 \%$ suggested that the government source was most appropriate and that although there were alternative sources the interviewees considered them as having less or the same effectiveness.

"I think it would be more powerful to have other campaigners apart from the state. It might be the victims of car crashes. So it's a shame that it's only ever the state that drives the message."

Member of the Public (3)

In terms of the Push Play prompted advertisement, $100 \%$ of the interviewees claimed that the government source was appropriate and in the Feeding Our Futures prompted advertisement, the interviewees offered no alternative for this type of message. 


\subsubsection{Attitude of Government as Source}

This section further explored the overall opinions that the interviewees expressed towards the government as the attributed source of social marketing messages, the data was collected from both unprompted and prompted questions.

As discussed previously, the researcher observed that interviewees were quite unfavourable towards government being the source of social marketing messages in general discussion and during unprompted questioning. Their responses were quite critical of government pursuing social marketing programmes to change the behaviour of individuals and being interfering and too directive. The interviewees believed that the high volume of social marketing messages being directed towards them compounded this. However, this attitude changed when the interviewees were provided examples of social marketing messages conducted by government. In these cases, interviewees reacted more favourably to the social marketing messages and could appreciate the reasons for the government's involvement.

"The only reason they are doing it is they're seeing negative results from current behaviour like food habits. It's creating a New Zealand wide obesity problem, smoking it's costing the health system so much when some of it's second-hand smoke."

Member of the Public (2)

"Unfortunately, the government's job is to remind us that our behavioural trends are not ideal. They have the knowledge and the vested interest, especially with the cost of healthcare."

Member of the Public (8)

Overall, the study revealed that $70 \%$ of the interviewees reacted positively to government being the source of social marketing messages and agreed that the government were responsible for providing information and persuasion to the public in order to influence a 
change away from unacceptable behaviours. The remaining $30 \%$ of interviewees were negative to the government being the source of social marketing messages.

The data analysis evidenced three themes that emerged from the discussions into the interviewee's attitudes and opinions of the government as the source of social marketing messages. Two themes reflected a positive attitude towards government as the source of social marketing messages, one focusing on the role of government and their policies and the second focusing government's motivation to reduce the costs to society of the unacceptable behaviours. The third theme was a negative response to government as a source for social marketing messages.

The first theme was the positive affirmation of government as the appropriate source of social marketing messages as interviewees believed that social marketing is core to the policies and obligations of government to improve the quality of life for society. Of the $70 \%$ of interviewees who reacted positively to government as a source of social marketing, more than half (some interviewees providing input on both themes) believed that social marketing is the application of government policy and the means by which government improves the quality of life for the population over time.

"Pretty sick of being told what to do by government but honestly, I guess they are trying to do something positive."

Member of the Public (10)

"Yeah it's probably a government ad because they're the people who are supposed to be socially responsible for our welfare. Absolutely part of their job because we put them in power to make our lives better."

Member of the Public (1)

"Well they're here for the people, they work for us and while they don't please everyone at the heart of it all they've got a responsibility to their constituents to make our world better for ourselves." 
"What it's trying to achieve is beneficial to the country."

Member of the Public (5)

"They're the most appropriate in terms of they've got a huge package of resources to assist people to stop smoking, so it can be linked to a whole bunch of others."

Member of the Public (2)

"I suppose they are the most informed source because that is their job. You would assume, after all the millions of dollars spent in these organisations you would want to hope they know what they are talking about."

Member of the Public (8)

The second theme to emerge from the data was a positive reaction to government as the source of social marketing based on the interviewee's belief that the government is motivated to reduce the costs to society of the unacceptable behaviours. Fundamentally, interviewees believed that the government is the only organisation suitably placed to make the significant changes necessary to reduce costs to society of the behaviour that is targeted by social marketing. Of the $70 \%$ of interviewee (some interviewees providing input on both themes) who reacted positively to government as the source of social marketing, more than half felt that government was motivated to reduce costs, particularly of healthcare.

"Unfortunately, the government's job is to remind us that our behavioural trends are not ideal. They have the knowledge and the vested interest, especially with the cost of healthcare."

Member of the Public (8)

"They're actually interested in having better choices being made by people; more active lifestyle generally equals wellbeing, longer life, healthier population and all sorts of things which is less of a drain on the health system."

Member of the Public (4)

"In the end, the government is motivated by pure reasons that benefit us all - even if it is reducing healthcare costs or road deaths. Unlike private enterprise who spend incredible amounts of money telling you oven fries are better for you." 
"See this is where it starts to get a bit animal farm I have to say. Because it's taxpayers money and government funded agencies that have to support the bad social habits of people. So they probably are accountable for addressing social behaviours that result in costs to the citizens."

Member of the Public (3)

The third theme to emerge from the data analysis was a negative response by the interviewees to government being the source of social marketing messages. Some $30 \%$ of interviewees felt that government being too directive and in many discussions, stated that the government was creating a 'nanny state' in order to control the behaviour of the population.

"A little nanny state I have to say. It's a little bit nanny state when the government talks about the need for vaccinating against cervical cancer or whatever."

Member of the Public (3)

"...because of the nature of the government at that time, they were fairly willing to intervene in peoples' lives. I think that was just the philosophy of the left leaning government, that they believe government's got a stronger role in that individual choice isn't necessary the best social outcome."

Member of the Public (5) 


\subsubsection{Message versus Source}

As with Phase 1 of this research study, the emergence of strong response around the importance of the message and lesser importance placed on the source of the social marketing message was unforeseen by the researcher. Moreover, the analysed data in the second phase of this study provides a strong indication that interviewees gave less importance to processing source credibility thoughts than advertisement creative or message thoughts. In the interview process, it was apparent to the researcher that interviewees gave little regard for the credibility of the source, particularly where the interviewees agreed with the core message, was positive towards the message or were the source was believed to be government.

Overall, $100 \%$ of the interviewees ascertained that the source did not matter and source credibility processing did not occur when the message was compelling or they were in agreement with the message, even when the source was easily identified.

"I mean most of these social advertisements are just common sense. We know we've got to be healthier and look after our finances and our wills and those sorts of things. I don't think it would make any difference to me who was putting the ads up it's the ad itself."

Member of the Public (1)

"...because the message surely is about getting you to do something, so if the message touches you that will galvanise action or belief or whatever, probably irrespective because surely if you're going to let yourself be coloured by who's delivering the message."

Member of the Public (4)

"So I think the positive message, maybe doesn't matter so much where they're coming from. Yes, because they reinforce positive thinking. It's not like you're buying something. So you don't need to find out where to go to get it."

Member of the Public (2) 
"I think it's more about the message now. I'm such a strong advocate for Smokefree that it wouldn't matter who put the ad out there. I don't think it would matter. It's about the message and that's because I feel passionate about it."

Member of the Public (6)

"The reason I'm remembering those ads is because of the content not the funding behind it. It's being fed to you, you absorb but there is no reason to carry on looking for it."

Member of the Public (2)

"I don't know if it does matter because the message was there. I mean, I don't think it's important for the effectiveness of the ad."

Member of the Public (9)

"So is Feeding Our Futures credible, is that the question? Because I don't know who they are, maybe it doesn't matter because the message still is credible. So maybe where it comes from doesn't matter."

Member of the Public (8)

Further data analysis indicated that when interviewees felt negative towards the social marketing message, the interviewees were more likely to then seek to identify the source and engage source credibility thoughts in order to understand more fully who, which organisation, would communicate such a message.

"Well, I probably process the ad first. I listen to the message, if I agree then I'm happy and in the most, don't care who sent it. If I disagree, then I probably tune out or change channel. Very occasionally, if it is something I strongly disagree with then I will want to know who it's from."

Member of the Public (5)

"I keep coming back to the government but I'm not sure that they would make any difference to me. It would probably matter more if I disagreed with the message."

Member of the Public (1)

"I think as long as the message is a good one, it doesn't really matter. I think they're a trustworthy source but I don't think it matters because the message is a good one. I think [knowing the source] it's probably more important if you disagree with the message." 


\subsubsection{Repetition Effects}

This section of the study aims to provide the researcher with data addressing the third research question namely, "How does the repetition of multiple similar advertisements from one attributed source impact on the effectiveness of social marketing messages?" During the interviews, the researcher directed a series of questions to interviewees aimed at establishing their opinions and attitudes towards the volume of social marketing advertising prominent in 2008. The researcher aimed to address the research questions through two key areas of study into repetition effects. Firstly, the researcher gathered data to quantify what level of social marketing advertising the interviewees believe they were exposed to during 2008 and the level of social marketing advertising that interviewees believed is appropriate. Secondly, the researcher further examined the topic by asking questions that identified the impact of volume of social marketing advertising on the effectiveness of the social marketing campaigns measured by the audience's ability to interpret the core message distinguish a source and engage in the message.

\subsubsection{Volume of Social Marketing}

Interviewees were asked a series of questions to assist the researcher to quantify the volume of social marketing advertising that the interviewees believed they were experiencing in 2008 and what level of social marketing advertising the interviewees believed is appropriate. In this way, the researcher aimed to be able to provide a suitable comparison with advertising data already collected from media research organisations. So too, understanding the interviewees opinion of the volume of social marketing messages experienced in the research period is relevant to the measurement of the impact of that volume on the effectiveness of the social marketing campaigns. 
Interviewees were asked to classify the volume of social marketing advertising that they had experienced in to a scale of low, medium or high. The analysed data revealed that $70 \%$ of the interviewees believed that the volume of social marketing advertising was high in repetition relative to other general advertising. Further, $80 \%$ of interviewees believed that social marketing advertising was medium to high.

"It would appear that in almost every ad break on television there is someone telling you not to drink and drive, have breast screening, feed your kids well, go and exercise, don't bash you wife, how to be a good parent, save power. You get the idea. I wonder what would happen if it all stopped. The volume of these kind of ads is diabolical."

Member of the Public (8)

"I felt for a long time that the proportion was too high. That the almost over stimulation and over controlled."

Member of the Public (9)

"I think it's probably more than I realised. It's just that some are more prominent about their message than others."

Member of the Public (7)

"There's probably quite a lot of it, really campaign driven. Whether it's the drink driving one or all the driving ones, all the smoking ones."

Member of the Public (3)

"I would imagine it would be relatively high because of the nature of the government in that time. They were fairly willing to intervene in people's lives."

Member of the Public (5)

"I wouldn't have thought about it before this but there's probably maybe $20 \%$ would be social marketing. They're probably on almost every ad break. Certainly a high level." 
Interviewees were asked to comment on the level of social marketing advertising that they considered appropriate for a three-hour television-viewing period. The collected data indicates that $70 \%$ of interviewees claimed that five to six social marketing advertisements per viewing period would be acceptable. The balance of the interviewees did not care about the number of advertisements they were exposed to in the viewing period.

"Anything more than half a dozen would probably be too many over a two to three hour period."

Member of the Public (3)

"Oh heck, based on what you tend to see now which is overwhelmingly negative. I get annoyed after five possibly, fives too much."

Member of the Public (9)

"More than a half a dozen of an evening is getting up there. I just lose interest and turn off mentally to the next message."

Member of the Public (8) 


\subsubsection{Interpreting the Message}

This area of the study aimed to identity the likely impact of high repetition of similar social marketing messages on the ability of the target audience to recall and interpret the core message contained within those advertisements.

The data was collected through a series of questions asked in an unprompted and prompted condition. Firstly, interviewees were asked questions about social marketing advertisements they could recall from their memory and secondly, interviewees were prompted with three social marketing advertisements previously discussed.

The analysis of the collected data identified that $100 \%$ of interviewees think that the message was relatively easy to distinguish in the advertisements despite the high number of repetitions of similar messages. Moreover, the data indicates that interviewees believed the messages were simple and clear, which was assisted by simple creative treatment of the social marketing advertisements.

"I agree that there are a plethora of advertisements, social type advertisements on the radio, televisions, etc but the message is usually simple, very simple in fact, certainly easy to decipher."

Member of the Public (8)

"I think the message is always kind of quite simple. I think that's always communicated in a generally simple fashion. So, I think they sort of go right for the jugular rather than sort of trying to be too creative or too clever."

Member of the Public (10) 


\subsubsection{Distinguishing the Source}

As with the previous section, the researcher aimed to identity the likely impact of high repetition of similar social marketing messages on the ability of the target audience to attribute a source or sources of the social marketing advertisements.

The data was collected through a series of questions asked in an unprompted and prompted condition with interviewees. The data analysis revealed that all interviewees acknowledged difficulty in distinguishing the source of social marketing messages caused by the high repetition of similar advertisements. Unlike the previous section, the data indicates that interviewees reacted differently between the unprompted and prompted condition, notably the longer running, more established social marketing campaigns were easier for interviewees to distinguish the source due to their existence when the volume of social marketing was low and the advertisements easy to recall.

In the unprompted condition, $40 \%$ of interviewees felt confident in distinguishing the source of the social marketing message. As previously stated, this was evident with campaigns recalled by the interviewees that were long running and more prominent. $60 \%$ of interviewees could not attribute a source to the social marketing messages that they could recall from memory but generally assumed it a government agency.

"It is really-hard to work it out. There are so many ads basically saying the same thing and you know its government. Well, I guess I think its government. There is just too many to tell and if I didn't agree perhaps I'd be interested in knowing who has that opinion."

Member of the Public (8)

"Well yes and no. I think if you're looking it's probably quite easy to find out. Like I said before, I think it probably does matter in some situations that it does come from a credible source." 
In terms of the prompted advertisement, the collected data indicates that $90 \%$ of interviewees correctly identified the source of the Push Play social marketing advertisements and $70 \%$ of interviewees could correctly identify the source of the Smokefree social marketing advertisements. In terms of the Feeding Our Futures prompted questions, no interviewees could identify the source or any branding in the advertisement and only $20 \%$ of interviewees could identify the branding immediately following the viewing of the advertisement. In this case and in the case of interviewees that could not identify the source, they assumed the source to be government. Notably, the data indicates that interviewees found distinguishing the source to be more difficult due to the high repetition of similar advertisements however, interviewees were also less inclined to devote the time to further interrogation of the advertisement if they agreed with the message. Although the interviewee's ability to recognise the source was varied, the responses indicate there was no material impact on the effectiveness of the social marketing message being communicated by the government agency.

"You know I didn't notice at all. I didn't notice the logo at the end. No, it doesn't matter at all because the message has still got through to me."

Member of the Public (1)

"Well I had trouble, other than the Smokefree one was the one I was absolutely certain about."

Member of the Public (4)

"Well they're competing for time and I think there's only so much room in anyone's head during one set of ads to actually take in a social message and I think we are sort of getting bombarded with do this, do this, don't do that, this where it is a bit silly. You eventually, you probably just switch off."

Member of the Public (9) 


\subsubsection{Impact of Repetition}

Overall, the research indicated that there was little material impact on the effectiveness of social marketing messages caused by high repetition of similar messages from a similar source. The data indicated that interviewee's could easily interpret the messages from social marketing advertisements and although the identification of source was more problematic, the low priority placed on identifying the source and low consideration of source credibility meant that the was little impact.

In measuring the interviewee's ability to distinguish the core messages and identify the source, the researcher identified a number of other impacts caused by high repetition of similar marketing messages that could negatively influence the effectiveness of the message, namely:

1. the interviewees ability to clearly retain the messages over time, and;

2. the interviewees to become disgruntled or apathetic towards the advertisements and the source.

As previously discussed, $30 \%$ of interviewees held negative opinions towards government as a source of social marketing messages. In this series of questions, it was further revealed that more than $30 \%$ of interviewees were more likely to develop a negative reaction to government, as the source of these social marketing messages, based on the interviewees reacting negatively towards the volume of social marketing advertisements. So too, the data revealed that interviewees felt apathetic towards the social marketing messages as high repetition and the increased exposure to a significant number of campaigns increased.

"It's the continuous or should I say, relentless stream of these ads that drive you crazy. Do this, don't do this, you have to question whether these agencies think we can work it all out. Sometimes I'm not sure whether they realise that they all blend together after a while." 
"I think it's too much and I think almost to their own detriment. Like everyone's trying to get their message out competing for advertising space and apathy can set in."

Member of the Public (9)

"...for me too much. It's very difficult to interpret the individual issues amongst all of the repeated ads. I wonder how these people think that we can recognise and retain it all. In fact, I'm not even sure who they all are, the advertisers. They all blur into nothing."

Member of the Public (3)

"There's so many more that are similar and they're probably on almost every ad break. Certainly a high level and they seem to run longer as well."

Member of the Public (1)

"I would suspect that government doesn't actually care that you get the message, do they? Perhaps it's some public servant whose job it is to do the ads, you know tick the box on the list. They don't care whether you give up smoking or not, they've done their job, eh. So they don't care that all the ads are confusing to us."

Member of the Public (8) 


\subsubsection{Persuasion (Effectiveness)}

In the final stages of the interviews with the members of the public, the researcher directed a series of questions to establish how successful social marketing campaigns had been in influencing a change in behaviour. Interviewees were asked their opinions on how persuasive the social marketing messages they had experienced in 2008 had been in influencing change in their behaviour or in friends and family, they had observed.

Overall, $70 \%$ of interviewees reacted positively to the persuasiveness of some social marketing messages that they had been exposed to during the research period. Of this $70 \%$, Thirty percent of interviewees observed that social marketing campaigns were effective in motivating or influencing behaviour change. Some $40 \%$ of interviewees believed some campaigns were persuasive, namely the more long-term and established campaigns such as Push Play, Smokefree and elements of the road safety social marketing but equally claimed that the majority of social marketing were ineffective. The final $30 \%$ of interviewees believed that all social marketing campaigns were ineffective.

Seven of the ten interviewees recalled several social marketing advertisements they felt were persuasive and had motivated them to make a behavioural change or consider a behaviour change. The majority of examples provided were from the road safety campaigns; especially effective was the Drink Drive campaign. However, a similar $70 \%$ of interviewees felt that overall the majority of social marketing messages had been ineffective.

"Why do people drink and drive? It's been so ingrained and there is so much sort of marketing out there be it police with their speed cameras, with the tests, the drink test and the marketing."

Member of the Public (10)

In the case of the prompted data, interviewees felt positive towards the message and agreed with the message however were not motivated or persuaded to change their current 
behaviour. This was evident in responses to the Push Play messages where $80 \%$ of the interviewees felt positive towards or agreed with the healthy activity message however only $20 \%$ were persuaded to consider a change in their behaviour.

Similarly, of the nine that responded seven interviewees agreed that the Feeding Our Futures message was persuasive but as reinforcement to their current attitudes and behaviour, therefore the campaign itself was unpersuasive in motivating any behaviour change.

"... if nothing else it probably reinforces what you think anyway. People can believe, it can be commonsense but you don't always carry out the actions."

Member of the Public (4)

"That ad reinforces a lot of other messages that are being received for a lot of other organisations. It's reinforcing behaviour but my behaviour tends to be healthy anyway"

Member of the Public (7)

"It's more about motivating and maintenance of good behaviour than necessarily motivating a change from bad behaviour to good behaviour."

Member of the Public (3)

In response to the prompted questions on the Smokefree social marketing message, interviewees were more critical of the creative and the negative nature of the campaign. $60 \%$ of interviewees believe that the target audience, smokers, would "turn-off" to the message and it would not be effective due to its negative message to smokers.

"If I was a smoker, I don't know whether it would just wear you down or you would just tune out to it."

Member of the Public (5)

"I think it is [effective] but to smokers they're use to blocking out messages so I don't think anything is an effective message for them."

Member of the Public (7) 
"Generally, smokers are that into their habit that if you try and tell them it's the wrong thing they tune-out or they get argumentative either about their rights or that you're wrong. Same with family violence, you see a lot of denial there too."

Member of the Public (8)

So too, $90 \%$ of interviewees were very critical of the creative style of some social marketing campaigns. Interviewees used examples of the Alcohol Advisory Council's It's How We're Drinking campaign and the youth targeted Drink Driving campaign that uses shock and fear tactics in the advertisements. In this case, interviewees believed them to be ineffective, as they do not watch them and are not engaged in the communication process.

"As soon as I see that ad with the kid in it, you know where the drunk guy swings him around. That's it, I change channels or get up and walk away. I don't even know who it's from or what they are saying to me. I don't care the ad is too distressing."

Member of the Public (5) 


\subsubsection{Summary of Results}

Phase 2 of the research focused on the gathering the opinions and attitudes of social marketing conducted in New Zealand in 2008 by a representative group of New Zealander public to address the research questions. Data was collected from ten interviewees using semi-structured face-to-face interviews. The semi-structured interview questions used in Phase 2 of the research study were developed to include specific discussion areas identified through the Phase 1 research. Phase 2 interviewees were directed to the same research topics as the social marketers in the first phase of this study.

In interviewing the members of the public, the researcher observed behaviour, from the interviewees, worth noting. Interviewees were quite unfavourable to being told what to do by government with their responses were quite critical of government providing messages highlighting unacceptable behaviour or provide positive guidance. However, this attitude and response appeared to change when the interviewees were provided with visual prompts or when the researcher verbally prompted the interviewee with examples of social marketing messages. When prompted, interviewees reacted more favourably towards the government social marketing messages.

In addressing the first research question, the researcher collected data that related to the impact that the high volume of social marketing messages during 2008 had on the credibility of the government agencies that were the source of these messages. The analysis of the collected data revealed two themes. The first theme was the correct attributed of the advertisements and the second theme was the interviewees' default, if the identification was inconclusive.

The first identified theme was the correct attribution of the source despite the branding used and the extent to which the government agencies went to avoid being associated to government. Over $70 \%$ of interviewees could clearly attribute the correct source to three quarters of the unprompted and prompted social marketing advertisements discussed. In the 
prompted condition, between $90 \%$ and $100 \%$ interviewees identified the source as a government agency with between 70 and $80 \%$ identifying the specific agency responsible for the social marketing programme. The exception was Feeding Our Futures advertisement; no interviewees could attribute a source to the advertisements, however $70 \%$ of interviewees assumed that the source was a government agency.

The second theme that emerged from the collected data was the interviewees default assumption of source, if the attribution of a source was inconclusive. Interviewees who could not identify the source or where the identification of the source was inconclusive, the interviewee's default was to assume the source was government. This default assumption was evident throughout the data collection irrespective of associated or independent brands.

Interviewees were asked to provide an opinion of the source's credibility, whether the high volume of social marketing messages had affected that credibility and how this credibility influenced the persuasion of the social marketing message. The collected data indicates that where the source could be correctly attributed interviewees believed the source was credible and where the source was assumed to be government rather than conclusively identified, less than half of the interviewees believed that the source was credible - trustworthy and knowledgeable.

The researcher identified that in the cases where the interviewee could easily interpret the message in the high volume environment and their attitude to the messages was favourable, less priority was placed on the importance of the source's credibility. Interviewees referred to the credibility of the social marketing campaigns or the core message rather than the credibility of the source. The analysed data also revealed that interviewees gave less importance to processing source credibility thoughts than advertisement creative or message thoughts. Interviewees stated that they did not consider the credibility of the source until they had considered whether the message creatively appealed to them and whether the message was engaging. 
The second research question, the researcher aimed to identify, if government is the not the most effective source of social marketing messages, then who or what would be a more effective source. In the analysis of the data, two distinct results emerged, $30 \%$ of the interviewees identified medical professionals and medical organisations as a more effective alternative to the government. Some $60 \%$ of interviewees considered that these messages should come from a combination of organisations and individuals. In response to prompted questions, interviewees were more likely to agree that government is an effective source, particularly if the interviewee agreed with the social marketing message.

The study explored the overall opinions that the interviewees expressed towards the government as the attributed source of social marketing messages. Some $70 \%$ of the interviewees reacted positively to government being the source of social marketing messages and agreed that the government were responsible for providing information and persuasion to the public in order to influence a change away from unacceptable behaviours. The data analysis evidenced three themes that emerged from the discussions into the interviewee's attitudes and opinions. Two themes reflected a positive attitude towards government as the source of social marketing messages, one focusing on the role of government and their policies and the second focusing government's motivation to reduce the costs to society of the unacceptable behaviours. The third theme was a negative response to government as a source for social marketing messages.

The first theme was the positive affirmation of government as the appropriate source of social marketing messages as interviewees believed that social marketing is core to the policies and obligations of government to improve the quality of life for society. Half of the interviewees believed that social marketing is the application of government policy and the means by which government improves the quality of life for the population over time. In the second theme, $70 \%$ of interviewees believed that the government is the only organisation suitably placed to make the significant changes necessary to reduce costs to society of the behaviour that are targeted 
by social marketing, they felt that government was motivated to reduce costs, particularly of healthcare.

As with Phase 1 of this research study, the emergence of strong response around the importance of the message and lesser importance placed on the source of social marketing messages. The analysed data in the second phase of this study provides a strong indication that interviewees gave less importance to processing source credibility thoughts than advertisement creative or message thoughts. It was apparent to the researcher that interviewees gave little regard for the credibility of the source, particularly where the interviewees agreed with the core message, were positive towards the message or were the source was believed to be government. Overall, $100 \%$ of the interviewees ascertained that the source did not matter and source credibility processing did not occur when the message was compelling or they were in agreement with the message, even when the source was easily identified. Further data analysis indicated that when interviewees felt negative towards the social marketing message, the interviewees were more likely to then seek to identify the source and engage source credibility thoughts.

In addressing the third research question namely, "How does the repetition of multiple similar advertisements from one attributed source impact on the effectiveness of social marketing messages?" Interviewees were asked to classify the volume of social marketing advertising that they had experienced in to a scale of low, medium or high. The analysed data revealed that $70 \%$ of the interviewees believed that the volume of social marketing advertising was high in repetition relative to other general advertising. Further, $80 \%$ of interviewees believed that social marketing advertising was medium to high.

Interviewees were asked to comment on the level of social marketing advertising that they considered appropriate for a three-hour television-viewing period. The collected data indicates that $70 \%$ of interviewees claimed that five to six social marketing advertisements per viewing period would be acceptable. The balance of the interviewees did not care about the number of advertisements they were exposed to in the viewing period. 
This area of the study aimed to identity the likely impact of high repetition of similar social marketing messages on the ability of the target audience to recall and interpret the core message and distinguish the source of the message. The analysis of the collected data identified that $100 \%$ of interviewees think that the message was relatively easy to distinguish in the advertisements despite the high number of repetitions of similar messages. Moreover, the data indicates that interviewees believed the messages were simple and clear, which was assisted by simple creative treatment of the social marketing advertisements. In terms of the source, interviewees reacted differently between the unprompted and prompted condition, notably the longer running, more established social marketing campaigns were easier for interviewees to distinguish the source due to their existence when the volume of social marketing was low and the advertisements easy to recall. In the unprompted condition, $40 \%$ of interviewees felt confident in distinguishing the source of the social marketing message. Some $60 \%$ of interviewees could not attribute a source to the social marketing messages that they could recall from memory but generally assumed it a government agency. Notably, the data indicates that interviewees found distinguishing the source to be more difficult due to the high repetition of similar advertisements however, interviewees were also less inclined to devote the time to further interrogation of the advertisement if they agreed with the message. Although the interviewee's ability to recognise the source was varied, the responses indicate there was no material impact on the effectiveness of the social marketing message.

Overall, the research indicated that there was little material impact on the effectiveness of social marketing messages caused by high repetition of similar messages from a similar source. The data indicated that interviewees could easily interpret the messages from the advertisements and although the identification of source was more problematic, the low priority placed on identifying the source and low consideration of source credibility meant that there was little impact.

Finally, $70 \%$ of interviewees reacted positively to the persuasiveness of some social marketing messages that they had been exposed to during the research period. Of this $70 \%$, Thirty 
percent of interviewees observed that social marketing campaigns were effective in motivating or influencing behaviour change. Some $40 \%$ of interviewees believed some campaigns were persuasive, namely the more long-term and established campaigns such as Push Play, Smokefree and elements of the road safety social marketing but equally claimed that the majority of social marketing were ineffective. The final $30 \%$ of interviewees believed that all social marketing campaigns were ineffective.

Interviewees were critical of social marketing messages that used negative or shock creative styles. Some $60 \%$ of interviewees believe that the target audience of the Smokefree message, smokers, would "turn-off" to the message and it would not be effective due to its negative message to smokers. All interviewees used examples of the Alcohol Advisory Council's Its How We're Drinking campaign and the youth targeted Drink Driving campaign that uses shock and fear tactics in the advertisements. In this case, interviewees believed them to be ineffective, as they do not watch them and are not engaged in the communication process. 


\section{DISCUSSION AND CONCLUSION}

\subsection{Introduction}

This research studied social marketing conditions in New Zealand in late 2008. It took advantage of the high-volume government-attributed social marketing advertising to explore the impact on the source credibility of the government (where the government is the main source and sponsor of social marketing). It further sought to identify alternative sources of social marketing messages, considered more effective than government by a sample of social marketers and members of the public. As a logical part of the study, the repetition effect of various similar messages from one source, the New Zealand Government, in a social marketing context was examined.

This chapter focuses on the discussion of the results, as detailed in the previous chapter. The previously discussed academic literature is applied here to the findings in order to compare and contrast the themes and key findings. Implications of the research and contribution to the academic literature, especially to social marketing discipline are discussed. In addition, managerial recommendations to social marketing practitioners are made. The limitations of this research arising from the application of qualitative research methods are discussed and a brief discussion on possible future research directions emerging from this study is given. 


\subsection{Discussion of Findings}

This section discusses and compares the themes and patterns identified in the research data with the academic literature. The findings are discussed in four major categories: source credibility, attribution, repetition effects and persuasion (effectiveness). Each section compares and contrasts the two phases of the study: the data collected from the interviews with the i) social marketers and ii) members of the public. The distinction between the two groups of interviewees has enabled the researcher to compare and contrast the intentions of the practitioners and their campaigns with the actual public perception, attitudes and observations of those campaigns.

\subsubsection{Source Credibility}

In addressing the first research question, data was collected which related to the impact that the high volume of social marketing messages during 2008 had on the credibility of the government agencies that were the source of these messages. There are four main themes to the discussion; the public's predisposition towards government messages; source credibility perception of the government; alternative message source and message processing priority of the interviewees.

\subsubsection{Predisposition of the Public}

Interviews with both social marketers and members of the public revealed a negative predisposition towards government-attributed social marketing created by the high volume of such messages in the public domain. Hassan et al. (2007) stated, "Hovland and Weiss demonstrated that people attached subjective a priori credibility levels to different sources, and that sources exhibiting expertise and trustworthiness are more effective in changing opinions" (p. 18). It appears social marketers interviewed in this study perceive the public as 
having attached a negative subjective a priori credibility level towards government social marketing which may not be accurate. Social marketers believed the high volume of social marketing has created a heightened public awareness of government as the source of social marketing messages and this in turn, has created a negative predisposition towards any government message that could be considered directive or interfering with the public's free choice. In contrast, the interviewed members of the public appeared unfavourable to being told what to do by government in the first instance. However, this attitude and response appeared to be superficial, and changed when the interviewees were provided with visual prompts or when the researcher verbally prompted the interviewee with examples of social marketing messages. Moreover, the predisposition did not appear to influence the interviewees' opinion of the government's credibility as the source of the social marketing messages.

Interviewed members of the public were more positive towards longer running and more established social marketing campaigns. Their recall of message and source was notably higher due to the campaigns' existence when the volume of social marketing was low and uncluttered. In this case, the volume of social marketing has contributed to the overall homogenisation of the social marketing advertisements both in attribution of source but also in the general predisposition of the interviewed public.

Interviews with both social marketers and members of the public revealed a general disapproval towards messages, which were negative or were based on shock/fear advertising styles. Three of the four social marketers believed that negative/shock social marketing messages failed to communicate the core message and repulsed the target audience. Some $90 \%$ of the interviewed public were critical of this style of advertising claiming that they do not watch the advertisements and do not engage in the message. The negative reaction to this style of message contributes to the overall negative predisposition discussed in this section. 


\subsubsection{Source Credibility Perception}

Smith et al. (2005) and Donovan and Henley (2003) stated that non-profit organisations such as the NSW Cancer Council and the Cancer Foundation of Western Australia were considered trustworthy and credible due to the expertise and the importance of the information. Both articles indicate that the organisations were considered a positive influence on the effectiveness of the messages, and considered credible sources. This research indicates that two of the four social marketers interviewed believed the government is a positive influence on the effectiveness of social marketing messages, as do seven of the ten members of the public interviewed; who believed that government was a credible and appropriate source.

The literature indicated that the audience of social marketing messages might believe the government has an ulterior motive or agenda or a perceived self-interest. Moreover, the audience's negative feeling towards government was due to the lack of trustworthiness in the government as the source of social marketing, due to the perception of self-interest or deception (Sternthal, Dholakia \& Leavitt, 1978; Forehand \& Grier, 2003; Perman \& Henley, 2003; Hassan et, al., 2007; Wall, 2007). Three of four social marketers interviewed support the literature by expressing their concern over the negative perception that the public may have towards government as the source of social marketing. They believe that government attribution was potentially detrimental to the effectiveness of the message and, as previously discussed, the public may have a predisposition against government messages. However, social marketers believe the government is the only source sufficiently resourced and motivated to conduct social marketing on the large scale necessary to address competitive advertising of deleterious goods. They believed that although public perception may potentially be negative due to the perceived ulterior motive or agenda, such as reducing healthcare costs, social marketers interviewed believed the government is the logical choice of source and cited the extensive resources, research and knowledge expertise necessary to develop a comprehensive social marketing programme. 
This perception of the public's attitude by the interviewed social marketers was not supported. $70 \%$ of the interviewed members of the public reacted positively to government being the source of social marketing messages and agreed that the government is responsible for providing information and persuasion to the public in order to influence a change away from unacceptable behaviours. They believed the government has an important role in improving the quality of life of the population and reducing the cost to society of poor health, accidental injury and death and anti-social behaviour. In this sense, they believed the government is justified in having an ulterior motive in the delivery of social marketing messages. This factor is in contrast to Forehand and Greer (2003) and Perman and Henley (2003) who believed that where the government was perceived to have an agenda or ulterior motive source credibility was reduced. Further, Hovland et al. (1953) concluded that the audience's attitude towards the apparent untrustworthiness of the communicator, the government, or the communicator being dishonest in their intent lead to the message being discounted. However, in contrast to Hovland et al. (1953), where the interviewed public agreed with the message or believed the message was commonsense the message effectiveness was not influenced by the interviewee's belief that the source may be dishonest or manipulative.

Further, Hovland et al. (1953) concluded that where the communication is perceived to be manipulative in intent, the audience has a tendency to reject that communication. In contrast, the evidence in this research suggests the decision to reject or accept the message occurs when the audience assesses the message and creative execution of the advertisement. The data indicates this processing by the interviewees occurs prior to any source credibility thoughts and interviewees gave less importance to processing source credibility thoughts than advertisement creative or message thoughts. 


\subsubsection{Alternative Source(s)}

In addressing the second research question, "Does the public believe the government is an appropriate message source for social marketing messages and if not, who or what would be a more appropriate messenger?" the researcher aimed to identify whom or what organisation would be a more effective source. All social marketers interviewed acknowledged the government was not the most credible source of social marketing messages. Contrasting the interviews between social marketers and members of the public, three of the four social marketers could identify a specific organisation or group of similar organisations that, in their opinion, would be a more effective source to their target audience. Conversely, $70 \%$ of the interviewed public were likely to agree that government is an effective source, particularly if the interviewee agreed with the social marketing message.

Perman and Henley (2003) found in their research that the target audience of anti-marijuana campaigns believed medical practitioners and medical websites were relevant alternative sources for information, which they believed to be confidential, factual and trustworthy. This study provided both a concurring and a contrasting comparison to Perman and Henley's study in that although $70 \%$ of the interviewed members of the public agreed the government was a credible source, $30 \%$ believed medical practitioners or medical organisations were an effective alternative to government.

Two of the 4 social marketers and $60 \%$ of the public interviewed believed social marketing messages would be more effective if they came from a combination of organisations and individuals, although the research indicated a lesser importance was placed on the source compared to the importance of the message. 


\subsubsection{Message Processing Priority}

The high volume of social marketing has created an abbreviated processing methodology that was identified in the interviews with both social marketers and members of the public. Evidence in this study provides a strong indication that interviewees gave less importance to processing source credibility thoughts than advertisement creative or message thoughts. It was apparent to the researcher that interviewed members of the public gave little regard for the credibility of the source, particularly where the interviewees agreed with the core message, were positive towards the message or where the source was believed to be government. Overall, $100 \%$ of the public interviewed asserted that the source did not matter and source credibility processing did not occur when the message was compelling or they were in agreement with the message, even when the source was easily identified. Further data analysis indicated that when interviewees felt negative towards the social marketing message, the interviewees were more likely to then seek to identify the source and engage source credibility thoughts.

The data from the interviewed members of the public also revealed that the abbreviated advertising processing appeared to have evolved to allow the interviewees to quickly process the high-volume of social marketing messages. This factor combined with a level of apathy and lack of motivation truncated the desire of the interviewees to engage with social marketing advertising in any depth. The simple messages and high level of agreement with the messages meant that interviewees where less engaged with the message and therefore minimal deep processing of the message occurred.

From the interviews, it is likely less importance is placed on the source credibility thoughts due to the interviewee's perception that the source of social marketing messages was the government. There was evidence that a homogenisation of the source and therefore, general opinion of the source, was predetermined by the interviewed members of the public. 


\subsubsection{Attribution}

In the discussion of attribution and understanding how the social marketers addressed their concerns around attribution to government, the researcher determined that extensive consideration was given to the campaign branding strategy to decide whether to associate or disassociate the campaign directly with the government. Two of the four social marketers interviewed advocated an association with government, conversely the other $50 \%$ developed brand strategies that excluded any reference to government, to hide the association with government. Where the social marketing practitioner chose to disassociate they appeared to go to significant lengths to develop and maintain a high degree of anonymity to avoid government association. In contrast, over $70 \%$ of the members of the public interviewed could correctly identify the source in three quarters of the unprompted and prompted social marketing advertisements. This was despite the use of actors and spokespeople, as well as unattributed brands in the prompted and recalled advertisements. It would appear from the evidence that all efforts to disassociate with government by the social marketers were unsuccessful.

Friestad and Wright (1994) and Buda (2003) contend that the consumer's perception of the spokesperson or actor as playing a part and are not perceived to be the source of the message. Lafferty, Goldsmith and Newell (2002) similarly state that brands are also subject to the scrutiny of the audience where they will actively seek the source of the message hidden by the brand. The evidence in this study concurred with the literature with interviewees making the clear distinction between the actors or spokesperson and the source of the message.

Interviews with members of the public revealed that where the individual could attribute the correct source (specific government agency) to the social marketing message, the interviewees believed the source agencies were trustworthy and knowledgeable. Conversely, where the source could not be conclusively identified but where the interviewees assumed the source generally as government, only $40 \%$ of interviewees believed that the source was trustworthy and knowledgeable. This is contrary to the findings detailed by McGinnies and 
Ward (1974) who contend that a persuasive communication in which the source is not identified may be assumed to have a credible communicator.

The result of the interviews with the members of the public showed that where the source was clearly identified, the source was considered knowledgeable and trustworthy. This concurs with Friestad and Wright (1994) who claimed that persuasion is only achieved when the target audience believes the source is knowledgeable, trustworthy and their message is relevant to the target. However, if the interviewees could not identify the source or where the identification of the source was inconclusive, the interviewees default was to assume the source was government. This default assumption was evident throughout the data collection irrespective of associated or independent brands and made little influence on the effectiveness of the message. 


\subsubsection{Repetition Effects}

Repetition effect in advertising is an area of study derived from the commercial marketing field. There is little existing academic literature that discusses the impact of repetition effects to the effectiveness of social marketing messages and therefore little comparative literature with which to contrast and compare the results of this study. In the commercial marketing field, there is much discussion of the impact on source credibility caused by repetition in advertising (Craig, Sternthal \& Olshan, 1972; Craig, Sternthal \& Leavitt, 1976; Calder \& Sternthal, 1980; Stephens \& Warrens, 1984; Kisielius \& Sternthal, 1984; Naples, 1997; Nordhielm, 2002). There was evidence that supported Calder and Sternthal (1980) who ascertained that repeated exposure to television advertisements created negative feelings towards the product and it was clear through the interviews that members of the public believed that over time the general attitude towards social marketing, as a whole, was negative due to the high volume. Further, this research supports Stephens \& Warrens (1984) statement that when repetition levels are much higher than those needed to learn, the target audience become inattentive and loses motivation to recall. The data from the interviewed members of the public revealed a level of apathy and a lack of motivation to engage with social marketing advertising in any depth.

The interviewed social marketers in this study appeared to be unaware of the impact of their high frequency advertising strategy and their lack of consolidation of similar messages with other agencies. This mismanagement was compounding the repetition effects through the high-volume of social marketing advertising on the target audience. Three of the four social marketers interviewed were favourable to maximising the advertising frequency of their messages to maximise their campaigns cut-through. However, it was clear that the social marketers did not consider other social marketing messages as competition for their target audience's time and attention.

In contrast, Gotlieb and Sarel (1991) offered that the more cluttered the advertising environment is, the less likely the target audience will be able to compare and contrast the 
offering contained within the advertisements. In this study, the results indicated that interpreting the core message of the social marketing advertisements was not impacted by the clutter of similar social marketing advertisements. However, it would appear also that the deep message processing of the advertisements was not evident despite the importance being highlighted in the academic literature, particularly the linkage to influencing and motivating long-term behaviour change (Nordhielm, 2002; Donovan and Henley, 2003; Hastings, 2007; Hassan et al., 2007). This study indicates the high-volume of social marketing has created a condition where the interviewees superficially process the core message and advertising creative within the advertisement without deep processing or thoughtful contemplation of the message. In this way, the research demonstrates a contrast to Nordhielm (2002) and Haugtvedt et al. (1994) who advocated a deeper processing in order to produce more effective advertising messages. Further, Moore et al. (1986) claimed the increased exposure limits the consumer's opportunity to elaborate upon the advertising and advertising information learned in each exposure. Interviewed social marketers acknowledged that the high volume and variety of social marketing could create a challenge for the target audience to recall advertising detail. They observed that social marketing advertisements were kept simple in their creative delivery. Therefore, interpretation of the message should be very simple. Three of the four social marketers interviewed did agree that the similarity of the social marketing messages, particularly with agencies that share the same root cause, could create difficulty for the target audience to identify the core message.

The academic literature and the findings of this study show significant variation in the level of repetition that researchers have recorded as influencing source credibility and message effectiveness. Naples (1997) stated that beyond three exposures in a four to eight week period effectiveness decreases. Bornstein's (1989) research states that the downturn occurs at approximately 21 exposures and Nordhielm (2002) observes that an extremely high exposure rate of 80 exposures was required before a downturn in effective response was evident. In this study, $70 \%$ of members of the public interviewed believed that $5-6$ social marketing advertisements per three-hour viewing period would be appropriate, although independent 
research indicates that audiences were viewing 32 social marketing advertisements per threehour viewing period (Nielsen Media Research AIS, 2008, p.21).

This study identifies the likely impact of high repetition of similar social marketing messages on the ability of the target audience to recall and interpret the core message and distinguish the source of the message. The analysis of the collected data from interviewed members of the public demonstrates that $100 \%$ of interviewees think that the message was relatively easy to distinguish in the advertisements, despite the high number of repetitions. They believed this was aided by the simple and clear messages and the uncomplicated creative execution of the social marketing advertisements. In terms of the source, interviewees reacted differently between the unprompted and prompted condition (notably the longer running) more established social marketing campaigns were easier for interviewees to distinguish the source due to their existence when the volume of social marketing was low and the advertisements easy to recall. The interviewees found distinguishing the source to be more difficult when there was a high repetition of similar advertisements. However, interviewees were also less inclined to devote the time to further interrogation of the advertisement if they agreed with the message or it concurred with their current beliefs.

Overall, this research indicates that there is little material impact on the effectiveness of social marketing messages caused by high repetition of similar messages from a similar source. The data indicates that interviewees could easily interpret the messages from the advertisements and although the identification of source was more problematic, the low priority placed on identifying the source and low consideration of source credibility meant there was little negative impact. 


\subsubsection{Persuasion (Effectiveness)}

The interviews with representatives of the public indicate a very low opinion of the success of social marketing. Generally, interviewees believe that the messages were commonsense or in agreement with their beliefs and therefore, do not require significant processing or deep contemplation. Kisielius and Sternthal (1984) observed that cognitive elaboration requires a substantial amount of time for the target audience to process information. In this study, it is evident that interviewed members of the public do not spend significant amounts of time processing the messages and therefore, there may exist a relationship between the interviewee's opinion that social marketing advertising is ineffective and the lack of cognitive elaboration and deep processing.

The social marketers interviewed were divided as to whether or not social marketing is successful in motivating or influencing change in the target audience. Three of the four interviewed believed social marketing through advertising is not working. They demonstrated little faith in their own programme's success while seeing very few effective campaigns in New Zealand. In contrast, the members of the public interviewed, $30 \%$ observed that social marketing is effective in influencing behaviour change and a further $40 \%$ believe some campaigns are persuasive, namely the long-term and established campaigns with more recent and less familiar campaigns being ineffective. The other $30 \%$ of interviewees believe that all social marketing campaigns were ineffective.

The overall persuasiveness of social marketing discussed in this study is called into question based on the interviews with both social marketers and members of the public. Hassan et al. (2007) stated that without a high level of motivation for behavioural change the consequential behaviour compliance is unlikely to take place or will be short-lived. Evidence in this study demonstrates that the level of message processing by the interviewed members of the public does not support the deep penetration or significant contemplation necessary to invoke behaviour change (Kisielius \& Sternthal, 1984; Haugtvedt et al. 1994; Sternthal, Dholakia \& Leavitt, 1978). 
Donovan and Henley (2003) identified that persuasion is moderated by three core types of selectivity. They stated that most appeals is derived from messages that have a personal relevance; that agree with the person's existing attitudes and beliefs and where the recall of those messages is done so in a way more aligned to the individual's attitudes and beliefs (p.64). Interviews with members of the public concur with Donovan and Henley, in the first instance, by identifying that interviewees analysed the social marketing advertisement for messages that matched their current beliefs and attitudes or messages that they agreed were commonsense. This initial analysis was combined with the individual's attitude to the way the message was communicated in the advertisement. However, interviewees appeared to offer no further consideration to the message regardless of whether the messages were personally relevant. Finally, messages, which were negative or based on shock/fear advertising styles, were commonly recalled from the interviewee's memory. Drink driving, alcohol abuse and speeding messages were the most commonly recalled advertisements. Messages with a positive creative or positive message were less likely recalled from the interviewee's memory.

Specifically, Donovan and Henley (2003) maintained that smokers who find it difficult to quit or want to keep smoking tend to avoid anti-smoking messages. This was evident in the study with $60 \%$ of those members of the public interviewed claiming that negative messages targeting smokers would more likely cause them to avoid or disregard the message than consider behaviour change. In a similar manner, interviewees used examples of shock and fear advertisements such as the Alcohol Advisory Council's It's How We're Drinking campaign and the youth targeted Drink Driving campaign and believed them to be ineffective, as they do not watch them or are not engaged in the message.

The academic literature offers many examples of social marketing that are ineffective in motivating or influencing behaviour change in the target audience (Perman \& Henley, 2003; Henley, 2006; Hassan et, al, 2007; Wall, 2007, Kotler \& Lee, 2008; Bridges, 2009). This study has highlighted the lack of belief in the effectiveness of social marketing campaigns from both the interviewed social marketers and the members of the public. Overall, they have stated 
their belief that the majority of social marketing campaigns have not significantly influenced the target audience to consider behaviour change.

In this study, there is no evidence that the interviewees considered the high levels of social marketing to be directly reducing the government's credibility, as the source. No doubt, the interviewed members of the public believe the government to be a credible source; however, the high-volume of social marketing has diminished the standing of the social marketing source, as simply government, and therefore, the importance of source credibility thoughts in the cognitive processing of advertisements is reduced. 


\subsubsection{Message versus Source}

This study considers the relationship between the high volume of social marketing and the possible impact this condition may have on the credibility of the source of social marketing, which in New Zealand, on the whole, is the government. The data collected from the interviewed members of the public, essentially the representatives of the social marketing target audience, has provided a likely scenario that indicates that the high volume has affected the target audience's ability to process the social advertisements in a manner traditionally represented in the commercial marketing literature. The Model of Cognitive Response compiled by Belch and Belch (2007) was used in this study to inform the researcher of an acceptable advertising processing methodology used by the target audience to process advertisements. Derived from commercial marketing theory, the model provides an appropriate framework to analyse the target audience's processing of message, source and advertisement execution thoughts.

An outcome of this research, unforeseen at the outset, is the emergence of an emphasis being placed on the message and advertising execution over other elements of Belch and Belch's (2007) cognitive response model. As previously discussed, the high-volume of social marketing has caused the target audience to abbreviate the cognitive response process illustrated by the model. In the collection of data, the researcher identified that the interviewed members of the public could easily interpret the message in the high volume environment. Where their attitude towards the messages was favourable or it conformed to their beliefs, less priority was placed on the importance of the source's credibility. Interviewees referred to the credibility of the social marketing campaigns or the core message rather than the credibility of the source.

Further data collected in the interviews indicate that the abbreviated processing was borne from the apathy and lack of desire to process the complex thoughts caused by the highvolume of social marketing messages combined with their desire to cope with processing high repetition advertisements. 


\subsection{Summary on the Main Points of Discussion}

In summary, this research has studied the New Zealand social marketing environment witnessed in 2008. During this period, the New Zealand government conducted over 53 separate social marketing programmes aimed at improving the lifestyle and behaviours of the New Zealand people. This situation has provided a niche environment to study how the highvolume of social marketing affects the target audience's opinion of the credibility of the message's source and how repetition affects social marketing messages.

This study has revealed a disconnection between the social marketer's perception of their target audience and the members of the public's perception of social marketing in addressing the research questions. This is evidenced in the interviews with four social marketers and ten members of the public.

In considering source credibility, this research has determined that the high-volume of social marketing messages has homogenised the source thoughts of the interviewed members of the public. It has lead the public to assume all social marketing is from government. They believe that generally, government is an appropriate and credible source and finally, that the source credibility considerations in their messages processing are less important than message and advertisement execution thoughts.

In contrast, social marketers believe that the association of social marketing messages to government may be detrimental to the effectiveness of the messages and their audience are predisposed to negative thoughts on government association with social marketing messages. In this way, half of the interviewed social marketers employ considerable effort to disassociate their campaigns from government and to their government agency. This effort is unwarranted as the homogenisation of source means interviewed members of the public assume source of all messages is the government. 
To summarise repetition effects, interviews with the social marketers revealed that, overall, they were unaware of the impact of high frequency advertising schedules and the effect that the lack of consolidation of messages between agencies had on the target audience. Moreover, social marketers did not consider their messages as competition to other social marketing messages, albeit for their audience's time and attention.

The interviews with members of the public revealed a number of responses to the high-volume social marketing environment generated by the audience's desire to cope with interpreting and processing the high number of messages. The non-distinction of source and some messages is the first noted behaviour, as is the abbreviated advertisement processing that was observed and previously discussed. Each of these parameters being a tool to assist the audience orientate towards more rapid messages processing. The underlying assumption of all social marketing messages as being from government has generated a predisposition of negativity towards government as a social marketing source; however, this predisposition proved to be superficial with interviewees offering a positive reaction to prompted social marketing examples.

This research study has highlighted several gaps in the academic literature addressing the overall opinion of government as the source of social marketing. Specifically, the impact of high-volumes of social marketing messages on the target audience and the persuasion of social marketing campaigns to motivate and influence behaviour change in the target audience is unclear. The combined opinion of the interviewed social marketers and members of the public on persuasiveness indicates that there is little overall confidence in the effectiveness of social marketing to influence behaviour. Moreover, those campaigns, which are considered effective, are those campaigns that were popularised when social marketing was relatively new and existed in a low-volume social marketing environment. 
As discussed in the previous sections, The Model of Cognitive Response compiled by Belch and Belch (2007) [Refer: Figure 5] is a widely accepted theory for examining audiences' cognitive processing of advertising messages and the processing of thoughts that occur to the audience when they are exposed to the advertisement. Belch and Belch (2007) claim the model is well used by academics and marketing practitioners to analyse the types of responses evoked by an advertising message and how these responses relate to the attitude towards the elements of the model, namely message, source and ad execution. This research

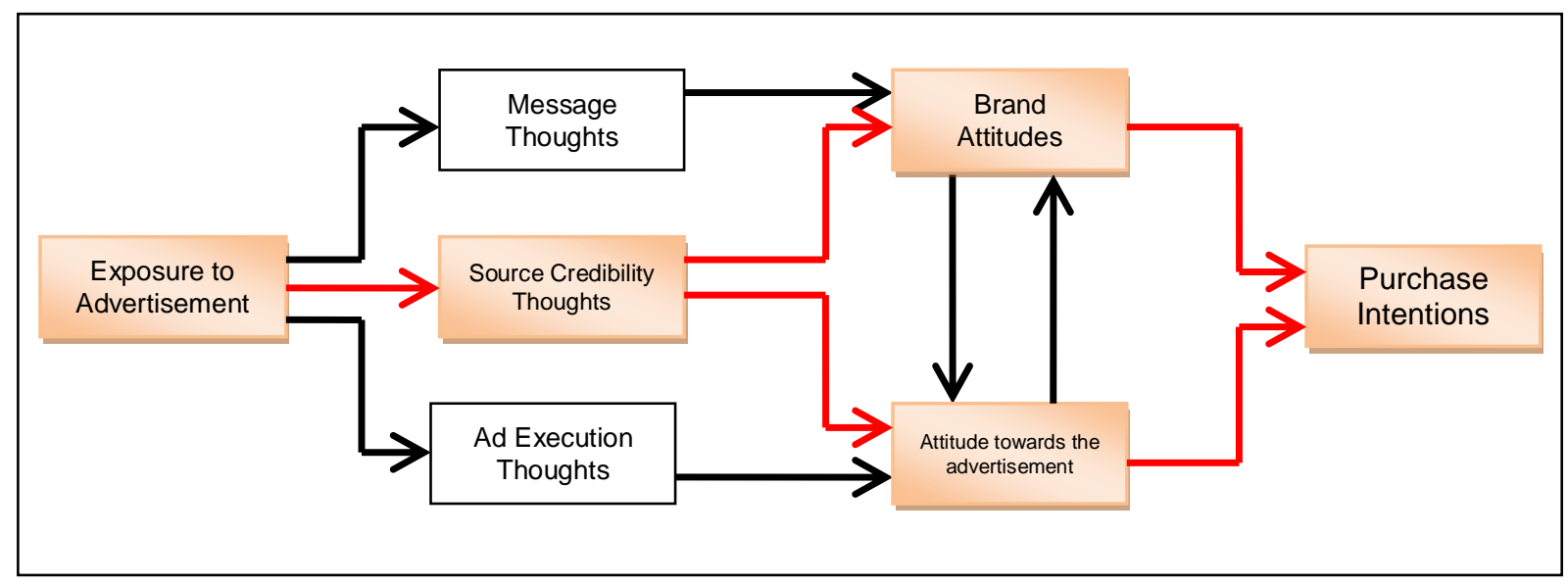

Figure 5: Model of Cognitive Response (Belch \& Belch, 2007, p. 156)

has discovered a variety of effects on interviewed members of the public caused by the high level of social marketing in New Zealand in 2008. In doing so, the researcher has observed the use of an abbreviated processing model that appears to have evolved to enable the target audience to cope with the high-volume of advertisements; the cumulative effect of similar messages; the assumption of government as the source; simple commonsense messages and the apathy towards processing these messages.

This abbreviated process places different emphasis on each of the elements and appears to treat the processing of message and ad execution thoughts with a higher priority. The researcher has attempted to illustrate the process, as described in the interviews with both social marketers and members of the public, in Figure 6: Proposed Abbreviated Social 
Marketing Processing Model. Although utilising the core elements of Belch and Belch's (2007) model, the proposed model changes the number of elements processed concurrently and demonstrates the rapid dismissal that was evident in the study.

In the proposed model, the initial processing of the social marketing advertisement takes place with consideration of the attitude towards the advertisement creative and message thoughts. These thoughts occur simultaneously, with the individual deciding whether the advertising style is appealing and whether they agree with the message or it conforms to their beliefs. The attitude towards the advertisement has an overriding influence on the balance of the process, if there is a negative reaction to the advertisement no further message processing occurs and the advertisement is dismissed. This was most evident in shock/fear style advertising, such as the Alcohol Advisory Council's It's How We're Drinking campaign and the youth-targeted Drink Driving campaign. In this case, the interviewees claimed they disengaged with the advertisement.

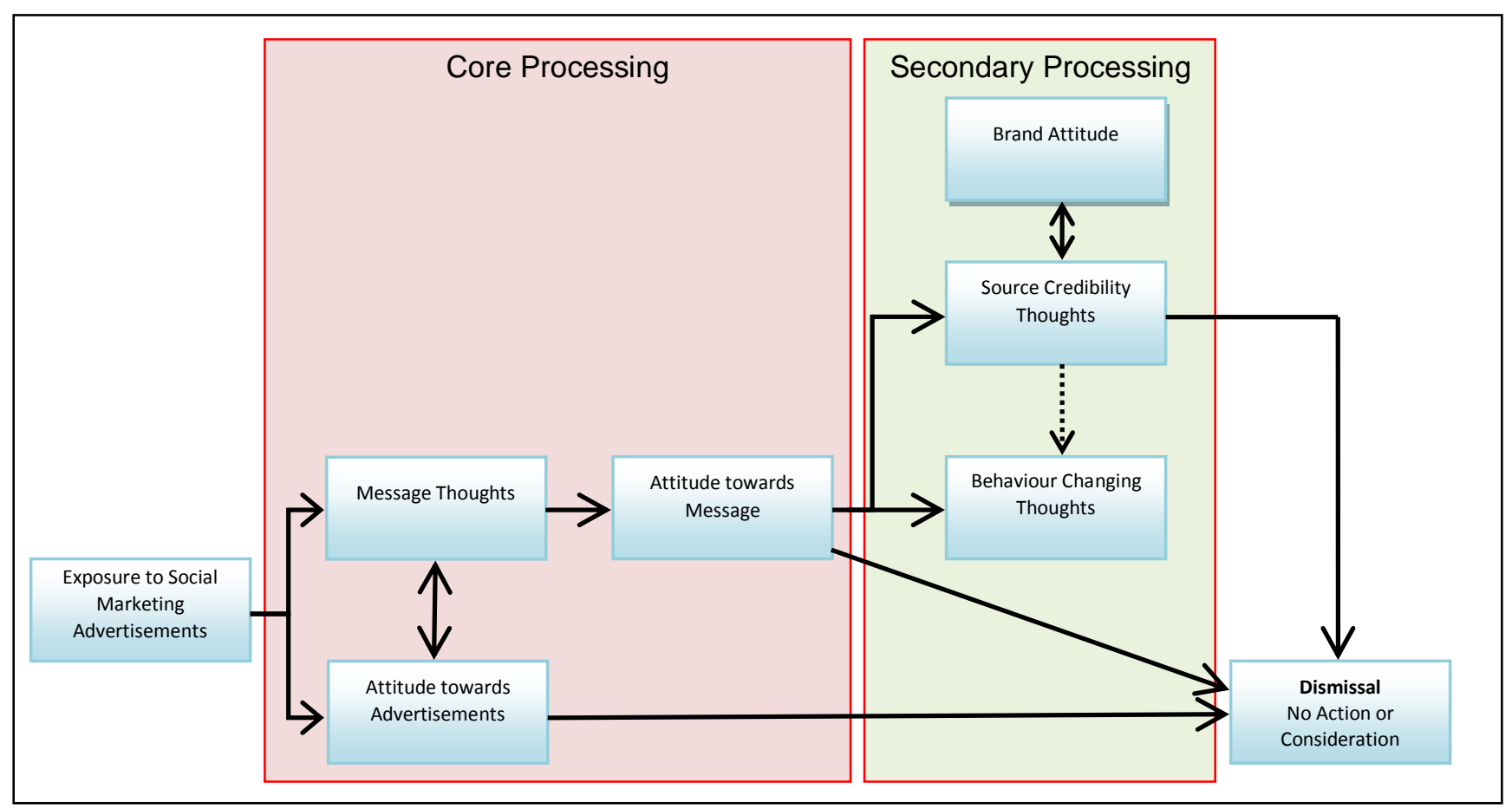

Figure 6: Proposed Abbreviated Social Marketing Processing Model 
If the attitude towards the advertisement is 'not negative' then message processing continues with the consideration of the individual's attitude towards the message. At this point, the individual will consider the message in regards to their positive or negative attitude towards the message. Negative attitude may see the advertisement dismissed. Equally however, the audience may have a positive reaction to the message but still dismiss the message on the grounds that they agree with the message and/or it affirms their behaviour and therefore, do not believe that behaviour change needs consideration.

The secondary processing occurs once the decision to engage with the message is made. The decision to process the message further is done selectively on the grounds that the individual is willing to consider behaviour change thoughts and in this process, they may consider the source credibility and their attitude towards the brand. If the attitude towards the message is negative then the audience may wish to discover the source to determine credibility.

The proposed model aims to represent the compiled data graphically, specifically the method used by the interviewed members of the public to quickly process social marketing messages. This proposed model highlights the difficulty in applying commercial marketing theory to social marketing happenings. The high-volume social marketing environment studied in this research has perhaps demonstrated the difficulty in utilising Belch and Belch's (2007) Model of Cognitive Response, however it is not known whether it is the unique processing of social marketing messages or the combination of this and the high-volume social marketing environment that has generated the difficulty. As Peattie and Peattie (2003) note, "The need for caution when applying commercial marketing principles indiscriminately to social marketing campaigns and for an appreciation of how particular social marketing contexts can make concepts derived from commercial marketing more or less applicable." (p. 367). 


\subsection{Study Limitations}

The nature of qualitative research can generate limitations in the data that reflect the exploratory research methodology. In the case of face-to-face semi-structured interviews, interviewees may feel compelled to answer in a way that is inconsistent with their beliefs to satisfy the researcher or be lead by the questions asked by the researcher, which may lead the interviewee to answer in an atypical manner.

This research has been ambitious in the choice of research paradigm, that is to utilise the postpostivist deterministic philosophy in which causes or conditions are likely to determine effects or outcomes, and to examine this philosophy through qualitative research methodology. In its nature, the research has set about to demonstrate a linkage between the conditions of the time and to seek the likely effect or resultant outcome, in the data collection by utilising existing commercial marketing theory and models to guide this collection (Creswell, 2003).

The small sample size may restrict the ability to generalise the study findings against any larger population group (Miles \& Huberman, 1994; Cavana, Delahaye, \& Sekaran, 2001; Creswell, 2003). Similarly, the sample was derived from the same geographic region in New Zealand, which may affect the randomisation of the data collected or mitigate against any regional influences or attitudes. However, in the sample of the members of the public redundancy was found after the sixth interview, in the commonality of opinions and attitudes.

Finally, the selection of social marketing advertisements for use in the interviews in the prompted questioning and discussion may not have been representative or typical of the advertisement known to the interviewees. The research relies on the individual opinions of the interviewees to comment on their reaction to the prompted advertisement, however if these ads have not been seen outside of this research, data may be affected by the context of the viewing. This has been mitigated in part by the selection of high recall or advertising frequency advertisement played through 2008. 


\subsection{Recommended Future Research}

Qualitative research was defined by Strauss and Corbin (1998) as, “...any type of research that produces findings not arrived at by statistical procedures or other means of quantification" (p. 10). They further discussed the suitability of qualitative research to explore substantive areas about which little is known. In the pursuit of academic research, there are significant gaps in the literature addressing social marketing, particularly in the areas of repetition effects, source credibility of government and persuasion theory. This study has utilised the exploration afforded by qualitative research methodology to explore the individual's attitudes, perspectives, opinions and observations to examine social marketing in New Zealand. However, the findings and discoveries are only those contained within the narrow boundaries of this research and in order for theory development to take advantage of this study significantly more research is required to test and validate this research.

\subsubsection{Generalisability}

"The real merit of substantive theory lies in its ability to speak specifically for the population from which it was derived" (Strauss \& Corbin, 1998, p. 267). The key findings related to the interviewed members of the public have been tested in this study to the extent of the research methodology. Saturation in the data collection was reached, however this was for a sample of ten individuals and the ability of these findings to be generalisable and therefore, applied to the population at large requires further research. Quantitative research may be more appropriate in future research to generate a sample and statistical rigour necessary to validate the finding and proposed model for the population at large.

\subsubsection{Further Development of Social Marketing Processing Model}

The proposed abbreviated social marketing processing model detailed in this study requires further research to test the viability and validity of the model to the observed behaviour. The model related to a high-volume social marketing environment, therefore, further testing and 
research into the suitability of the model to explain the observed behaviour would require future research within this environment.

\subsubsection{Other Related Research}

There is an opportunity for further research that can be suggested as a result of this study. It would appear to the researcher that this study raised more questions than it answered. The areas of academic literature dealing with repetition effects, high-volume conditions and government as the source in social marketing are almost non-existent and therefore, lend themselves to future research. However, perhaps the greatest potential lays in future research into the effectiveness and persuasion of social marketing in influencing and motivating change in behaviour. Although popularised by marketing professionals, social marketing's ability to be effective in changing behaviour appears to warrant more research. Further, the development of specific social marketing theory will improve the effectiveness of social marketing practice and make a difference in our communities and for our high-risk groups. 


\subsection{Theoretical Contribution}

This research attempted to add further to the social marketing theory through the study of the microenvironment of the New Zealand social marketing scene that existed in 2008. Peattie \& Peattie (2003) state the development of social marketing practice and theory over the last twenty years has been based on a downplaying of the differences between the two fields, commercial and social marketing, rather than a willingness to confront them and understand their implication. This research has drawn from both social marketing and commercial marketing theory to develop a study that aims to add to the literature in four ways. Firstly, to affirm some of the existing social marketing theories in the literature and secondly, to provide a social marketing context to the commercial marketing theories through the data collected in this research. Thirdly, to propose an alternative social marketing processing model that is more appropriate. Fourth, through the support of empirical evidence, proffer some observations into the reaction of audiences to high-volume and high repetition of social marketing messages and its subsequent impact on the effectiveness of those messages.

This research has provided some affirmation of social marketing research as discussion by Perman and Henley, (2003), Donovan and Henley (2003), Smith et al. (2005), Henley (2006) and Hassan et al. (2007). There are aspects of this study that support their finding and theories and further solidify the collaborating research into this field. Overall, this study indicates that initial social marketing research or findings have been extended or altered as a result of the high-volume social marketing environment. As an example, Donovan and Henley (2003) discussed the three core types of selectivity moderating persuasion in social marketing messages. This research concurs with two of the three moderating factors; however, the highvolume environment affects the third factor.

This research compares and contrasts the social marketing data to well-accepted commercial marketing theory and principles and attempts to provide a social marketing context to these theories. "The need for caution when applying commercial marketing principles indiscriminately to social marketing campaigns and for an appreciation of how particular social marketing 
contexts can make concepts derived from commercial marketing more or less applicable" (Peattie \& Peattie, 2003, p. 367). Importantly, the commercial marketing literature has provided the understanding and foundation theories into areas that do not have significant social marketing research, such as source credibility, repetition effects and attribution. This study has brought some social marketing context to the wider marketing knowledge in the absence of specific studies addressing these areas of study in the social marketing field.

The development of the proposed abbreviated social marketing advertisement processing model, based in part on the Model of Cognitive Response compiled by Belch and Belch (2007), furthers Peattie and Peattie's (2003) and Donovan and Henley's (2003) belief that commercial marketing principles are not always suitable to explain the occurrences in social marketing practice. Moreover, the absence of exchange that lies at the heart of commercial marketing and the Model of Cognitive Response (Belch \& Belch, 2007), is what fundamentally changes the concepts and assumptions in commercial marketing theory due to the lack of a significant exchange in social marketing. The model adds to the literature, albeit in a modest way, to attempt to explain the processing of social marketing advertisements, which cannot be comfortably explained through the application of the Model of Cognitive Response (Belch \& Belch, 2007) or other similar commercial marketing theory.

Finally, this study affords an insight into the possible reaction by the target audience to the highvolume environment and that audience's ability to process, interpret and consider the broad and intense programmes of social marketing. Further, this research, through the support of empirical evidence, proffers some theories into the reaction of audiences to high-volume and high repetition of social marketing messages and its subsequent impact on the effectiveness of those messages. Specifically, the study looks to help fill the gaps in the social marketing literature dealing with source credibility, repetition effects, persuasion and impacts to the effectiveness of social marketing.

Overall, the wider body of knowledge may benefit from utilising New Zealand as a niche environment to study a condition that has not been evidenced in the other developed countries. 


\subsection{Practical Contribution}

“...instead of a more rigorous application of conventional marketing principles, we need more thoughtful and selective application that emphasises the difference between commercial and social marketing" (Peattie \& Peattie, 2003, p. 367).

One of the objectives of this research study was to make recommendations to social marketing practitioners for the planning of social marketing campaigns, particularly in regards to message source. In providing empirical evidence from this study, social marketers may be more reliably informed to the areas that should be considered in the planning process.

Perhaps the most significant finding of this research is that the high-volume social marketing condition studied in this research is caused by social marketers being unaware of the impact of their high frequency advertising schedules and the lack of consolidation of messages between the agencies. Moreover, social marketers interviewed did not consider their messages as competition to other social marketing messages, albeit for the audience's time and attention and this needs to be considered to improve the effectiveness of social marketing messages. In support of this, the most effective social marketing messages recalled by the interviewed members of public were long-running messages that existed in an uncluttered, low-volume social marketing environment.

This study reveals a clear difference between social marketer's perceptions of the attitudes and opinion of their audiences and the actual reality, as expressed by the interviewed members of the public. This study may act to provide better clarity in the subject areas of source credibility and repetition effects, in particular the potential issues related to highvolumes of social marketing messages on the target audience.

Overall, the discussion and findings in relation to repetition effects in social marketing may be valuable for social marketers in their considerations and campaign planning, in the following areas: 
- In order to better plan in a high-volume social marketing environment, social marketers should consider that members of the public interviewed had a tendency to homogenise the source and some core messages and they appeared to utilise an abbreviated advertisement processing to assist them orientate towards more rapid messages processing.

- In reference to brand strategies, this study reveals that considerable effort has been employed to disassociate campaigns away from government and to the corresponding government agency. This may require review as a result of the finding in this research. Interviews with members of the public suggest this effort to be unwarranted due to the homogenisation of source and the assumption that all social marketing messages are from government.

- From the interviewed social marketers' perspective, the association of social marketing messages to government may be detrimental to the effectiveness of the messages and their audience are predisposed to negative thoughts on government association to social marketing messages. However, evidence in this study indicates that interviewed members of the public assume all social marketing messages are from government and that although there is a predisposition of negativity towards government as a social marketing source, the predisposition proved to be superficial.

- A negative reaction to shock/fear advertising was recorded, such that the audience avoided or refused to engage in the communications process 


\subsection{Conclusion and Final Remarks}

During 2007 and 2008, social marketing was constantly being criticised by the New Zealand popular media for the large quantities of government spending being dedicated to telling the public what to do. The regular use of the term, "Nanny State", and the media's constant questioning of the effectiveness of social marketing against the opportunity cost of improving hospitals or employing more doctors became the unwavering background noise to the social marketing environment of the time. Towards the end of the centre-left government's third term in late 2008, New Zealand was enveloped in a wave of government initiated social marketing covering all topics from obesity to cervical screening to family violence and accidental farm deaths. It seemed from the variety and extent of the advertisements that social marketing could reach no bounds. However, many of the social marketing programmes were managed by a variety of government policy advisors and subject matter experts with very few programmes being run by marketing professionals. Further, the relatively limitless funds of government departments meant that advertising agencies and media companies were enjoying a period of creative and financial freedom that saw the airwaves filled with awardwinning advertising with probably very little impact on the audience and high-risk groups it was created to help. However, there were some excellent social marketing campaigns amongst the plethora of campaigns that shone out as being the benchmark and despite all else, demonstrated solid intervention logic and marketing principles.

The opportunity existed to utilise the social marketing environment in New Zealand to provide an ideal niche environment to study the impact and affects of high-volumes of social marketing on the target audience. As countries such as the UK, Canada, Australia and the US continue to increase the level of social marketing the study into the New Zealand social marketing environment may provide an ideal opportunity to afford some insight into the aspects of social marketing theory and practice at one end of the spectrum. So too, the level of social marketing has created a series of anecdotal beliefs amongst social marketers that perhaps has given way to some erroneous decision making in the planning process. One such belief, evidenced 
in this study, is the effort some social marketers dedicate to disassociating their campaigns from their government roots and generating anonymity in a desire to minimise the detrimental effects of being seen as 'government telling the people what to do'. Many social marketers that implement these brand strategies do so with little or no empirical evidence. As revealed in this study, the public attribute all social marketing to government, regardless.

As a marketing professional, the researcher has instigated this research project to gain a better understanding of social marketing. In the application of the researcher's own commercial marketing skills and amongst the many conversations with other social marketers, it was evident that commercial marketing could not adequately explain what was being witnessed in the social marketing environment or adequately equip the marketer to manage complex social marketing programmes. Hence, this research project was initiated to help explain some of what was witnessed, albeit in a modest way. As Peattie and Peattie (2003) state, "social marketing has been characterised by a tendency to over-emphasise the similarities to conventional commercial marketing, and to underplay the differences" (p. 378). 
APPENDIX A

1. Interview Guide - Social Marketing Practitioners

2. Interview Guide - Member of the Public 


\section{Interview Guide}

\section{Interview (Social Marketing Practitioner)}

\section{[Researcher to Read]}

Thank you for agreeing to take part in this research project. Now that you have signed the Consent Form, I would like to proceed with the interview that was mentioned.

The interview will take approximately 60 minutes and we can stop at anytime for a rest, if required.

The purpose of this interview is to understand your views and opinions on social marketing in New Zealand and gain insight into your social marketing practices during 2008. Firstly, I have some questions that deal with general information such as the nature of your organisation, etc to get a sense of your background as a respondent. The other questions will relate specifically to the subject matter.

Please feel free to be honest and as frank as you like, your answers are completely confidential and you or your organisation will not be identified by name or any other detail that can identify you or the organisation as the respondent when this research is complete.

\section{Questions:}

1. What is the nature of your organisation: Ministry, Government Department, Crown Entity or Government Agency?

2. What is the core function of your organisation?

3. How many different social marketing programmes are managed by your organisation?

4. Can you give me an indication of the budget for these programmes for $2007 / 08$ ?

5. What is the focus of the organisation's social marketing programmes: Chronic Disease Prevention, Injury or Fatal Injury Prevention, Antisocial Behaviour Prevention, Community Impact Minimisation or Environmental/Climate Change Management?

6. What would you consider the main or flagship social marketing programme that ran in 2007 and/or 2008?

If we can now spend some time exploring your flagship social marketing programme [name from Q6] that ran in 2008.

7. What are the core objectives of [name from Q6]?

8. What does success look like for this programme?

9. What was the target audience for that marketing campaign? 
10. What marketing activities constituted the campaign?

11. How were the channels selected? What was the main channel?

12. In your campaign planning did you:

a. Did you consider competitive messages in the public domain? If yes, which ones?

b. Did you consider other social marketing advertising? If yes, what aspects did you consider?

c. How did you brand your TVC? Why?

d. Did you consider your frequency of TVC placement in that planning? If so, what strategy or intention did you have?

e. Did you consider using a spokesperson or specific actors in the TVC? Why?

f. Did you consider who the most effective source for this message is? If yes/no, why?

13. Why would your target audience be motivated to change their behaviour from your messages?

14. You said before that you did/didn't consider the frequency of TVC placement in your planning [Q13 c.], did you consider the impact of other similar social marketing messages being aired at the same time?

15. What impact do you believe other social marketing messages have on your messages? Why?

16. Who else would be considered credible as a source of your social marketing messages?

17. Was your campaign successful? If yes/no, why?

I would like to move on to ask you a few questions about social marketing in general. Think about the period between the start of 2007 and the end of 2008 .

18. Can you think of other two social marketing advertisements that really stood out for you?

a. What is your opinion of those advertisements?

b. How do they make you feel as a social marketer? As a member of the public?

c. Did you feel the advertisements motivated the audience to do what they said? If yes, why?

d. Who do you think is the source of these advertisements?

e. In your opinion, are they the best source of this type of message?

19. When you think about social marketing advertising, what is your opinion of the number of different social marketing advertisements compared to other general advertisements?

20. Is it easy to distinguish the messages in each of the advertisements? If yes/no, why? 
21. [If Q19 answer indicates difficulty in distinguishing] Has the number of advertisements made it hard to distinguish the messages within the different ads? If yes, why?

22. Is it easy to distinguish who is the source or owner of the messages? If yes/no, why?

23. [If Q21 answer indicates difficulty in distinguishing] Has the number of advertisements made it hard to distinguish who are the sources of the different messages?

24. How many different television messages per night would you consider too many?

25. If you cannot tell how the source is, whom do you think it is?

26. Overall, how effective do you think social marketing campaigns have been in influencing your behaviour?

That is all the questions that I had for you. Are there any other comments that you would like to make on the subject of social marketing advertising?

Thank you for your time. 


\section{Interview Guide}

Interview (Member of the Public)

\section{[Researcher to Read]}

Thank you for agreeing to take part in this research project. Now that you have signed the Consent Form, I would like to proceed with the interview that was mentioned.

The interview will take approximately 60 minutes and we can stop at anytime for a rest, if required.

The purpose of this interview is to understand your opinion and reaction to the social marketing messages communicated through advertising in 2008. Firstly, I have some questions that deal with general information such as your age, etc to get a sense of your background as a respondent. The other questions will relate specifically to the subject matter, and I am keen to explore your attitudes and opinions regarding advertising messages.

Please feel free to be honest and as frank as you like, your answers are completely confidential and you will not be identified by name or any other detail that can identify you as the respondent when this research is complete.

\section{Questions:}

1. Age: $18-29,30-39,40-49,50-59,60-69$, Over 70

2. Gender: Male or Female

3. Education Level: College, Polytechnic, University Degree, Post Grad Degree (Name PostGrad Degree)

4. Ethnicity: Māori, Pacific Islander, NZ European, Other

5. What is your occupation?

6. Where you in New Zealand in 2007 and 2008?

7. Did you watch television then? If yes, how many hours per day?

8. Where were you living during 2007 and 2008 ?

9. Thinking of that time, $2007 \& 2008$ - have you heard of social marketing?

a. If yes, what do you think it is?

b. Can you give me examples of social marketing advertising that you saw during that time?

10. Can you think of two social marketing advertisements that really stood out for you?

a. What is your opinion of those advertisements? 

b. How do they make you feel?
c. Did you feel motivated to do what they said? If yes, why?
d. Who do you think is the source of these advertisements?
e. In your opinion, are they the best source of this type of message?

I am now going to show you three social marketing television advertisements. These television advertisements are all from social marketing campaigns run during 2008. After you have seen the advertisements, I would like to explore your attitudes and reactions to the messages and the campaigns, in general.

Play in order: (1) Push Play "Feeling Greatness" 2008 [SPA_45_5295]; (2) Feeding our Futures [FOF_01_Kids]; and (3) Health Sponsorship Council - Smokefree House [HSC_030_056]

\section{[Repeat for each TVC]}

11. What is your opinion of this advertisement?

12. What do you think are the core messages?

13. Do you feel motivated to do what the advertisement says?

14. Who do you think is the source of this message?

15. How can you tell?

16. Do you think that these messages should come from [source Q13]? If yes/no, why?

17. Do you think [source Q13] is knowledgeable or trustworthy source for this message?

18. Who would be more appropriate as the source? Why?

19. Why would they motivate you more to change your behaviour?

I would like to move on to ask you a few questions about social marketing in general. Think about the period between the start of 2007 and the end of 2008.

20. When you think about social marketing advertising, what is your opinion of the number of different social marketing advertisements compared to other general advertisements?

21. Is it easy to distinguish the messages in each of the advertisements? If yes/no, why?

22. [If Q19 answer indicates difficulty in distinguishing] Has the number of advertisements made it hard to distinguish the messages within the different ads? If yes, why?

23. Is it easy to distinguish who is the source or owner of the messages? If yes/no, why?

24. [If Q21 answer indicates difficulty in distinguishing] Has the number of advertisements made it hard to distinguish who are the sources of the different messages?

25. How many different television messages per night would you consider too many? 
26. If you cannot tell how the source is, whom do you think it is?

27. How effective do you think the campaigns have been in influencing your behaviour?

That is all the questions that I had for you. Are there any other comments that you would like to make on the subject of social marketing advertising?

Thank you for your time. 
APPENDIX B

Interview Information Sheet 
Social Marketing Study

Interview Information Sheet

Thank you for agreeing to be a part of my social marketing study.

I am a Masters student in the Faculty of Commerce and Administration at Victoria University. As part of my Masters programme, I am preparing a thesis based on the study into the impact of social marketing in New Zealand.

For this study, I will be conducting a small number of face-to-face individual interviews with social marketing practitioners, and members of the public, to seek their attitudes and feelings towards the mass media social marketing that was prevalent in New Zealand in 2008.

The purpose of this study is to examine the different aspects of social marketing messages and the public reaction to those messages. The study aims to understand the attitudes, motivators, feelings and opinions on the delivery and effectiveness of this style of advertising.

The overall results of this study will be useful for marketing practitioners, in the social marketing field, and those others who are involved in developing social messages for chronic disease prevention, accident and injury prevention, and for ethical reasons. The study's application will provide better understanding of the public attitude towards social marketing messages and ways these messages can be better delivered. From this information, communication messages can be developed and delivered in a way that is more likely to have more meaning and motivation to the individual.

The results and findings of this research may be published in academic and professional journals, be presented at academic and professional conferences. In addition, the final written thesis will be publically available through the Victoria University of Wellington's Library.

The benefits to you as an individual in taking part in this study is the understanding that you will be contributing to a study aimed at improving the quality of social marketing and the desired outcome of improving the New Zealand lifestyle.

The interview will be conducted at a place and time that is convenient to you. The interview will take up to sixty minutes. You may have anyone of your choosing present with you at the interview. The interview will be semi-structured, with opportunity to explore issues or points that are raised during the interview.

Before the interview commences, you will be asked to sign an interview consent form. With your consent, the interview will be tape-recorded and transcribed (a written record made) later for interpretation by myself or a person contracted by myself for this task.

Participation in this interview is voluntary. Your answers are completely confidential and you will not be identified by name or any other detail that can identify you as the respondent when this research is complete. All information you give will be seen or heard only by the interview transcriber, my supervisors and myself and will be kept strictly confidential by all parties. All 
tape recordings and typed transcriptions of interviews will be destroyed within twelve months of completion of the study. You may withdraw your involvement, and any information you may have given, at any stage of the interview prior to commencement of analysis.

This study has received ethical approval from the Human Ethics Committee of the Faculty of Commerce and Administration at Victoria University, which reviews all such studies conducted by the School.

A summary of the study findings will be available to participants following completion of the study. If you wish to be sent a copy of the results, please ensure your contact details are included on the consent form.

Thank you very much for your time. If you require any further information or wish to discuss the interview or the results of this study, please feel free to contact me via email or call me as detailed below.

Andy Millard

Phone: 021866555

Email: andymillard@clear.net.nz 
1. Consent to Participate in Research (Interviewee)

2. Confidentiality Contract for Transcribing of Participant Interviews. 


\section{CONSENT FORM \\ VICTORIA UNIVERSITY OF WELLINGTON \\ CONSENT TO PARTICIPATION IN RESEARCH}

Title of project: Source Credibility in Government Attributed Social Marketing Messages.

I have been given and have understood an explanation of this research project.

I have had an opportunity to ask questions and have them answered to my satisfaction.

I understand that I may withdraw myself (or any information I have provided) from this project (before data collection and analysis is complete) without having to give reasons.

I understand that any information I provide will be kept confidential to the researcher, the supervisors and the person who transcribes the tape recordings of our interview, the published results will not use my name, and that no opinions will be attributed to me in any way that will identify me.

I understand that the tape recording of interviews will be electronically wiped at the end of the project.

I understand that the data I provide will not be used for any other purpose or released to others without my written consent.

I agree to take part in this research

Signed:

Name of participant:

Date:

If you would like a copy of the research summary, please include your email or telephone number: 


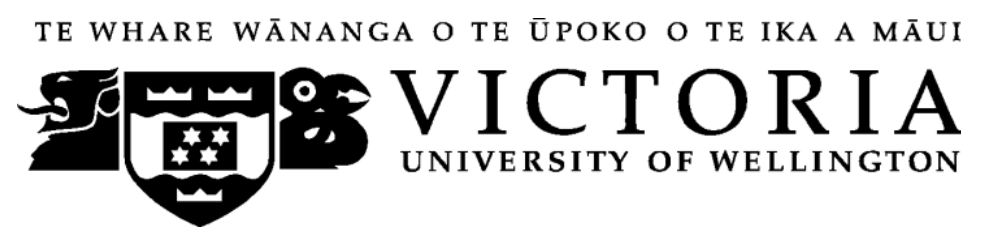

\section{Social Marketing Study}

\section{Confidentiality Contract for Transcribing of Participant Interviews.}

To ensure the anonymity of the persons being interviewed,

of (Address)

Declare that I will not divulge any information gained from the transcripts I produce for the researcher, Andy Millard

Transcriber Signature

Date

Researcher Signature

Date 
APPENDIX D

Ethics (HEC) Approval Form 
Andreasen, A. R. (1995). Marketing Social Change: Changing Behaviour to Promote Health, Social Development and the Environment (1st ed.). Washington DC: Jossey-Bass.

Aronson, J. (1994, Spring). A Pragmatic View of Thematic Analysis. Retrieved 5 24, 2009, from The Qualitative Report, Volume 2, Number 1,: www.nova.edu/ssss/QR/Backlssues/QR2-1/aronson.html

Arora, R., Stoner, C., \& Arora, A. (2006). Using Framing and Credibility to Incorporate Exercise and Fitness in Individuals' Lifestyle. The Journal of Consumer Marketing , 23 (4), 199-207.

Bazeley, P. (2007). Qualitative Data Analysis with NVivo. London: Sage Publications Ltd.

Belch, G. E., \& Belch, M. A. (2007). Advertising and Promotion: An Integrated Marketing Communications Perspective (7th ed.). New York: McGraw-Hill Irwin.

Bridges, T. (2009, March). Social Marketing: Is it Working? NZ Marketing Magazine , 28 (2), pp. 1418.

Buda, R. (2003). The Interactive Effect of Message Framing, Presentation Order, and Source Credibility on Rercuitment Practices. International Journal of Management , 20 (2), 156-163.

Calder, B. J., \& Sternthal, B. (1980). Television Commercial Wearout: An Information Processing View. Journal of Marketing Research , 17 (2), 173-186.

Cavana, R. Y., Delahaye, B. L., \& Sekaran, U. (2001). Applied Business Research: Qualitative and Quantative Methods (3rd ed.). Milton, Queensland: John Wiley \& Sons Australia Ltd.

Cialdini, R. B., \& Goldstein, N. J. (2002). The Science and Practice of Persuasion. Cornell Hotel and Restaurant Administration Quarterly , 43 (2), 40-50.

Craig, S. C., Sternthal, B., \& Leavitt, C. (1976). Advertising Wearout: An Experimental Analysis. Journal of Advertising Research , 13 (4), 365-372.

Craig, S. C., Sternthal, B., \& Olshan, K. (1972). The Effects of Overlearning on Retention. The Journal of General Psychology , 87, 85-94.

Creswell, J. W. (2003). Research Design: Qualitive, quantative, and mixed method approaches (2nd ed.). Thousand Oaks, California: Sage Publications, Inc.

Crotty, M. J. (1998). The Foundations of Social Research: Meanings and Perspectives in the Research Process (1st ed.). Thousand Oaks, California: Sage Publications, Inc.

Daugherty, T., Logan, K., Chu, S.-C., \& Huang, S.-C. (2008). Understanding Consumer Perceptions of Advertising: A Theoretical Framework of Attitude and Confidence. American Academy of Advertising Conference Proceedings (Online), (pp. 308-312).

Denzin, N. K., \& Lincoln, Y. S. (2005). The Sage Handbook of Qualitative Research (3rd ed.). Thousand Oaks, California: Sage Publications, Inc.

Donovan, R. J., \& Henley, N. (2003). Social Marketing: Principles \& Practice (First ed.). East Hawthorn, Victoria: IP Communications Pty Ltd.

Finch, J. E. (1997, June). The Role of Involvement and Source Credibility as Determinants of Vehicle-Source Effects in Print Advertising. American Business Review , 43-51. 
Folkes, V. S. (1988). Recent Attribution Research in Consumer Behaviour: A Review and New Direction. The Journal of Consumer Research , 14 (4), 548-565.

Forehand, M. R., \& Grier, S. (2003). When is Honesty the Best Policy? The Effect of Stated Company Intent on Consumer Skepticism. Journal of Consumer Psychology , 13 (3), 349-356.

Fox, K. F., \& Kotler, P. (1980). The Marketing of Social Causes: The First 10 Years. Journal of Marketing , 44 (4), 24-33.

Friestad, M., \& Wright, P. (1994). The Persuasion Knowledge Model: How People Cope with Persuasion Attempts. Journal of Consumer Research , 21, 1-31.

Gotlieb, J. B., \& Sarel, D. (1991). Comparative Adertising Effectiveness: The Role of Involvement and Source Credibility. Journal of Advertising , 20 (1), 38-45.

Hassan, L. M., Walsh, G., Shiu, E. M., Hastings, G., \& Harris, F. (2007). Modeling Persuasion in Social Advertising: A Study of Responsible Thinking in Antismoking Promotion in Eight Eastern EU (European Union) Member States. Journal of Advertising , 36 (2), 15-31.

Hastings, G. (2007). Social Marketing: Why should the devil have all the best tunes? (1st ed.). Oxford: Butterworth-Heinermann.

Haugtvedt, C. P., Schumann, D. W., Schneier, W. L., \& Warren, W. L. (1994). Advertising Repetition and Variation Strategies: Implications for Understanding Attitude Strength. Journal of Consumer Research , 21 (1), 176-189.

Henley, N. (2006, September). Free to be Obese in a 'Super Nanny State'? Retrieved October 14, 2008, from M/C Journal: Journal of Media \& Culture: http://journal.media-culture.org.au/0609/6henley.php

Herbig, P., \& Milewicz, J. (1995). The Relationship of Reputation and Credibility to Brand Success. Jounal of Consumer Marketing , 12 (4), 5-10.

Homer, P. M., \& Kahle, L. R. (1990). Source Expertise, Time of Source Identification, and Involvement in Persuasion: An Elaborative Processing Perspective. Journal of Advertising , 19 (1), 30-39.

Hovland, C. I., \& Weiss, W. (1951). The Influence of Source Credibility on Communication Effectiveness. The Public Opinion Quarterly , 15 (4), 635-650.

Hovland, C. I., Janis, I. L., \& Kelley, H. H. (1953). Communication and Persuasion: Psychological Studies of Opinion Change. New Haven: Yale University Press.

Jones, L. W., Sinclair, R. C., \& Courneya, K. S. (2003). The Effects of Source Credibility and Message Framing on Exercise Intentions, Behaviors, and Attitudes: An Integration of the Elaboration Likelihood Model and Prospect Theory. Journal of Applied Social Psychology , 33 (1), 179-196.

Kahle, L. R., \& Homer, P. M. (1985). Physical Attractiveness of the Celebrtiy Endorser: A Social Adaption Perspective. The Journal of Consumer Research , 11 (4), 951-961.

Kelley, H. H. (1973, Februray). The Processes of Casual Attribution. Amercian Psychologist, 107128.

Kisielius, J., \& Sternthal, B. (1984). Detecting and Explaining Vividness Effects in Attitudinal Judgments. Journal of Marketing Research , 21, 54-64. 
Kitchen, P. J. (1994). The Marketing Communications Revolution- A Leviathan Unveiled? Marketing Intelligence \& Planning , 12 (2), 19-26.

Kotler, P., \& Lee, N. R. (2008). Social Marketing: Influencing Behaviours for Good (Third Edition ed.). Thousand Oaks, California: Sage Publications, Inc.

Lafferty, B. A., Goldsmith, R. E., \& Newell, S. J. (2002). The Dual Credibility Model: The Influence of Corporate and Endorser Credibility on Attitudes and Purchase Intentions. Journal of Marketing Theory and Practice , 10 (3), 1-12.

Lofland, J., \& Lofland, L. H. (1984). Analysing Social Settings: A Guide to Qualitative Observation and Analysis (2nd ed.). Belmont, California: Wadsworth Publishing.

McGinnies, E., \& Ward, C. D. (1974). Persuasibility as a function of source credibility and locus of control: Five cross cultural experiments. Journal of Personality , 42, 360-371.

Mehta, A. (1994, May/June). How Advertising Response Modeling (ARM) Can Increase Ad Effectiveness. Journal of Advertising Research , 62-74.

Miles, M. B., \& Huberman, M. (1994). Qualitative Data Analysis: An Expanded Sourcebook (2nd ed.). Thousand Oakes, California: Sage Publications, Inc.

Moore, D. L., Hausknecht, D., \& Thamodaran, K. (1986). Time Compression, Response Opportunity and Persuasion. Journal of Consumer Research , 13 (1), 85-99.

Naples, M. J. (1997, July-August). Effective Frequency: Then and Now. Journal of Advertisisng Research , 7-12.

Neilsen Global Omni. (2007a). Consumer \& Nutritional Labeling: A Global Neilsen Report. Sydney: AC Neilsen.

Nielsen Global Omni. (2007b). Labelling ... What is Myth and What is Reality; Consumer and Nutritional Labeling. Wellington: The Nielsen Company.

Nielsen Media Research AIS. (2008, September). Expenditure by Product for August 2007 to July 2008 > Central Government Departments, Services. On Demand Report Generation . Wellington, New Zealand: The Nielsen Company.

Nordhielm, C. L. (2002). The Influence of Level of Processing on Advertising Repitition Effects. Journal of Consumer Research , 29 (3), 371-382.

Onwuegbuzie, A. J., \& Leech, N. L. (2005, Fall). Academic Exchange Quarterly. Retrieved June 03, 2009, from FindArticles.com: http://findarticles.com/p/articles/mi_hb3325/is_3_9/ai_n29219699/

Peattie, S., \& Peattie, K. (2003). Ready to Fly Solo? Reducing Social Marketing's Dependence on Commercial Marketing Theory. Marketing Theory (3), 365-385.

Perman, F., \& Henley, N. (2003). Marketing the anti-drug message: Media, source and message credibility interactions. Journal of Research for Consumers (5).

Reid, L. N., Soley, L. C., \& Vanden, B. G. (1981). Does Source Affect Response to Direct Advocacy Print Advertisements? Journal of Business Research , 9, 309-319.

Smith, B. J., Bauman, A. E., McKenzie, J., \& Thomas, M. (2005). Awareness of message source and its association with the impacts of sun protection campaigns in Australia. Health Education, $105(1), 42-53$.

Smith, R. E., \& Swinyard, W. R. (1982). Information Response Models: An Integrated Approach. Journal of Marketing , 46 (1), 81-93. 
State Services Commission. (2008, April 7). All-of-Government Brand. Retrieved December 12, 2009, from State Service Commission: http://www.ssc.govt.nz/upload/downloadable_files/a-o-gpolicy-and-guidelines.pdf

Statistics New Zealand. (2007). 2006 Census - Quick Stats. Retrieved January 5, 2010, from Statistics New Zealand: http://www.stats.govt.nz/Census/2006CensusHomePage/QuickStats.aspx

Stephens, N., \& Warrens, R. A. (1984). Advertising Frequency Requirements for Older Adults. Journal of Advertising Research , 23 (6), 23-32.

Sternthal, B., Dholakia, R., \& Leavitt, C. (1978). The Persuasive Effect of Source Credibility: Tests of Cognitive Response. Journal of Consumer Research , 4 (4), 252-260.

Strauss, A., \& Corbin, J. (1998). Basics of Qualitative Research: Techniques and Procedures for Developing Grounded Theory (2nd ed.). Thousand Oaks, California: Sage Publications, Inc.

The Dominion Post. (2007, November 19). Clark Rejects Voter's Fears of a Nanny State. The Dominion Post .

Till, B. D., \& Busler, M. (1998). Matching Products with Endorsers: Attractiveness Versus Expertise. The Journal of Consumer Marketing , 15 (6), 576-584.

Tormala, Z. L., Brinol, P., \& Petty, R. E. (2007). Multiple Roles for Source Credibility under High Elaboration: It's all in the timing. Social Cognition , 25 (4), 536-552.

Tormala, Z. L., Brinol, P., \& Petty, R. E. (2006). When credibility attacks: The reverse impact of source credibility on persuasion. Journal of Experimental Social Psychology , 42, 684-691.

Walker, S. (2008). The Problem Gambling Campaign - A 360 degree Approach in Total Campaign Design and Implementation. 7th Annual Marketing \& Public Information Campaigns for Public Sector, NGOs \& Not-for-Profit Organisations (pp. On-Line). Wellington: Conferenz.

Wall, A. P. (2007). Government "demarketing" as viewed by its target audience. Marketing Intelligence \& Planning , 25 (2), 123-135.

Wolcott, H. F. (2008). Writing Up Qualitative Research (3rd ed.). Thousand Oaks, California: Sage Publications, Inc.

Wright, P. (1980). Message Evoked Thoughts: Persuasion Research Using Thought Verbalizations. Journal of Consumer Research , 7, 151-175.

Yin, R. K. (2002). Case Study Research: Design and Methods (3rd ed.). Thousand Oaks, California: Sage Publications, Inc. 
